\title{
Chromosomal aberrations during head and neck carcinogenesis
}

Citation for published version (APA):

Veltman, J. A. (1999). Chromosomal aberrations during head and neck carcinogenesis. [Doctoral Thesis, Maastricht University]. Datawyse / Universitaire Pers Maastricht. https://doi.org/10.26481/dis.19991125jv

Document status and date:

Published: 01/01/1999

DOI:

10.26481/dis.19991125jv

Document Version:

Publisher's PDF, also known as Version of record

\section{Please check the document version of this publication:}

- A submitted manuscript is the version of the article upon submission and before peer-review. There can be important differences between the submitted version and the official published version of record.

People interested in the research are advised to contact the author for the final version of the publication, or visit the DOI to the publisher's website.

- The final author version and the galley proof are versions of the publication after peer review.

- The final published version features the final layout of the paper including the volume, issue and page numbers.

Link to publication

\footnotetext{
General rights rights.

- You may freely distribute the URL identifying the publication in the public portal. please follow below link for the End User Agreement:

www.umlib.nl/taverne-license

Take down policy

If you believe that this document breaches copyright please contact us at:

repository@maastrichtuniversity.nl

providing details and we will investigate your claim.
}

Copyright and moral rights for the publications made accessible in the public portal are retained by the authors and/or other copyright owners and it is a condition of accessing publications that users recognise and abide by the legal requirements associated with these

- Users may download and print one copy of any publication from the public portal for the purpose of private study or research.

- You may not further distribute the material or use it for any profit-making activity or commercial gain

If the publication is distributed under the terms of Article $25 \mathrm{fa}$ of the Dutch Copyright Act, indicated by the "Taverne" license above, 
Chromosomal aberrations during head and neck carcinogenesis 
(C) JA Veltman, Maastricht 1999

Maastricht: Universitaire Pers Maastricht ISBN 90-5278-255-5

Cover illustration by Mieke Veltman-Hoedemaker 


\title{
Chromosomal aberrations during head and neck carcinogenesis
}

\author{
PROEFSCHRIFT \\ ter verkrijging van de graad van doctor aan de \\ Universiteit Maastricht, op gezag van de Rector Magnificus, \\ Prof. Dr. A.C. Nieuwenhuijzen Kruseman \\ volgens het besluit van het College van Decanen, \\ in het openbaar te verdedigen op donderdag \\ 25 november 1999 om 14.00 uur \\ door \\ Joris André Veltman \\ geboren op 28 augustus 1971 te Heerlen
}

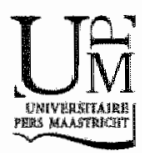


Promotores:

\author{
Prof. Dr. J.J. Manni \\ Prof. Dr. F.C.S. Ramaekers
}

Co-promotor:

Dr. A.H.N. Hopman

Beoordelingscommissie:

Prof. Dr. J.P.M. Geraedts (voorzitter)

Prof. Dr. J.W. Arends

Dr. A.J.M. Balm (Nederlands Kanker Instituut)

Prof. Dr. C.J. Cornelisse (Universiteit Leiden)

Prof. Dr. J. Wagstaff

This thesis was prepared at the Department of Otorhinolaryngology and Head \& Neck Surgery and the Department of Molecular Cell Biology \& Genetics, Research Institute Growth \& Development, University of Maastricht.

The publication of this thesis was financially supported by:

Beter Horen Maastricht, Glaxo Wellcome, Nutricia Nederland, RhonePoulenc Rorer, Schering-Plough, Smith \& Nephew, SmithKline Beecham Farma, Stöpler Instrumenten en Apparaten, and the Dr. Ir. van der Laar Stichting. 


\section{Contents}

Chapter 1

General Introduction

Chapter 2

Chromosome instability as an indicator of malignant progression in laryngeal mucosa

Chapter 3

Specific steps in aneuploidization correlate with $\mathrm{LOH}$ of $9 \mathrm{p} 21$, $17 p 13$ and $18 q 21$ in the progression of premalignant laryngeal lesions

Chapter 4

Double-target fluorescence in situ hybridization distinguishes multiple aberrant clones in head and neck squamous cell carcinoma

Chapter 5

P53 overexpression and chromosome instability are strongly correlated in early stages of oral carcinogenesis

Chapter 6

Detection of chromosomal aberrations in cytologic brush specimens from head and neck squamous cell carcinoma

Chapter 7

General Discussion

Chapter 8

Summary

Chapter 9

Samenvatting

Dankwoord

Curriculum Vitae 
Chapter 1

General Introduction 


\subsection{Head and neck squamous cell carcinoma}

Head and neck cancer, as defined in this thesis, includes the common squamous cell carcinomas of the oral cavity, pharynx, and larynx (see figure 1.1). Skin, brain, ocular, thyroid, and salivary-gland tumors and the infrequent tumors of other histopathological types (sarcomas and lymphomas) will not be discussed. Head and neck cancer is the sixth most common cancer in the world, with an estimate of 500,000 new cases annually 1 . In the western world this tumor type occurs predominantly in men over 50 years of age with a prolonged exposure to tobacco and/or alcohol ${ }^{2,3}$. Despite advances in the management of this disease during the past two decades, overall survival for patients has not improved significantly ${ }^{4}$. An important reason for this lack of progress is the development of second primary neoplasia in the upper aerodigestive tract ${ }^{5}$. Both preinvasive and invasive forms of cancer are known, and progression from preinvasive to invasive carcinoma is frequently observed. Because the mucosa covering the main sites in the head and neck region is easily accessible and biopsy material is relatively easy to obtain, premalignant head and neck lesions provide an excellent model to study the carcinogenic process.

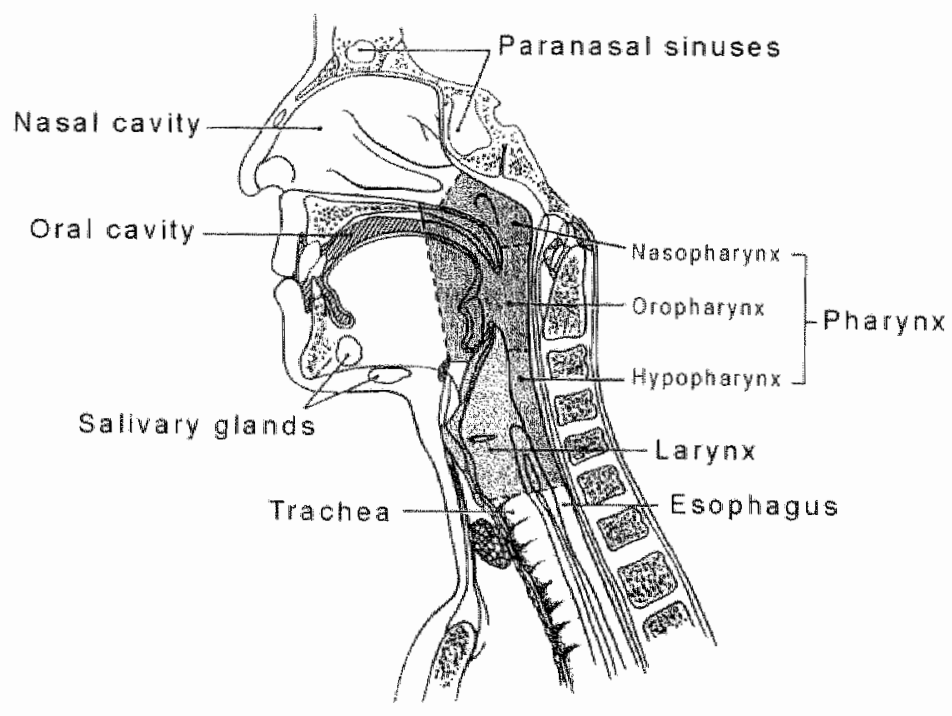

Figure 1.1. Sagittal section of the upper aerodigestive tract (reproduced from Vokes et al. $\left.{ }^{4}\right)$. 


\subsection{The road to cancer}

\subsubsection{Step by step}

Cancer is a genetic disease. The development of cancer involves the expansion of clonal cell populations that have a growth advantage over other cells. Epithelial neoplastic lesions like head and neck squamous cell carcinoma (HNSCC) find their origin near the basement membrane as a focal, clonal overgrowth of altered stem cells, which expand upward and laterally, thereby replacing normal epithelium. This growth advantage over normal epithelial cells is due to the accumulation of multiple genetic changes in these cells, affecting cell cycle control, genetic stability and DNA repair. In the past decade specific insight has been gained into the genetic alterations, which occur in the different forms of cancer. As a result of all these studies, a complex picture of genetic changes emerges for most solid tumors, including HNSCC. Among the frequently detected genetic aberrations are gene mutations, amplifications and deletions of specific genes, but also numerical and structural chromosome alterations. Some of these changes may be essential for tumor development and progression, whereas others may simply result from genetic chaos in tumor cells. For a fundamental understanding of the carcinogenic process, it is important to study (a) the exact stages at which the different genetic changes occur during the development of a tumor, and (b) the effect of a certain genetic change on the carcinogenic process. Such studies will lead to the identification of genetic processes essential for the initiation of a cell to start the carcinogenic process on the one hand; on the other hand they will provide clues with respect to the genetic alterations that are associated with aggressive growth or metastatic capacity. It is this understanding of neoplasia that will allow the selection of molecular markers with specific implications for diagnosis and prognosis.

\subsubsection{Loss of cell cycle control}

Cancer is also a cell cycle disease ${ }^{6}$. The cell cycle consists of an orderly sequence of phases $\left(G_{1}, S, G_{2}, M\right)$, which are strictly regulated by the activity of proteins such as cyclins, cyclin-dependent kinases (CDKs) and $C D K$ inhibitors (see figure 1.2). In cancer cells this regulation is not as strict as in normal cells due to either an enhanced expression of positive regulators called oncogenes (for example members of the cyclin family such as cyclin D1), or a decreased expression of negative 
regulators called tumor suppressor genes (the retinoblastoma gene (pRb) and CDK inhibitors such as p16 $6^{\text {INK } 4 a}$ and p21 Cip1 (through functional inactivation of its transcriptional activator p53)) ${ }^{7.8}$. As a result, cancer cells have the ability to proliferate at a higher rate, even in the presence of extensive DNA damage which would normally lead to cell cycle arrest followed by either DNA repair or the start of a programmed way of cell death called apoptosis.

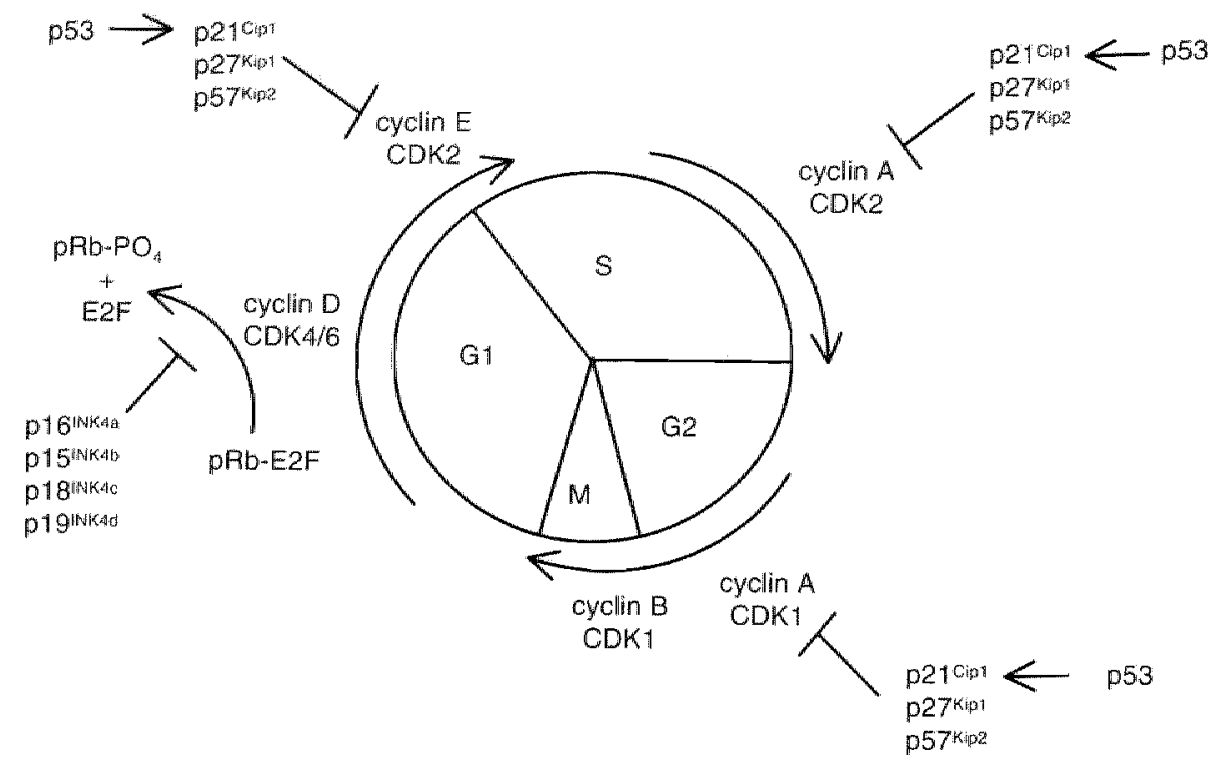

Figure 1.2. Molecules involved in the cell cycle machinery.

\subsubsection{Genetic instability is required}

The acquisition of genetic instability is required for the generation of multiple mutations that underlie cancer ${ }^{9,10,11,12}$. In a small percentage of solid tumors, including hereditary nonpolyposis colorectal cancer, deficiencies in mismatch repair genes lead to instability at the nucleotide level $13,14,15$. In most other tumors, the presence of abnormal chromosome numbers (aneuploidy) indicates another form of genetic instability. There is increasing evidence that mutations in chromosomesegregation genes could disrupt a cell division checkpoint, thereby causing alterations in chromosome numbers ${ }^{12,16}$. Once aneuploid, cells will continue to be subject to asymmetric chromosome segregation at mitosis, a process called "chromosome error propagation" 47 . 
An alternative hypothesis stresses the importance of the telomere sequences in stabilizing the genome ${ }^{18}$. One of the functions of the telomere (a repetitive sequence capping the ends of all human chromosomes) is to protect chromosomal ends from fusions and other rearrangements. Loss of telomere function can initiate genetic instability in the early stages of tumorigenesis ${ }^{19}$.

\subsubsection{Clonal yet heterogeneous}

Monoclonality is a fundamental characteristic of human neoplasia ${ }^{20,21}$. One transformed cell gives rise to daughter cells, most of which exhibit the same genetic changes that initially provided the growth advantage to the parent cell. The accumulation of further genetic changes in subsequent daughter cells, followed by a constant selection of the clones with growth advantage over other clones, will lead to an expansion of clonally related cells. However, due to genetic instability tumors may become more and more heterogeneous during their evolution. Both genetic and phenotypic heterogeneity has been observed in many solid tumors, and this heterogeneity might even play a role in the clinical behavior of tumors ${ }^{22,23}$. Different subpopulations within a single tumor may differ in for example metastatic capacity or response to radiotherapy ${ }^{24,25}$.

\subsubsection{Fields of cancer}

Multiple lesions, both preinvasive and invasive, occur frequently in the upper aerodigestive tract, either at different stages of time or simultaneously $5,26,27$. This phenomenon was originally explained by the field cancerization theory, stating that a prolonged carcinogenic exposure of the mucosa of the entire upper aerodigestive tract results in multiple lesions that have acquired independent genetic changes ${ }^{26}$. An alternative theory suggests that multiple tumors are of common clonal origin, with a single cell being transformed which gives rise to genetically related tumors through mucosal spread 28,29 . The two competing hypotheses are depicted in figure 1.3. The distinction between the multiple lesions is not possible merely based on the histological appearance. It is however possible to test the two hypotheses by molecular analysis of these lesions. If multiple tumors originate from the same clone, early genetic alterations should be common to all of the tumors, whereas they should differ when not of clonal origin. Genetic alterations taking place in late stages of tumorigenesis are not suitable 
for these kind of analyzes, since they might even differ amongst tumors with a clonal origin due to their distinct evolution ${ }^{30}$. Numerous molecular studies have indicated that multiple primary tumors arise from a single clone in some patients but may be of independent origin in others $29,30,31,32,33$

\section{Field cancerization}

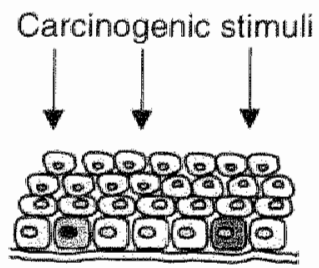

Multiple cells with different genetic aberrations

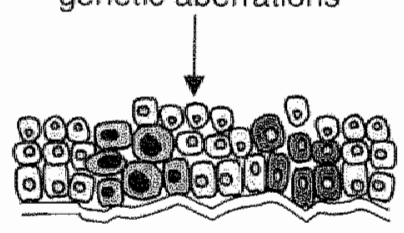

Outgrowth of genetically abnormal cells

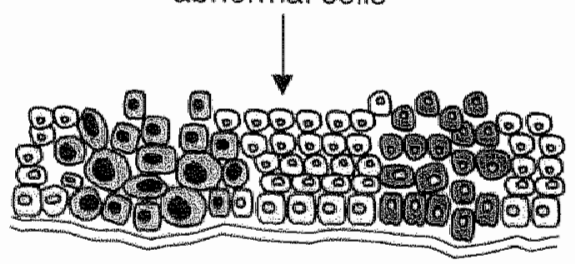

Multiple lesions; genetically unrelated
Clonal origin

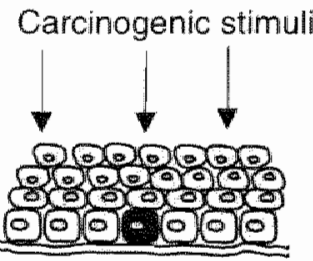

One cell with genetic aberrations

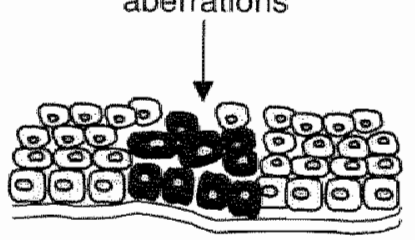

Migration and outgrowth of genetically abnormal cell population

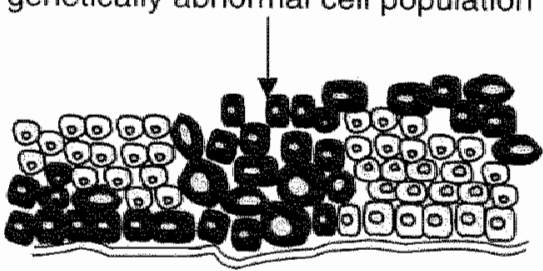

Multiple lesions, genetically related

Figure 1.3. Two hypotheses explaining the frequent detection of multiple head and neck neoplasia within the same patient. 


\subsection{Genetic alterations during head and neck carcinogenesis}

\subsubsection{General}

Head and neck cancer is thought to progress through a series of welldefined clinically and histologically distinguishable stages. Various types of mucosal lesions, which do not fulfil the criteria for malignancy, are frequently observed, and some of these lesions appear to progress towards invasive growth. These so-called premalignant, precursor or preinvasive lesions are usually graded according to the presence and severity of dysplasia (none, mild, moderate, severe). Although the risk for malignant transformation increases with the degree of dysplasia, this histopathological classification is subjective and cannot identify which lesion will show malignant transformation. The identification of (genetic) biomarkers that can predict this neoplastic change more accurately would be of great clinical importance.

As with most solid tumors, the information on the genetic basis of head and neck carcinogenesis has accumulated rapidly during the past ten years. The majority of reports deal with the detection of genetic changes in invasive head and neck cancer. Because preinvasive stages are often very small this makes a detailed genetic analysis problematic. Due to technical improvements in the last years, allowing the genetic study of small numbers of cells prepared from archival material, a generalized genetic progression model, similar to that already proposed for colorectal cancer ${ }^{34}$, is evolving. One of these models, based on microsatellite analysis has been published recently by Califano et al. ${ }^{35}$. The number of chromosome loci showing loss of heterozygosity ( $\mathrm{LOH}$ ) increases in subsequent histological stages of head and neck carcinogenesis. Importantly, it appeared that the loss of some chromosome regions precede evident histological changes. It is clear that this model is far from complete and the authors admit that the temporal placement of most genetic events in this model is still arbitrary. The timing of many other important genetic changes, such as for example the development of DNA aneuploidy, the amplification of specific chromosome regions like 11q13, and the acquisition of alterations in for example the p53 gene, has not yet been accurately deterrnined for head and neck carcinogenesis. 


\subsubsection{Abnormal DNA content, numerical chromosomal alterations}

The accumulation of abnormal chromosome numbers (aneuploidy) is a key characteristic of most solid tumors including HNSCC ${ }^{36,37}$. Flow cytometric DNA-ploidy measurements can easily be performed on solid tumor specimens to determine the overall DNA content of a tumor. The DNA content of numerous head and neck cancers has been studied in this way, and an abnormal DNA content is present in approximately $75 \%$ of these cancers (for a review see Stell et al. ${ }^{38}$ ). The value of DNA flow cytometry in predicting the development of lymph node metastasis, response to therapy and survival is still not established. Although most studies show that patients with a tumor displaying a normal DNA profile have favorable prognosis as compared to patients with a tumor exhibiting an abnormal DNA profile ${ }^{39,40.41}$, there are other studies that have reported the exact opposite ${ }^{42,43}$.

Disadvantages of the DNA flow cytometric technique are (a) that small cell numbers (obtained for example from a premalignant lesion or a cytologic specimen) cannot be evaluated and (b) that no detailed information on the chromosome content can be obtained. No flow cytometric data are therefore available on premalignant lesions of the head and neck region. A few publications have reported the use of image cytometry on tissue sections to study the DNA content of these lesions $44,45,46,47$. These studies have indicated that the DNA content of epithelial cells increases with the severity of preneoplasia as determined histopathologically. In addition, an interesting study by Högmo et al. ${ }^{48}$ indicated that the DNA content from dysplastic lesions preceding cancer was significantly higher than the DNA content of dysplastic lesions that did not show progression.

A procedure that can be used to study numerical and structural chromosomal aberrations in interphase cells is the in situ hybridization (ISH) technique (for a review, see Hopman et al. ${ }^{49}$ ). During the past ten years this method, also referred to as interphase cytogenetics, has been explored for most types of malignancies. Composite probes, compiled from several single copy gene sequences, cosmid clones, phages or yeast artificial chromosomes (YACs), in combination with DNA probes for repetitive sequences in centromeric and telomeric regions, can be used in the hybridization procedures to detect chromosome imbalances, deletions, translocations and rearrangements.

The ISH technique has been applied before to a large series of frozen tissue specimens from primary HNSCC using centromere specific DNA probes for the chromosomes $1,7,9,11,17$ and $18^{37}$. In this study, the 
authors showed that numerical chromosomal aberrations occur frequently in HNSCC and that the pattern of chromosomal abnormalities can characterize and distinguish different stages of head and neck carcinogenesis. Furthermore, several studies have shown that there is a high degree of concordance between aberrant DNA content and magnitude of numerical chromosomal alterations in $\mathrm{HNSCC}^{50.51}$.

A limited number of ISH studies have been published on the presence of chromosomal abnormalities in premalignant stages of head and neck carcinogenesis. This is mainly due to the fact that these (often very small) lesions are routinely fixed in formalin and paraffin embedded, thereby allowing a good preservation of histological architecture essential for proper diagnosis, but making interphase cytogenetics more problematic. In one study on oral leukoplakias 5 out of the 13 cases reported showed aneusomy for chromosomes 7 and/or 17 in more than $5 \%$ of the premalignant cells ${ }^{52}$. Interestingly, 3 of the 5 cases harboring chromosomal abnormalities showed progression to invasive growth, whereas only 1 out of the 8 cases without chromosomal abnormalities progressed. A study by Voravud et al. ${ }^{53}$ on normal and premalignant mucosa present in the vicinity of invasive head and neck cancer, reported that the frequency of cells with aneusomy for the chromosomes 7 and 17 increased gradually as the tissues progressed from histologically normal, via hyperplasia and dysplasia to cancer. Noteworthy was their observation that histologically normal-appearing epithelium adjacent to the tumors contained (a low percentage of cells with) chromosome aneusomy in $35 \%$ of the cases. Aneusomic cells were reported to occur randomly throughout this mucosa and clonal outgrowth of an aneusomic cell population was not found. As also discussed by these authors in other publications ${ }^{54,55}$, this finding can be interpreted as a chromosomal change that is caused by a prolonged carcinogenic exposure of the entire field in these patients with HNSCC.

\subsubsection{Deletions and amplifications of specific chromosomal} regions

Functional loss of tumor suppressor genes is one of the most common genetic alterations in human solid neoplasia. The loss of specific chromosomal regions harboring these genes can be studied by analyzing microsatellite sequences. These tandem repeat DNA sequences represent a very common and highly polymorphic class of genetic elements in the human genome. PCR amplification of these repeats allows rapid assessment for loss of heterozygosity $(\mathrm{LOH})$ of 
specific chromosomal regions. Several detailed allelotypes of HNSCC have been obtained by PCR-based microsatellite marker analysis $56,57,58$. These studies have demonstrated loci of frequent chromosomal loss in head and neck cancer. Chromosomal regions showing a high frequency of allelic loss include at least three loci at chromosome $3 p$ (containing the candidate suppressor gene FHIT), the $9 p 21$ locus (linked to the tumor suppressor gene $p 16^{\mathrm{NKK} 4 \mathrm{~A}}$ ), the p53 gene locus at $17 \mathrm{p} 13$ and a region on chromosome $18 \mathrm{q}$ containing the tumor suppressor gene DCC.

Another powerful technique for studying both losses and gains of DNA sequences is the comparative genomic hybridization $(\mathrm{CGH})$ technique 59.60. Several studies have reported the use of this technique in HNSCC and confirmed $\mathrm{LOH}$ of regions on $3 p, 9 p$, and $17 p^{61,62,63,64}$. In addition, these analyzes identified a frequent loss on $5 q$, with the FAP gene on 5 q21 as a possible target tumor suppressor gene ${ }^{65}$.

A common problem that may hamper an accurate DNA analysis from malignant and especially small premalignant lesions is a contamination with surrounding (normal epithelial and stromal) cells. Microdissection is therefore essential to obtain genomic DNA derived from pure populations of cells of these lesions. Laser-facilitated microdissection can be used routinely to obtain single cells, cell clusters or tissue fragments for DNA isolation 66,67 . LOH has so far been studied in a limited series of microdissected samples of premalignant lesions of the head and neck region ${ }^{35,68}$. From these studies it appears that losses of loci on chromosome $3 p$ and $9 p$ are amongst the earliest detectable genetic events in head and neck tumorigenesis, taking place somewhere in the transition from benign hyperplasia to dysplasia. In both studies it was shown that the use of only one microsatellite-marker for each studied chromosome region results in a high detection frequency of $\mathrm{LOH}$. This finding is promising for the clinical application of these markers because premalignant lesions often contain a limited number of cells and cannot therefore be analyzed with a large number of markers. The CGH-technique has recently been applied to microdissected premalignant lesions of the oral cavity. In agreement with LOH-data, losses on $3 p$ and $9 p$ were among the most prominent genetic alterations

Next to the functional loss of tumor suppressor genes, amplification of chromosome regions harboring putative (proto)oncogenes occurs frequently in carcinogenesis. The $\mathrm{CGH}$ technique can also detect such amplified DNA sequences. In HNSCC the chromosome region most frequently amplified is located on chromosome band 11q13, harboring the CCND1 (PRAD1) gene encoding for the cell cycle regulating protein 
cyclin D1 ${ }^{70,71}$. It has been shown that amplification of the CCND1 gene has an impact on expression of cyclin D1 in HNSCC 72.73. Another highlevel amplification region, 3q26-qter, has been identified in HNSCC, but it is unclear at this moment which oncogene is located in this region.

\subsubsection{Gene mutations and modifications}

Many other genetic alterations, apart from chromosomal alterations, can be detected in head and neck carcinogenesis. Two of the most common genetic alterations detected in HNSCC, but also in most other solid tumors, involve the tumor suppressor genes $p 16^{\text {INK4a }}$ and $p 53^{74}$. Both genes have been shown to function as cell cycle checkpoints, and inactivation of these genes will contribute to a loss of cell cycle control, leading to an accumulation of genetic damage. There are strong indications that a loss of normal p53 function leads to a destabilization of the genome and facilitates development of DNA aneuploidy ${ }^{75,76,77}$.

The chromosomal loci to which both genes are located (9p21 for $p 16^{\text {INKAa }}$ and $17 \mathrm{p} 13$ for $\mathrm{p} 53$ ) show a very high percentage of allelic loss in head and neck lesions, even in premalignant stages of the disease. Based on the two-hit hypothesis ${ }^{78}$, it is to be expected that the high frequency of $\mathrm{LOH}$ at these loci is accompanied by mutations affecting the remaining allele.

Mutations in the p53 gene are indeed present in approximately $50 \%$ of all head and neck cancers ${ }^{79,80}$. P53 mutations have also been detected in a subset of premalignant lesions (mostly severe dysplasias and carcinoma in situ), but it is as yet unknown where this alteration should be placed in the carcinogenic process. Alterations in $p 53$ can be easily detected immunocytochemically because of the stabilization of the mutated protein, and numerous studies have shown the overexpression of p53 in both premalignant and malignant stages of disease ${ }^{81}$.

Mutations in the $p 16^{\text {INKAa }}$ gene are not as frequent and occur in approximately $10 \%$ of head and neck cancers 82,83 . Alternative mechanisms of p16 gene inactivation include homozygous deletion and methylation of the $5^{\prime} \mathrm{CpG}$ island within its promotor region ${ }^{84,85}$. Both homozygous deletions and methylations have indeed been detected in a large proportion of head and neck lesions ${ }^{86,87}$. An indication of p16 gene inactivation is also obtained immunohistochemically if a loss of p16 expression is observed. Papadimitrakopoulou et al. ${ }^{88}$ found that $43 \%$ of oral dysplastic lesions had lost p16 expression, whereas $35 \%$ of the nondysplastic lesions demonstrated such a loss. This finding suggests 
that $p 16$ inactivation takes place as one of the first steps in the multistep process of head and neck carcinogenesis.

\subsubsection{A genetic progression model for head and neck tumorigenesis}

In figure 1.4 the most important genetic alterations, as discussed in the previous paragraphs, have been implemented in a model for the histological progression of head and neck carcinogenesis. Since there is no clear histological starting point for each of these genetic changes known to date, they are all placed within a wide histological window. It is important to note that some genetic changes like loss of chromosome regions on $3 p, 9 p$ and $17 p$ have been studied extensively in different histological stages, whereas other changes, like those in the DNA ploidy and the amplification of cyclin D1, have been studied mainly in invasive head and neck cancer. This figure shows that most genetic alterations occur in preinvasive stages of disease. Although many authors have suggested that specific genetic changes take place in a distinct order, it appears that many changes, taking place at different levels in the genome, accur more or less simultaneously. The relationship between the different genetic changes is unclear until now. Alterations in the p53 gene might for example lead to the development of DNA tetraploidy followed by the acquisition of genetic instability ${ }^{89,90}$. On the other hand there are also reports suggesting that genetic instability results in the loss of tumor suppressor genes like p53 ${ }^{91}$.

\subsection{Scope of this thesis}

As may be obvious from the foregoing overview, information on the genetic basis of head and neck carcinogenesis has accumulated rapidly during the last decade. Key changes in a multi-step progression towards HNSCC have been identified, but a better understanding of these changes is essentiall for the identification of new biomarkers that predict clinical behavior. The overall aim of this study was to investigate in detail the acquisition of chromosomal alterations during head and neck carcinogenesis. Specific changes in the chromosome content were correlated with histological classification, with other genetic alterations and with clinical follow-up. In addition, chromosome patterns in HNSCC were studied to evaluate the presence and extent of intra- and inter- 


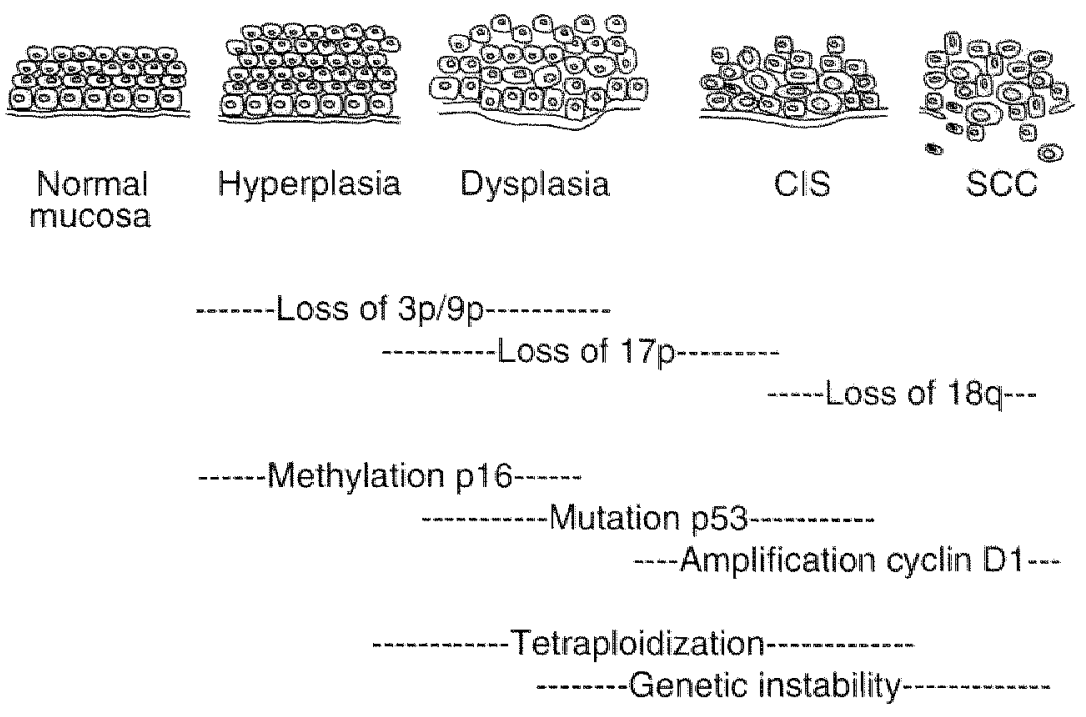

Figure 1.4. Genetic progression model for head and neck carcinogenesis.

tumor heterogeneity. Aberrations in the chromosome content were used as markers for malignancy in both resection margins of HNSCC and in exfoliate cytology.

More specifically, the following questions were addressed during this study:

1. At what stage during head and neck carcinogenesis can numerical chromosomal alterations be detected? Can different steps in the development of DNA aneuploidy be recognized in subsequent phases of head and neck carcinogenesis? Are premalignant lesions genetically instable?

2. Is the presence of (specific patterns of) chromosome alterations indicative for the malignant potential of a premalignant lesion?

3. Does a relationship exist between the aneuploidization process and the functional inactivation of important tumor suppressor genes such as $\mathrm{p} 16^{\mathrm{INK} 4 \mathrm{a}}$ and $\mathrm{p} 53$ in premalignant stages of head and neck carcinogenesis?

4. Are head and neck lesions genetically heterogeneous?

5. Can the ISH technique be used to detect (pre)malignant cells in resection margins and in exfoliate cytology of head and neck cancers? 


\subsection{References}

1. Parkin, D. M., Pisani, P., and Ferlay, J. Estimates of the worldwide incidence of eighteen major cancers in 1985, Int $J$ Cancer. 54: 594-606, 1993.

2. Decker, J. and Goldstein, J.C. Risk factors in head and neck cancer, $N$ Engl J Med. 306:1151-5, 1982.

3. Falk, R. T., Pickle, L. W., Brown, L. M., Mason, T. J., Buffler, P. A.y and Fraumeni, J. F., Ji. Effect of smoking and alcohol consumption on laryngeal cancer risk in coastal Texas, Cancer Res. 49: 4024-9, 1989.

4. Vokes, E. E. Weichselbaum, R. A. Lippman, S. M., and Hong, W. K. Head and neck cancer, N Engl J Med. 328: 184-94, 1993.

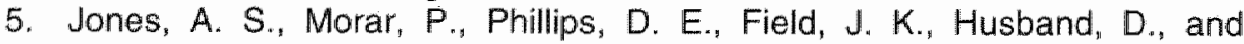
Helliwell, T. R. Second primary tumors in patients with head and neck squamous cell carcinoma, Cancer. 75: 1343-53, 1995.

6. Bartek J., Lukas, J., and Bartkova, J. Perspective: Defects in cell cycle control and cancer, J Pathol. 187: 95-9, 1999.

7. Hartwell, L. H., and Kastan, M. Cell cycle control and cancer, Science. 266: $1821-8,1994$.

8. Hunter, T., and Pines, J. Cyclins and cancer: II-Cyclin D and CDK inhibitors come of age, Cell. 79: 573-82, 1994.

9. Loeb, L. A. Mutator phenotype may be required for multistage carcinogenesis, Cancer Res. 51: 3075-9, 1991.

10. Hartwell, L. Defects in a cell cycle checkpoint may be responsible for the genomic instability of cancer cells, Cell. 71:543-6, 1992.

11. Lengauer, $C_{.,}$Kinzler, $K . W_{\text {, }}$ and Vogelstein, B. Genetic instabilities in human cancers, Nature. 396: 643-9, 1998.

12. Orr Weaver, T. L. and Weinberg, R. A. A checkpoint on the road to cancer, Nature. 392: 223-4, 1998.

13. Uonow, Y., Peinado, M. A., Malkhosyan, S., Shibata, D., and Perucho, M. Ubiquitous somatic mutations in simple repeated sequences reveal a new mechanism for colonic carcinogenesis, Nature. 363: 558-61, 1993.

14. Bronner, C. E., Baker, S. M., Morrison, P. T., Warren, G., Smith, L. G., Lescoe, M. K., Kane, M." Earabino, C., Lipford, J."Lindblom, A., Tannergard, P., Bollag, R. J., Godwin, A. R., Ward, D. C., Nordenskjold, M., Fishel, R., Kolodner, R., and Liskay, R. M. Mutation in the DNA mismatch repair gene homologue hMLH1 is associated with hereditary non-polyposis colon cancer, Nature. 368: 258-61, 1994.

15. Arzimanoglou, I., Gilbert, $F_{\text {, }}$ and Barber, H. R. Microsatellite instability in human solid tumors, Cancer. 82: 1808-20, 1998.

16. Cahill, D. P., Lengauer, C., Yu, J., Riggins, G. J., Willson, J. K., Markowitz, S. D. Kinzler, K. W., and Vogelstein, B. Mutations of mitotic checkpoint genes in human cancers, Nature. 392: 300-3, 1998.

17. Holliday, R. Chromosome error propagation and cancer, Trends Genet. 5: 42-5, 1989.

18. Greider, C. W. Telomere length regulation, Ann Rev Biochem. 65: 337-65, 1996.

19. Rudolph, K., Chang, S., Lee, H., Blasco, M., Gottlieb, G. J., Greider, C., and 
DePinho, R. A. Longevity, stress response, and cancer in aging telomerasedeficient mice, Cell. 96: 701-12, 1999.

20. Nowell, P. C. The clonal evolution of tumor cell populations, Science. 194: $23-8,1976$.

21. Woodruff, M. F. Tumor clonality and its bilological significance, Adv Cancer Res. 50:197-229, 1988.

22. Shackney, S. E. and Shankey, T. V. Genetic and phenotypic heterogeneity of human malignancies: finding order in chaos, Cytometry. 21:2-5, 1995.

23. Pathak, S. Cytogenetic abnormalities in cancer: with special emphasis on tumor heterogeneity, Cancer Metastasis Rev. 8: 299-318, 1990.

24. Poste, G., Doll, J., and Fidler, I. J. Interactions among clonal subpopulations affect stability of the metastatic phenotype in polyclonal populations of B16 melanoma cells, Proc Natl Acad Sci USA. 78: 6226-30, 1981.

25. Leith, J. T., Dexter, D. L., DeWyngaert, J. K., Zeman, E. M., Chu, M. Y., Calabresi, P., and Glicksman, A. S. Differential responses to x-irradiation of subpopulations of two heterogeneous human carcinomas in vitro, Cancer Res. 42: 2556-6, 1982.

26. Slaughter, D. P., Southwick, H. W., and Smejkal, W. "Field cancerization" in orall stratified squamous epithelium, Cancer. 6: 963-8, 1953.

27. Lippman, S. M. and Hong, W. K. Second malignant tumors in head and neck squamous cell carcinoma: the overshadowing threat for patients with early-stage disease, Int J Radiat Oncol Biol Phys. 17: 691-4, 1989.

28. Sidransky, D., Frost, P., Von Eschenbach, A., Oyasu, R., Preisinger, A. C., and Vogelstein, B. Clonal origin bladder cancer, $N$ Engl J Med. 326: 737-40, 1992.

29. Bedi, G. C., Westra, W. H., Gabrielson, E., Koch, W., and Sidransky, D. Multiple head and neck tumors: evidence for a common clonal origin, Cancer Res. 56: 2484-7, 1996.

30. Scholes, A. G., Woolgar, J. A., Boyle, M. A., Brown, J. S., Vaughan, E. D., Hart, C. A., Jones, A. S., and Field, J. K. Synchronous oral carcinomas: independent or common clonal origin? Cancer Res. 58: 2003-6, 1998.

31. Worsham, M. J., Wolman, S. R., Carey, T. E., Zarbo, R. J., Benninger, M. S., and Van Dyke, D. L. Common clonal origin of synchronous primary head and neck squamous cell carcinomas: analysis by tumor karyotypes and fluorescence in situ hybridization, Hum Pathol. 26: 251-61, 1995.

32. Chung, K. Y., Mukhopadhyay, T., Kim, J., Casson, A., Ro, J. Y., Goepfert, H., Hong, W. K., and Roth, J. A. Discordant p53 gene mutations in primary head and neck cancers and corresponding primary cancers of the upper aerodigestive tract, Cancer Res. 53:1676-83, 1993.

33. Leong, P. P., Rezai, B., Koch, W. M., Reed, A., Eisele, D., Lee, D.-J.. Sidransky, D., Jen, J., and Westra, W. H. Distinguishing second primary tumors from lung metastases in patients with head and neck squamous cell carcinoma, J Natl Cancer Inst. 90:972-7, 1998.

34. Fearon, E. R. and Vogelstein, B. A genetic model for colorectal tumorigenesis, Cell. 61:759-67, 1990.

35. Califano, J., van der Riet, P., Westra, W., Nawroz, H., Clayman, G., Piantadosi, S., Corio, R., Lee, D., Greenberg, B., Koch, W., and Sidransky, D. Genetic progression model for head and neck cancer: implications for field cancerization, Cancer Res. 56: 2488-92, 1996. 
36. Mitelman, F, Catalog of chromosome aberrations in cancer, Vol. 5. New York: Wiley-Liss, 1994.

37. Soder, A. I., Hopman, A. H. N., Ramaekers, F. C. S., Conradt, C ", and Bosch, F. X. Distinct non-random patterns of chromosomal aberrations in the progression of squamous cell carcinomas of the head and neck, Cancer Res. 55: 5030-7, 1995.

38. Stell, P. M. Ploldy in head and neck cancer: a review and meta-analysis, Clin Otolaryngol. $16: 510-6,1991$.

39. Rua, S. Comino, A. Fruttero, A., Cera, G., Semeria, C., Lanzilotta, L., and Boffetta, P. Relationship between histological features, DNA flow cytometry, and clinical behavior of squamous cell carcinoma of the larynx, Cancer. 67 : $141-9,1991$

40. Kearsley, J. H., Bryson, G., Battistutta, D., and Collins, R. J. Prognostic importance of cellular DNA content in head and neck squamous cell cancers: A comparison of retrospective and prospective series, Int J Cancer. 47: 31-7, 1991.

41. Hemmer, J., Thein, T., and Van Heerden, W. F. The value of DNA flow cytometry in predicting the development of lymph node metastasis and survival in patients with locally recurrent oral squamous cell carcinoma, Cancer. 79: 2309 13, 1997.

42. Goldsmith, M. M., Cresson, D. H., Arnold, L. A."Postma, D. S., Askin, F. B., and Pillsbury, H. C. Part 1. DNA flow cytometry as a prognostic indicator in head and neck cancer, Otolaryngol Head Neck Surgery. 96: 307-18, 1986.

43. Tytor, M., Olofsson, J., Ledin, T., Brunk, U., and Klintenberg, C. Squamous cell carcinoma of the oral cavity. A review of 176 cases with application of malignancy grading and DNA measurements, Clin Otolaryngol. 15: 235-51, 1990.

44. Crissman, J. D. and Zarbo, R. J. Quantitation of DNA ploidy in squamous intraepithelial neoplasia of the laryngeal glottis, Arch Otolaryngol Head Neck Surg. 117: 182-8, 1991.

45. Dreyer, T., Popella, C., Hinrichs, B., Bohle, R. M., Pohlmann, U., Schulz, A., and Glanz, H. Grading of precancerous laryngeal lesions by multiparameter image analysis at separate epithelial layers, J Pathol. 177: 385-93, 1995.

46. Högmo, A., Munck Wikland, E. Kuylenstierna, R., Lindholm, J., and Auer, G. Nuclear DNA content and p53 immunostaining in metachronous preneoplastic lesions and subsequent carcinomas of the oral cavity, Head Neck. 18: 433-40, 1996.

47. Munck Wikland, E., Kuylenstierna, R., Lindholm, J., and Auer, G. p53 immunostaining and image cytometry DNA analysis in precancerous and cancerous squamous epithelial lesions of the larynx, Head Neck. 19:107$15,1997$.

48. Högmo, A., Lindskog, S., Lindholm, J., Kuylenstierna, R., Auer, G., and Munck Wikland, E. Preneoplastic oral lesions: the clinical value of image cytometry DNA analysis, p53 and p21/WAF1 expression, Anticancer Res. 18: 3645-50, 1998.

49. Hopman, A. H., Voorter, C. E., and Ramaekers, F. C. Detection of genomic changes in cancer by in situ hybridization, Mol Biol Rep. 19: 31-44, 1994.

50. El-Naggar, A. K., Dinh, M., Tucker, S., Luna, M. A., Goeptert, H., Hsu, P., 
and Batsakis, J. G. Genotypic analysis of primary head and neck squamous carcinoma by combined fluorescence in situ hybridization and DNA flow cytometry. Am J Clin Pathol. 105: 102-8, 1996.

51. Hemmer, J. and Prinz, W. Comparison of DNA flow cytometry and fluorescence in situ hybridization with a set of 10 chromosome-specific DNA probes in four head and neck carcinomas, Cancer Genet Cytogenet. 97: 35 $8,1997$.

52. Lee, J. S., Kim, S. Y., Hong, W. K., Lippman, S. M., Ro, J. Y., Gay, M. L., and Hittelman, W. N. Detection of chromosomal polysomy in oral leukoplakia, a premalignant lesion, J Natl Cancer Inst. 85: 1951-4, 1993.

53. Voravud, N., Shin, D. M., Ro, J. Y., Lee, J. S., Hong. W. K., and Hittelman, W. N. Increased polysomies of chromosomes 7 and 17 during head and neck multistage tumorigenesis, Cancer Res. 53: 2847-83, 1993.

54. Hittelman, W. N., Voravud, N., Shin, D. M., Lee, J. S., Ro, J. Y., and Hong, W. K . Early genetic changes during upper aerodigestive tract tumorigenesis, J Cell Biochem. Suppl 17f: 233-6, 1993.

55. Hittelman, W. N., Kim, H. J., Lee, J. S., Shin, D. M., Lippman, S. M., Kim, J., Ro, J. $Y .$, and Hong. W. K. Detection of chromosome instability of tissue fields at risk: in situ hybridization, J Cell Biochem. 25S: 57-62, 1996.

56. Field, J. K., Kiaris, H., Risk, J. M., Tsiriyotis, C., Adamson, R., Zoumpourlis, V., Rowley, H., Taylor, K., Whittaker "J. Howard, P., Belrne, J. C. Gosney. J. R. Woolgar, J., Vaughan, E. D., Spandidos, D. A., and Jones, A. S. Allelotype of squamous cell carcinoma of the head and neck: fractional allele losis correlates with survival, $\mathrm{Br} J$ Cancer. 72: 1180-8, 1995.

57. Ah See, K. W. Cooke, T. G., Pickford, I. R, Soutar, D., and Balmain, A. An allelotype of squamous carcinoma of the head and neck using microsatellite markers, Cancer Res. 54: 1617-21, 1994.

58. Nawroz, H., Riet, P. v. d., Hruban, R. H., Koch, W., Ruppert, J. M., and Sidransky, D. Allelotype of head and neck squamous cell carcinoma, Cancer Res. 54: 1152-5, 1994.

59. Kallioniemi, A., Kallioniemi, O. P., Sudar, D., Rutovitz, D., Gray, J. W., Waldman, F., and Pinkel, D. Comparative genomic hybridization for molecular cytogenetic analysis of solid tumors, Sclence. 258: 818-21, 1992.

60. Knuutila, S., Bjorkqvist., A. M., Autio, K., Tarkkanen, M., Wolf, M., Monni, O., Szymanska, J., Larramendy, M. L., Tapper, J., Pere, H., El Rifai, W., Hemmer, S., Wasenius, V. M., Vidgren, V., and Zhu, Y. DNA copy number amplifications in human neoplasms: review of comparative genomic hybridization studies, Am J Pathol. 152: 1107-23, 1998.

61. Speicher, M. R., Howe, C., Crotty, P., De Manoir, S., Costa, J., and Ward, D. C. Comparative genomic hybridization detects novel deletions and amplifications in head and neck squamous cell carcinomas, Cancer Res. 55: $1010-3,1995$.

62. Brzoska, P. M., Levin, N. A., Fu, K. K., Kaplan, M. J., Singer, M. I., Gray, J. W.y and Christman, M. F. Frequent novel DNA copy number increase in squamous cell head and neck tumors, Cancer Res. 55: 3055-9, 1995.

63. Bockmühl, U., Schwendel, A., Dietel, M., and Petersen, I. Distinct patterns of chromosomal alterations in high- and low-grade head and neck squamous cell carcinomas, Cancer Res. 56: 5325-9, 1996.

64. Bockmühl, U. Petersen, S., Schmidt, S., Wolf, G., Jahnke, V., Dietel, M., 
and Petersen, I. Patterns of chromosomal alterations in metastasizing and nonmetastasizing primary head and neck carcinomas, Cancer Res. 57: $5213-6,1997$.

65. Kinzler, K. W. and Vogelstein, B. Life (and death) in a malignant tumor, Nature. 379: 19-20, 1996.

66. Bonner, R. F., Emmert Buck, M., Cole, K., Pohida, T., Chuaqui, R. Goidstein, S., and Liotta, L. A. Laser capture microdissection: molecular analysis of tissue, Science. 278: 1481-3, 1997.

67. Becker, I., Becker, K. F., Rohrl, M. H., Minkus, G., Schutze, K., and Hofler, $H$. Single-cell mutation analysis of tumors from stained histologic slides, Lab Invest. 75: 801-7, 1996.

68. Mao, L., Lee, J. S., Fan, Y. H., Ro, J. Y., Batsakis, J. G., Lippman, S., Hittelman, W., and Hong, W. K. Frequent microsatellite alterations at chromosomes 9p21 and 3p14 in oral premalignant lesions and their value in cancer risk assessment, Nat Med. 2: 682-5, 1996.

69. Weber, R. G., Scheer, M., Born, I. A., Joos, S., Cobbers, J. M., Hofele, C., Reifenberger, G., Zoller, J. E., and Lichter, P. Recurrent chromosomal imbalances detected in biopsy material from oral premalignant and malignant lesions by combined tissue microdissection, universal DNA amplification, and comparative genomic hybridization. Am J Pathol. 153: 295-303, 1998.

70. Motakura, T., Bloom, T., Kim, H. G., Juppner, H., Ruderman, J. V., Kronenberg, H. M., and Arnold, A. A novel cyclin encoded by a bcl1-linked candidate oncogene, Nature. 350:512-5, 1991

71. Imoto, M., Doki, Y., Jiang, W., Han, E. K., and Weinstein, I. B. Effects of cyclin D1 overexpression on G1 progression-related events, Exp Cell Res. 236: 173-80, 1997.

72. Akervall, J. A., Michalides, R. J., Mineta, H., Balm, A., Borg, A., Dictor, M. R., Jin, Y., Loftus, B., Mertens, F., and Wennerberg, J. P. Amplification of cyclin D1 in squamous cell carcinoma of the head and neck and the prognostic value of chromosomal abnormalities and cyclin D1 overexpression, Cancer. 79: 380-9, 1997.

73. Izzo, J. G., Papadimitrakopoulou, V. A., Li, X. Q., Ibarguen, H., Lee, J. S., Ro, J. Y., El-Naggar, A., Hong, W. K., and Hittelman, W. N. Dysregulated cyclin D1 expression early in head and neck tumorigenesis: in vivo evidence for an association with subsequent gene amplification, Oncogene 17: 2313-22, 1998.

74. Hussain, S. P., and Harris, C. C. Molecular epidemiology of human cancer: Contribution of mutation spectra studies of tumor suppressor genes, Cancer Res. 58: 4023-37, 1998

75. Livingstone, L. R., White, A., Sprouse, J., Livanas, E., Jacks, T., and Tlsty, T. D. Altered cell cycle arrest and gene amplification potential accompany loss of wild-type p53, Cell. 70:923-35, 1992.

76. Cross, S. M., Sanchez, C. A., Morgan, C. A., Schimke, M. K., Ramel, S., Idzerda, R. L., Raskind, W. H., and Reid, B. J. A p53-dependent mouse spindle checkpoint, Science. 267: 1353-6, 1995.

77. Fukasawa, K., Choi, T., Kuriyama, R., Rulong, S., and Vande Woude, G. F. Abnormal centrosome amplification in the absence of $p 53$, Science. 271: 
$1744-7,1996$.

78. Knudson, A. G., Jr. Mutation and cancer: statistical study of retinoblastoma, Proc Natl Acad Sci USA. 68: 820-3, 1971.

79. Boyle, J. O.. Hakim, J., Koch, W., van der Riet, P., Hruban, R. H., Roa, R. A., Correo, R., Eby, Y. J., Ruppert, J. M., and Sidransky, D. The incidence of p53 mutations increases with progression of head and neck cancer, Cancer Res. 53: 4477-80, 1993.

80. Maestro, R., Dolcetti, R., Gasparotto, D., Doglioni, C., Pelucchi, S., Barzan, L., Grandi, E., and Boiocchi, M. High frequency of p53 gene alterations associated with protein overexpression in human squamous cell carcinoma of the larynx, Oncogene. 7:1159-66, 1992.

81. Raybaud-Diogene, H., Tetu, B., Morency, R., Fortin, A., and onteil, R. A. P53 overexpression in head and neck squamous cell carcinoma: Review of the literature, Eur J Cancer B Oral Oncol. 32B: 143-9, 1996.

82. Zhang, S. Y., Klein Szanto, A. J. P., Sauter, E. R., Shafarenko, M. Mitsunaga, S., Nobori, T., Carson, D. A., Ridge, J. A., and Goodrow, T. L. Higher frequency of alterations in the p16/CDKN2 gene in squamous cell carcinoma cell lines than in primary tumors of the head and neck, Cancer Res. 54: 5050-3, 1994.

83. Cairns, P., Mao, L., Merlo, A., Lee, D. J.s Schwab, D., Eby, Y., Tokino, K., Riet, P. v. d., Blaugrund, J. E., and Sidransky, D. Rates of p16 (MTS1) mutations in primary tumors with 9p loss, Science. 265: 415-6, 1994.

84. Kamb, A., Gruis, N. A., Weaver Feldhaus, J., Liu, Q., Harshman, K., Tavtigian, S. V., Stockert, E., Day, R. S., 3rd, Johnson, B. E., and Skolnick, M. H. A cell cycie regulator potentially involved in genesis of many tumor types, Science. 264: 436-40, 1994.

85. Merlo, A., Herman, J. G., Mao, L., Lee, D. J., Gabrielson, E., Burger, P. C., Baylin, S. B., and Sidransky, D. 5' CpG island methylation is associated with transcriptional silencing of the tumor suppressor p16/CDKN2/MTS1 in human cancers, Nat Med. 1:686-92, 1995.

86. Gonzalez, M. V., Pello, M. F., Lopez Larrea, C., Suarez, C., Menendez, M. $\mathrm{J}$, and Coto, E. Deletion and methylation of the tumor suppressor gene p16/CDKN2 in primary head and neck squamous cell carcinoma, $J$ Clin Pathol. 50: 509-12, 1997.

87. Reed, A. L., Califano, J., Caims, P., Westra, W. H., Jones, R. M., Koch, W., Ahrendt, S., Eby, Y., Sewell, D., Nawroz, H., Bartek, J., and Sidransky, D. High frequency of p16 (CDKN2/MTS-1/INK4A) inactivation in head and neck squamous cell carcinoma, Cancer Res. 56: 3630-3, 1996.

88. Papadimitrakopoulou, V., lzzo, J., Lippman, S. M., Lee, J. S., Fan, Y. H., Clayman, G., Ro, J. Y., Hittelman, W. N., Lotan, R., Hong, W. K., and Mao, $\mathrm{L}$. Frequent inactivation of $\mathrm{p} 16(\mathrm{NK} 4 \mathrm{a})$ in oral premalignant lesions, Oncogene. 14. 1799-1803, 1997.

89. Cross, S. M., Sanchez, C. A., Morgan, C. A., Schimke, M. K., Ramel, S., Idzerda, R. L., Raskind, W. H., and Reid, B. J. A p53-dependent mouse spindle checkpoint, Science. 267: 1353-6, 1995.

90. Fukasawa, K., Choi, T., Kuriyama, R., Rulong, S., and Vande Woude, G. F. Abnormal centrosome amplification in the absence of $p 53$, Science. 271: 1744-7, 1996.

91. Albertoni, M., Daub, D. M., Arden, K. C., Viars, C. S., Powell, C., and Van 
Meir, E. G. Genetic instability leads to loss of both p53 alleles in a human glioblastoma, Oncogene. 16:3211-6, 1998. 


\section{Chapter 2}

\section{Chromosome instability as an indicator of malignant progression in laryngeal mucosa}

Joris A. Veltman, Fredrik J. Bot, Ference C. Huynen, Frans C. S.

Ramaekers, Johannes J. Manni, and Anton H. N. Hopman 
Purpose: Routine histological examination cannot predict whether or not premalignant laryngeal lesions will progress towards invasive growth. The acquisition of changes in chromosome constitution has been suggested to be essential for driving tumor progression by enhancing mutagenic mechanisms. The aim of the present study was to determine whether chromosomal changes occur in the subsequent stages of early laryngeal carcinogenesis and if so, whether these changes can be of prognostic value.

Material and Methods: Numerical aberrations for chromosomes 1 and 7 were detected in tissue sections from archival material using an improved in situ hybridization protocol. In total 8 benign laryngeal lesions, 37 premalignant laryngeal lesions and 16 specimens containing histologically normal epithelium adjacent to laryngeal squamous cell carcinoma were studied. Both the histological and the cytogenetic classification were correlated with progression to laryngeal cancer.

Results: No evidence for chromosome alterations was obtained in the control group, nor in histologically normal epithelium adjacent to laryngeal squamous cell carcinomas, nor in all but one hyperplastic lesions $(n=11)$. In contrast 14 out of 15 dysplasias and 9 out of 11 carcinomas in situ contained numerical chromosomal aberrations. Tetrasomy was present in the majority of the dysplastic lesions. An instable chromosome content (indicated by the presence of chromosome imbalances and/or polyploidization) in the premalignant lesion strongly predicted its malignant progression.

Conclusion: Our results show that different steps in chromosome aneuploidization occur in subsequent stages of early laryngeal carcinogenesis. The change from a stable to an instable chromosome constitution is of importance for malignant progression. 


\subsection{Introduction}

The generation of abnormal chromosome numbers (aneuploidy) is a key characteristic of most solid tumors including head and neck squamous cell carcinoma (HNSCC) ${ }^{1-3}$. Although the patterns of chromosomal alterations amongst HNSCC differ widely, intratumoral heterogeneity seems to be limited: Identical patterns of chromosomal alterations, including extensive chromosomal copy number imbalances and chromosome polysomy, have recently been detected by us in macroscopically distinct areas of individual HNSCC specimens ${ }^{4}$. It can be deduced from these results that abnormal chromosome patterns are present in an early stage of head and neck carcinogenesis and remain relatively stable during clonal expansion. It has been suggested that the development of aneuploidy, indicative for genetic instability, is crucial for cells to progress through the initial stages of the carcinogenic process by enhancing mutagenic mechanisms ${ }^{5-8}$. Although there are some reports on the presence of chromosome aberrations in premalignant head and neck epithelium, no detailed information is available on the complexity of the chromosome patterns in this epithelium ${ }^{2,9}$.

In this study the in situ hybridization (ISH) technique using chromosome specific probes was performed on a clinically and histologically welldefined series of premalignant lesions of the larynx. In addition, extensive stretches of histologically normal epithelium adjacent to laryngeal squamous cell carcinoma (LSCC) were investigated in order to find out whether numerical chromosome aberrations could be detected in these carcinogen-exposed areas as reported by others ${ }^{2}$. The improved protocol was applied to thin tissue sections and allowed a direct coupling of the genetic information to the histopathological phenotype. Based on previous studies with HNSCC DNA probes directed against the centromeric regions of the chromosomes 1 and 7 were chosen ${ }^{2-4,10}$. Using these techniques, we were able to study the presence of aneuploidy, chromosomal copy number imbalances and polyploidization in different histological stages of laryngeal preneoplasia. This allowed us to draw conclusions about the sequence of changes in the chromosome content that occur during early laryngeal carcinogenesis. In addition, the chromosome classification of premalignant lesions was correlated to clinical follow-up in order to find out whether the different steps in chromosome aneuploidization were indicative for malignant transformation. 


\subsection{Materials and methods}

\subsubsection{Patient material}

42 formalin-fixed, paraffin-embedded specimens were avallable from premalignant laryngeal lesions of 33 patients. From 6 of these patients, subsequent biopsies containing premalignant laryngeal lesions were included. As a control group, benign vocal cord polyps of 10 patients were included. All of these specimens were obtained by microlaryngeal surgery. In addition, from each of 9 patients with LSCC who underwent total laryngectomy, two formalin-fixed, paraffin-embedded specimens containing histologically normal epithelium either adjacent to laryngeal carcinomas or at the margin of resection were used. From all these specimens a heamatoxylin-eosin stained serial section was thoroughly reviewed by an experienced pathologist (F.J.B.) and classified as normal, hyperplastic, dysplastic, carcinoma in situ or infiltrative carcinoma according to Friedmann "11. Hyperplasia is defined as keratosis and acanthosis with at most slight atypia of the basal cell layer. Dysplasia shows in addition more than just slight individual cell atypia, increasing keratosis and sometimes parakeratosis. Carcinoma in situ (CIS) is characterized by, in addition to the above, increasing, often full thickness cell atypia, loss of polarity and frequent mitoses and lacking infiltrative growth. Normal epithelium is regular non-keratinizing squamous epithelium without the features mentioned above.

\subsubsection{In situ hybridization}

ISH was essentially performed using a recently optimized protocol ${ }^{12}$. Briefly, after deparaffinization $4 \mu \mathrm{m}$ thick sections were pre-treated with $85 \%$ formic acid containing $0.3 \% \mathrm{H}_{2} \mathrm{O}_{2}$, followed by incubating at $80^{\circ} \mathrm{C}$ in $1 \mathrm{M}$ sodium thiocyanate. After digestion with pepsin from porcine stomach mucosa (800-1,200 U/mg protein; Sigma Chemical Co., St.Louis, MO) at a concentration of $4 \mathrm{mg} / \mathrm{mml}$ in $0.02 \mathrm{~N} \mathrm{HCl}_{\text {, individual }}$ sections were hybridized using either a centromere-specific probe for the human chromosome 1 or 7 , both labeled with biotin-11-dUTP (Boehringer, Mannheim, Germany) ${ }^{13}$. Immunochemical detection of hybridization products was performed by a standard avidin-biotin complex procedure. Signals were developed using diaminobenzidine/ $\mathrm{H}_{2} \mathrm{O}_{2}$, sections were counterstained with heamatoxylin and mounted in Entellan (Merck, Darmstadt, Germany). 


\subsubsection{Evaluation of $1 \mathrm{SH}$ results}

Evaluation was performed qualitatively by three investigators (J.A.V. F.C.H., and A.H.N.H.) by analyzing in detail the histopathologically normal and premalignant laryngeal epithelium, scoring for the presence of nuclei with aberrant copy numbers, studying the distribution of these nuclei and determining the highest copy number. In all evaluations strict criteria for the classification of individual nuclei were applied ${ }^{14}$ "Based on this evaluation, lesions were classified as either disomic, trisomic, tetrasomic or polysomic based on the maximum chromosome copy number present in the lesion $(2,3,4$, or more than 4 , respectively). In addition to this qualitative analysis, a quantitative analysis was performed by counting the chromosome copy number in 400 nuclei per histological area. Based on these results, ISH spot-count distribution patterns were obtained for each specimen with each chromosome probe and the chromosome index (Cl) was calculated, defined as the mean number of chromosome copies per nucleus.

\subsubsection{Statistical analysis}

Statistical analysis was performed with SPSS (Statistical Package for the Social Sciences) 7.5 (SPSS, Chicago, IL). For this analysis only patients without a previous history of LSCC were included. The twosided Fisher's exact test was used to investigate whether there was a significant difference in progression to invasive cancer in (a) different histological subgroups, and (b) groups with distinct patterns of chromosomal aberrations. The limit for significance was set at $p=0.05$. In addition, the Kaplan-Meier method was used for plotting a cancer-free survival curve. Log rank test was used for survival analysis. 


\subsection{Results}

Using the ISH protocol described, discrete hybridization signals were obtained in combination with the retention of a proper nuclear and tissue morphology in 8 of 10 control specimens $(80 \%)$, in 16 of 18 biopsies from histologically normal epithelium in the surroundings of laryngeal cancers $(89 \%)$, and in 37 of the 42 premalignant lesions $(88 \%)$. Figure 2.1 illustrates typical ISH results for normal epithelium and different premalignant stages of laryngeal epithelium. Because of nuclear truncation in the tissue sections many nuclei in the normal epithelium exhibited less than two chromosome-specific signals. Therefore, a control study was performed to determine the ISH distribution pattern in normal laryngeal epithelium.

\subsubsection{ISH on normal laryngeal epithelium}

Normal epithelium from 8 patients with benign vocal cord lesions showed 0,1 , or 2 signals per nucleus for both chromosomes 1 and 7 . No nuclei with more than 2 signals were identified by detailed analysis of the entire epithelia of these 8 cases, nor were differences observed between the ISH patterns of chromosomes 1 and 7 . As an example, figure 2.1a shows a detail of the ISH pattern observed for chromosome 1 in normal laryngeal epithelium. In addition, figure 2.2a shows the mean ISH distribution patterns and standard deviations for the chromosomes 1 and 7 in these specimens. Based on these results, the mean number of chromosome copies per nucleus (chromosome index; $\mathrm{Cl}$ ) was calculated to be 1.4 for both chromosomes (ranging from 1.3 to 1.5 ). Using the mean value plus 3 times the standard deviation, a $\mathrm{Cl}$ of $* 1.7$ is highly suggestive for gain of chromosomes.

\subsubsection{ISH on normal epithelium adjacent to LSCC}

Extensive areas of histologically normal epithelium adjacent to LSCC $(n=8)$ and at the margin of resection of the same cases $(n=8)$ were analyzed both qualitatively and quantitatively. In this group, no nuclei with three or more chromosome copies were identified in either the qualitative or the quantitative analysis, nor were differences observed between the ISH patterns of chromosomes 1 and 7 . The mean ISH distribution patterns and standard deviations for the chromosomes 1 and 7 are shown in figure $2.2 \mathrm{~b}$. Comparable ISH patterns were observed in 
normal epithelium adjacent to LSCC and in normal epithelium at the margin of resection of the same tumors (results not shown). The mean $\mathrm{Cl}$ values of both chromosomes, 1.5 for chromosome 1 (ranging from 1.3 to 1.6) and 1.4 for chromosome 7 (ranging from 1.2 to 1.6 ), were also comparable in this group.

\subsubsection{ISH on premalignant laryngeal epithelium}

Based on the qualitative analysis, the 37 premalignant laryngeal lesions were classified as disomic, trisomic, tetrasomic or polysomic for chromosome 1 and 7 (summarized in table 2.1). An ISH pattern identical to that of the normal laryngeal epithelium was obtained in 10 hyperplastic lesions (figure 2.1b). In these specimens, not a single nucleus exhibiting more than two ISH signals was identified after detailed analysis by three observers. In contrast, 1 hyperplastic lesion contained an area of approximately 300 nuclei with trisomy for chromosome 7 (figure $2.1 \mathrm{c}$ ), whereas no numerical aberrations were detected in the same area for chromosome 1. Chromosomal aberrations (i.e. trisomy, tetrasomy or polysomy) were detected in 14 out of 15 dysplasias and in 9 out of $11 \mathrm{CIS}$. Taking the nuclear truncation into consideration, it appeared that all nuclei within these lesions contained aberrant chromosome copy numbers. Nuclell located in the basal cell layer contained the same pattern of chromosomal aberrations as the other cell layers. Not orly nuclei with three or four ISH signals were frequently observed (figure 2.1d), but in some cases nuclei with 6 to 8 signals, indicating polyploidization, were clearly present (figure $2.1 \mathrm{e} / \mathrm{f}$ ). In addition, imbalances in the copy number of chromosome 1 and 7 were frequently observed by comparing the hybridization results of the two different probes in the same histological area in serial sections. Histologically normal or hyperplastic epithelium, often present adjacent to an aneusomic dysplasia or CIS, was never shown to contain nuclei with aberrant copy numbers for both chromosome 1 and 7 (results not shown).

In order to validate the qualitative classification, and to obtain detailed information on the presence of chromosome imbalances and polyploidization, the $\| \mathrm{SH}$ results of 22 lesions were further quantified by counting the chromosome copy number in 400 nuclei per specimen. Lesions classified by the qualitative approach as disomic for either chromosome 1 or 7 showed an ISH pattern similar to the pattern obtained for these chromosomes in the normal epithelium (figure 2.2c). In contrast, all lesions classified as aneusomic for chromosome 1 and/or 
7 revealed an aberrant $\mathrm{ISH}$ pattern (figure $2.2 \mathrm{~d}$-f). The percentage of nuclei with aberrant chromosome copy numbers ranged from $28 \%$ to $65 \%$ in these lesions. Evidence for the existence of both chromosome copy number imbalances and polyploidization in these premalignant lesions confirmed in all cases the qualitative analysis (see for example figure 2.2e/f). Taking the results of both chromosomes together, the $\mathrm{Cl}$ of the lesions classified as disomic by the qualitative approach varied between 1.3 and 1.6 (mean 1.4), whereas the $\mathrm{Cl}$ of the lesions classified as aneusomic varied between 1.9 and 2.9 (mean 2.5).

From 6 cases included in this study, subsequent biopsies, taken from the same laryngeal location and containing premalignant lesions, were analyzed by ISH. Although the time interval between different biopsies was 2 to 4 years in some of these cases, a remarkable stability in the chromosome constitution was observed. Tetrasomy for the chromosomes 1 and 7 was observed in subsequent biopsies of two cases, whereas polysomy for chromosome 1 and/or 7 was detected in subsequent biopsies of three other cases. Only for one case a change from disomy for chromosome 1 and 7 in the first two biopsies to tetrasomy for both chromosomes in the third biopsy was detected.

Table 2.1. Overview of the qualitative classification of the ISH results in normal and (pre)malignant laryngeal epithelium.

\begin{tabular}{|c|c|c|c|c|c|}
\hline \multirow[t]{2}{*}{ Histology } & \multirow{2}{*}{$\begin{array}{c}\text { Disomy } \\
1 \text { and } 7{ }^{a} \\
\text { Total no. } \\
\text { of } \\
\text { specimens }\end{array}$} & \multicolumn{4}{|c|}{ Aneusomy 1 and/or $7^{b}$} \\
\hline & & $\begin{array}{l}\text { Total no. } \\
\text { of } \\
\text { specimens }\end{array}$ & $\begin{array}{c}\text { Tetrasomy } \\
1 \text { and } 7\end{array}$ & $\begin{array}{c}\text { Imbalances } \\
1 \text { and } 7{ }^{\circ}\end{array}$ & $\begin{array}{l}\text { Polysomy }{ }^{-1} \\
1 \text { and/or } 7\end{array}$ \\
\hline Normal control epithelium & $8(100 \%)$ & $0(0 \%)$ & - & - & - \\
\hline $\begin{array}{l}\text { Normal epithelium } \\
\text { adjacent to LSCC }\end{array}$ & $16(100 \%)$ & $0(0 \%)$ & - & - & - \\
\hline Hyperplasia & $10(91 \%)$ & $1(9 \%)$ & . & $1(9 \%)$ & - \\
\hline Dysplasia & $17 \%$ & $14(93 \%)$ & $7(46 \%)$ & $3(20 \%)$ & $4(27 \%)$ \\
\hline CIS & $2(18 \%)$ & $9(82 \%)$ & $2(18 \%)$ & $2(18 \%)$ & $5(46 \%)$ \\
\hline LSCC & $4(25 \%)$ & $12(75 \%)$ & $3(19 \%)$ & $4(25 \%)$ & $5(31 \%)$ \\
\hline
\end{tabular}

a No evidence of nuclei with more than two ISH signals for both chromosomes.

${ }^{b}$ Containing multiple nuclei with more than two ISH signals for one or both chromosomes. As evidenced by comparing the hybridization resulls of the chromosomes 1 and 7 in identical histological
areas of serial sections.

Containing multiple nuclei with more than four ISH signals for one or both chromosomes.

- Selected from previously published data of our group (ref. 4 and 10). 


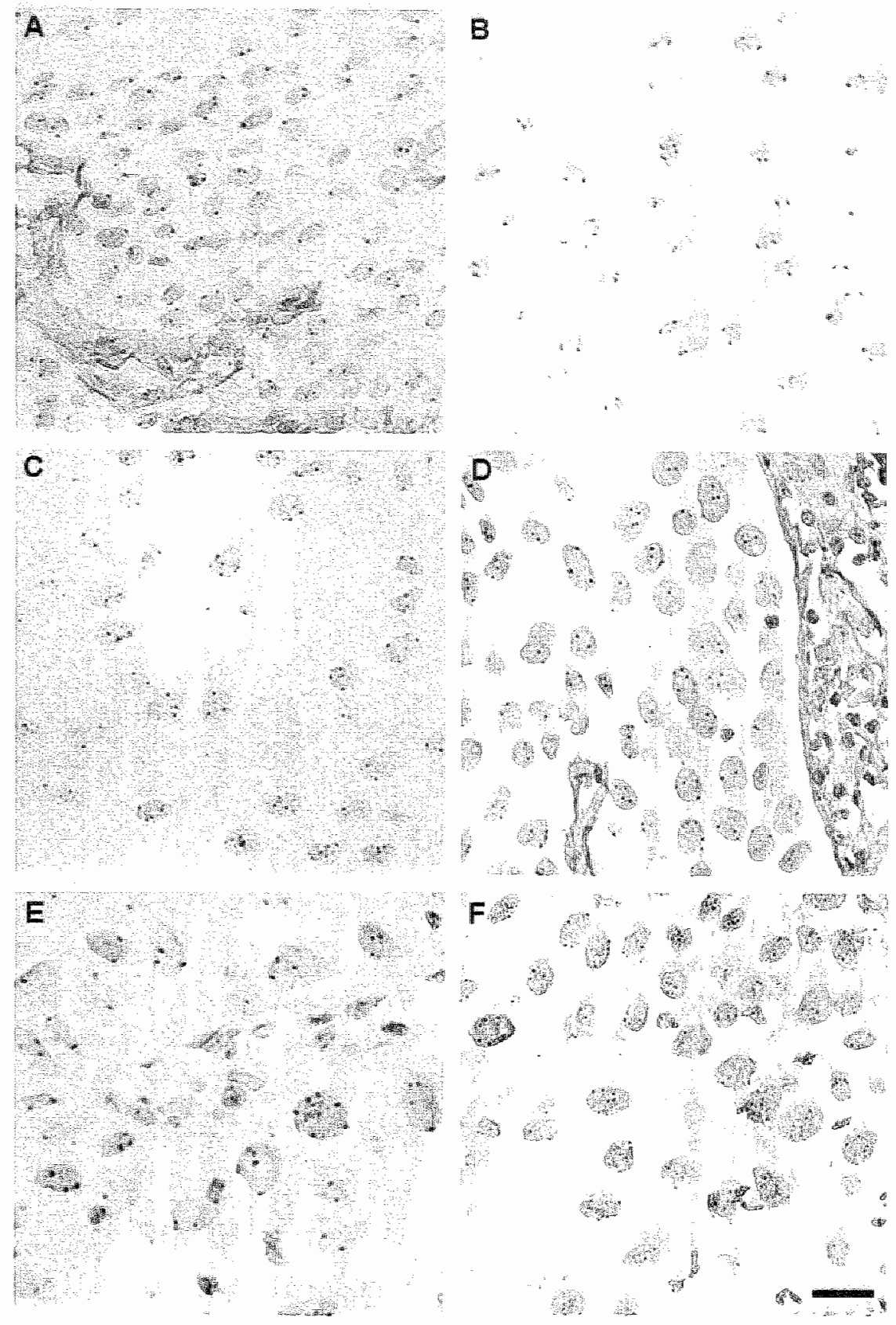

Figure 2.1. Examples of $I S H$ analyzes on $4 \mu \mathrm{m}$ thick sections of histopathologically normal and premalignant laryngeal epithelium.

Chromosome 1 analysis of normal epithelium (A) and a dysplasila (D). Chromosome 7 analysis of two hyperplastic lesions $(B, C)$ and two CIS lesions (E,F). Scale bar, $10 \mu \mathrm{m}$. 

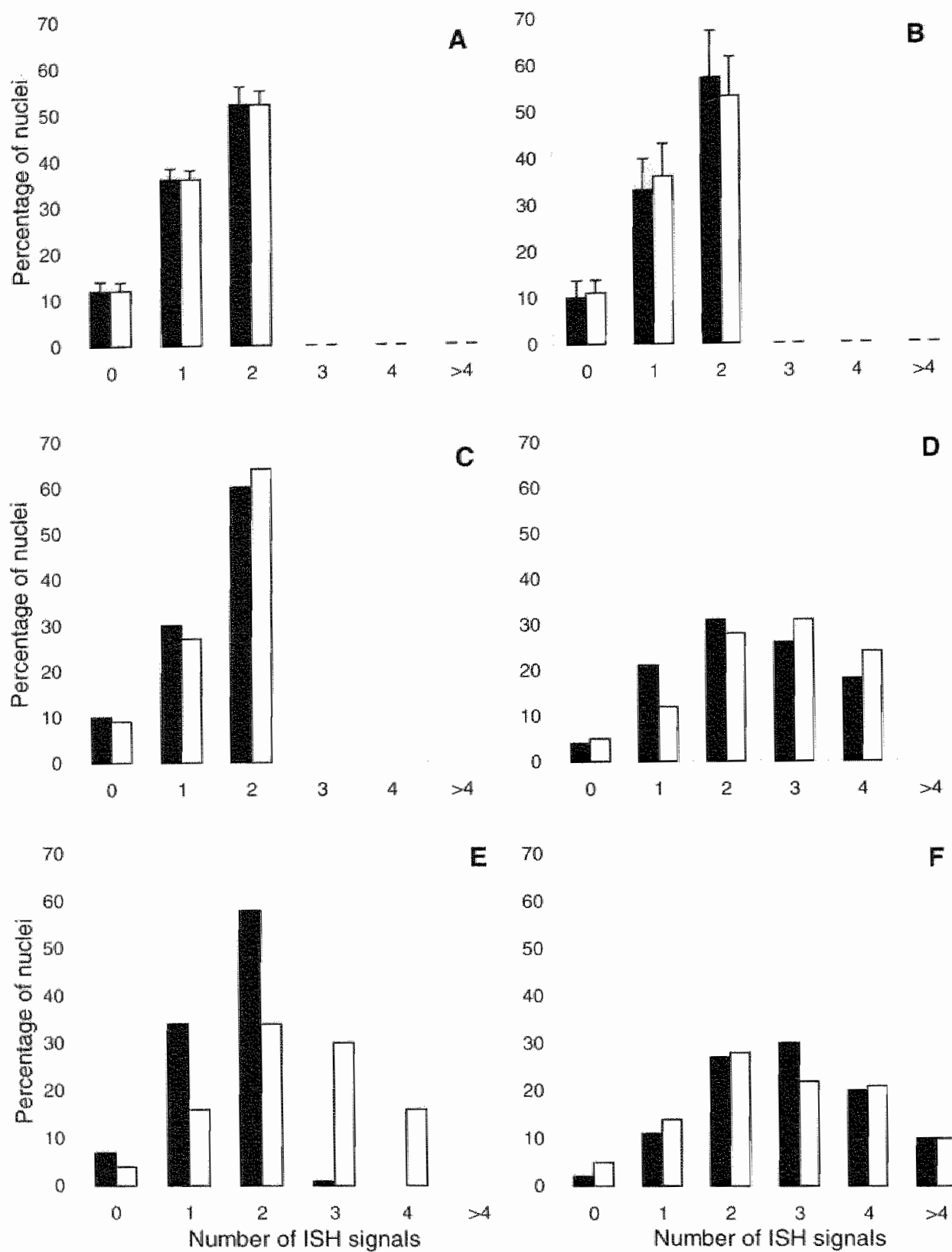

$\mathbf{F}$

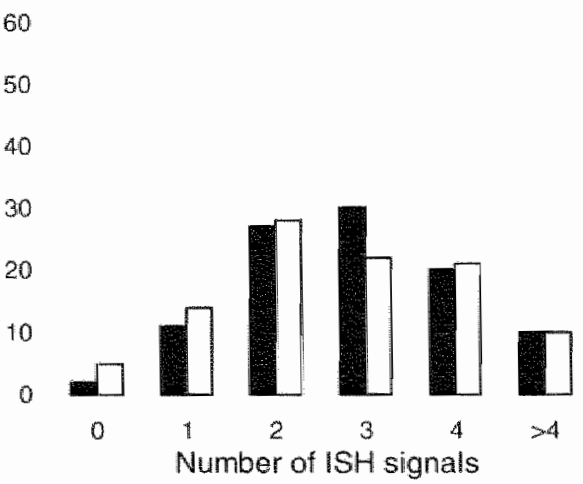

Figure 2.2. ISH distribution patterns in $4 \mu \mathrm{m}$ thick sections.

Black and white bars indicate ISH results of chromasome 1, and chromosome 7, respectively. Mean ISH distribution pattens plus standard deviations in epithelium from benign laryngeal lesions $(A)$ and in histologically normal epithelium adjacent to LSCC (B). ISH distribution pattern of a hyperplasia classified as disomic for chromosome 1 and 7 (C) a dysplasia with tetrasomy for both chromosomes (D), a CIS with chromosome copy number imbalances (E) and a CIS with polypioidization (F). 


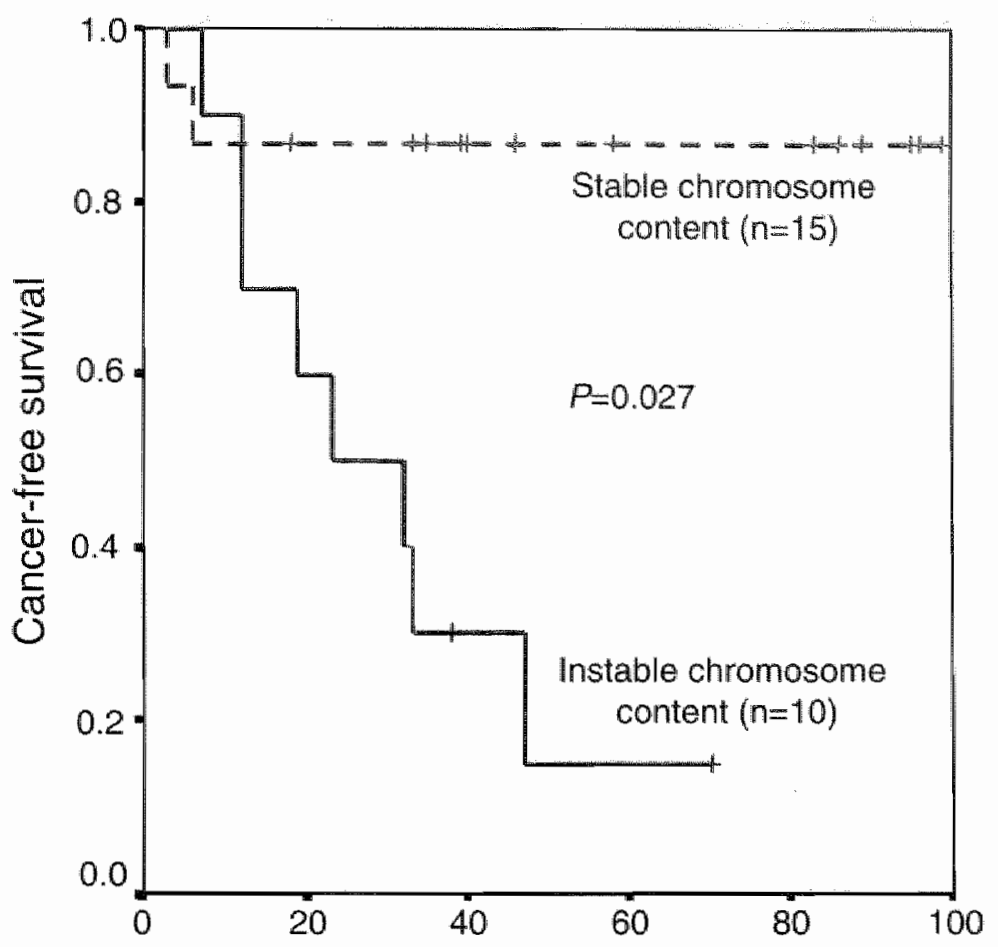

Time in months

Figure 2.3. Cancer-free survival in patients with a stable and an instable chromosome content.

Kaplan-Meier curves are shown for 25 patients with premalignant laryngeal lesions. Data on patients who did not develop LSCC were censored in the analysis. The group of patients with a stable chromosome content consisted of the lesions with disomy or tetrasomy for chromosomes 1 and 7 . The group of patients with an instable chromosome content consisted of the lesions with chromosome copy number imbalances and polysomy for chromosomes 1 and 7 . The difference in cancer-free survival time was tested using the log rank test.

\subsubsection{Correlation between histology, chromosome classification and progression to laryngeal cancer}

10 of 25 evaluable cases developed a LSCC. The median follow-up of the progressive and the non-progressive group was 72 (ranging from 25 to 149 months) and 61 months (ranging from 18 to 99 months), respectively. All LSCCs developed within 47 months after diagnosis of the first premalignant lesion. 
There was a significant difference in clinical follow-up between patients with a hyperplastic lesion and patients with dysplasia or CIS $(p=0.01)$. No significant difference in progression was observed between patients with dysplasia and patients with CIS $(p>0.05)$. Also no significant difference in progression was observed between the group of patients with lesions without evidence of chromosomal abnormalities and the group of patients containing chromosome abnormalities ( $p>0.05)$. However, within the group of patients with aneusomic lesions a significant difference in progression was observed between patients with lesions containing tetrasomy for both chromosomes and patients with lesions containing chromosome copy number imbalances and/or chromosome polysomy $(p=0.03)$.

The time to cancer development from the baseline biopsy was significantly shorter in the group with an instable chromosome content (i.e. chromosome copy number imbalances and chromosome polysomy) than in the group with a stable chromosome content (i.e. disomy and tetrasomy for both chromosomes) ( $p=0.027$ by the log rank test) (figure 2.3).

\subsection{Discussion}

In this study the chromosomal constitution of premalignant laryngeal lesions was investiglated by applying the in situ hybridization technique to paraffin sections. The use of a strongly improved $\mathrm{ISH}$ protocol, resulting in an improved retention of tissue morphology, sharply localized ISH signals and a reduced minor binding of the DNA probes, proved to be essential for a detailed analysis of both normal and premalignant laryngeal epithelium ${ }^{12}$. The use of a suboptimal protocol easily leads to misclassification. In our study, both a qualitative and a quantitative analysis was performed, while applying strict evaluation criteria for the classification of individual nuclei ${ }^{14}$. An advantage of the qualitative approach is that it allows the classification of small lesions that can often not properly be analyzed quantitatively because of the low numbers of nuclei.

Our results show no numerical aberrations for chromosomes 1 and 7 in control laryngeal epithelium, while also histologically normal epithelium adjacent to laryngeal tumors showed a normal chromosome content. This finding is in contrast with data in the literature, reporting low percentages of nuclei with numerical aberrations for chromosomes 7 
and 17 in normal epithelium adjacent to head and neck cancer ${ }^{2}$. Based on the data presented in the underlying study and our recent work on resection margins from oral squamous cell carcinomas ${ }^{15}$, we conclude that numerical aberrations for the chromosomes 1 and 7 are not detected in histologically normal epithelium adjacent to HNSCC. Although all kinds of (epi)genetic changes might occur randomly in this carcinogen-exposed tissue, our data indicate that these changes do not cause major alterations in the chromosome content, such as chromosome copy number changes. Numerical chromosome alterations were only detected in expanded cell populations that have accumulated extensive genetic changes and which are in most cases histologically altered to at least mild degrees of dysplasia (see discussion below). Similar results were recently described for morphologically normal cervical epithelium adjacent to CIN lesions ${ }^{16}$.

No numerical chromosomal aberrations were found also in 10 of 11 laryngeal hyperplasias. Interestingly, in one hyperplasia an area with trisomy for chromosome 7 was observed. Trisomy for chromosome 7 was also identified in 2 dysplastic lesions and $1 \mathrm{CIS}$ lesion included in this series. Trisomy for chromosome 7 has been described in many tumor types, often as the sole chromosomal aberration, and has therefore been interpreted as a primary change in cancer development ${ }^{1}$. In contrast to the ISH results for hyperplasias, $93 \%$ of the dysplasias and $82 \%$ of the CIS contained numerical aberrations for one or both of the chromosomes examined, a percentage that is comparable to that of HNSCC ${ }^{4}$. This shows that the acquisition of abnormal chromosome numbers is an early event in laryngeal carcinogenesis and can be detected in nearly all lesions with dysplasia. Expansion of these aneusomic cell populations was evidenced by the fact that the entire dysplastic or CIS lesions contained nuclei with abnormal chromosome numbers, whereas adjacent non-dysplastic areas did not contain chromosome aneusomy.

Tetrasomy for both chromosome 1 and 7 , indicating a more or less balanced tetraploid chromosome status, was present in a considerable group of dysplastic lesions (46\%), whereas only a minority of the CIS lesions (118\%) contained a balanced chromosome status. These results provide support to the theory that tetraploidization takes place as one of the first steps in the change of the genomic content, and indicate that this change is correlated with the histological change from hyperplasia to dysplasia. The cells containing these excessive chromosome numbers will then become cytogenetically unstable, both losing and gaining chromosomes randomly over the course of successive cell divisions ${ }^{17}$. Chromosome copy number imbalances and/or polyploidization, 
indicative for an overall chromosomal instability, indeed appeared to be more common in CIS lesions, although they were also found in a number of dysplastic lesions. The identification of these complex chromosome patterns in premalignant stages of laryngeal carcinogenesis strongly resembled the chromosome patterns identified by us in $\mathrm{HNSCC}^{3-4}$.

Interestingly, progression to invasive cancer was significantly more common in patients with a lesion containing these chromosome imbalances or polyploidization as compared to patients with a lesion with a balanced tetrasomic chromosome status. In contrast to these genetic subgroups, there was no significant difference in clinical follow-up between dysplastic lesions and CIS lesions. In our opinion, this is the first report demonstrating a correlation between tumor development and the presence of chromosomal instability in a premalignant lesion. These data strongly indicate that the acquisition of chromosomal instability is crucial for cells to progress through the initial stages of laryngeal carcinogenesis. In this respect our data complement a genetic progression model for head and neck carcinogenesis showing an increase of loss of heterozygosity of specific chromosome regions with histological progression, predominantly at the transition from hyperplasia to dysplasia ${ }^{18}$. It might be expected that both genomic changes, i.e. loss of heterozygosity and chromosome instability, are essential for driving tumor progression. This hypothesis is supported by a study showing that HNSCCs showing marked loss of heterozygosity are mostly DNA aneuploid $^{19}$.

In conclusion, this study showed that the correlation of numerical chromosome aberrations with morphological parameters helped to define sequences of genetic events that occur in premalignant laryngeal lesions. The chromosome patterns observed in these lesions strongly suggest that most laryngeal tumors develop via a genetic pathway involving chromosome tetraploidization, followed by the acquisition of genetic instability, as evidenced by chromosome copy number imbalances and chromosome polyploidization. These different steps in chromosome aneuploidization occur in subsequent phases of early laryngeal carcinogenesis and especially the acquisition of genetic instability appeared to be associated with progression to invasive growth. The identification of these chromosome patterns can easily be applied as an additional tool in the diagnosis of these preinvasive lesions. 


\subsection{References}

1. Mitelman, F. Catalog of chromosome aberrations in cancer, $5^{\text {th }}$ ed. New York: Wiley-Liss, 1994.

2. Voravud, N., Shin, D. M., Ro, J. Y., Lee, J. S., Hong. W. K., and Hittelman, W. N. Increased polysamies of chromosomes 7 and 17 during head and neck multistage tumorigenesis, Cancer Res. 53: 2847-83, 1993.

3. Soder, A. I., Hopman, A. H. N., Ramaekers, F. C. S., Conradt "C., and Bosch, F. X. Distinct non-random patterns of chromosomal aberrations in the progression of squamous cell carcinomas of the head and neck, Cancer Res. 55: $5030-7,1995$.

4. Veltman, J. A., Hopman, A. H. N., Vlies, S. A. v. d., Bot, F. J., Ramaekers F, C. S. and Manni, J. J. Double-target fluorescence in situ hybridization distinguishes multiple genetically aberrant clones in head and neck squamous cell carcinoma. Cytometry. 34: 113-120, 1998.

5. Lengauer, C., Kinzler, K. W., and Vogelstein, B. Genetic instability in colorectal cancers, Nature. 386: 623-6, 1997.

6. Orr-Weaver, T. L., and Weinberg, R. A. A checkpoint on the road to cancer, Nature. 392: 223-4, 1998.

7. Shackney, S. E., and Shankey T. V. Common patterns of genetic evolution in human solid tumors, Cytometry. 29: 1-27, 1997.

8. Lengauer, $C .$, Kinzler, $K_{.}, W$. and Vogelstein B. Genetic instabilities in human cancers, Nature. 396: 643-9, 1998.

9. Lee, J. S., Kim, S. Y., Hong, W. K., Lippman, S. M., Ro, J. Y., Gay, M. L., and Hittelman, W. N. Detection of chromosomal polysomy in oral leukoplakia, a premalignant lesion, J Natl Cancer Inst. 85: 1951-4, 1993.

10. Veltman, J. A., Hopman, A. H. N., Bot, F. J., Ramaekers, F. C. S., and Manni, J. J. Detection of chromosomal aberrations in cytologic brush specimens from head and neck squamous cell carcinoma, Cancer. 81: 309314, 1997 .

11. Friedmann, I. Precursors of squamous cell hyperplasia, in Ferlito A (ed): Surgical pathology of laryngeal neoplasms, London, Chapman \& Hall. pp107-22, 1996.

12. Hopman, A. H. N., and Ramaekers, F. C. S. Processing and staining of cell and tissue material for interphase cytogenetics, in Robinson $P$ (ed): Current protocols in cytometry, New York, NY, John Wiley \& Sons Inc. chapter 8.5.1-8.5.22, 1998 .

13. Willard, $H_{\text {. }}$, and Waye, J. Hierarchical order in chromosome-specific human alpha satellite DNA, Trends Genet. 3: 192-8, 1987.

14. Hopman, A. H. N., wan Hooren, E., van de Kaa, C. A., Vooijs, P. G. P., and Ramaekers, F. C. S. Detection of numerical chromosome aberrations using in situ hybridization in paraffin sections of routinely processed bladder cancers, Mod Pathol. 4: 503-13, 1991.

15. Toorn, P. P.G. v. d., Veltman, J. A., Bot, F. J., dle Jong, J. M. A., Manni, J. J., Ramaekers, F. C.S., and Hopman, A. H. N. P53 overexpression and chromosome instability are strongly correlated in early stages of oral carcinogenesis. Submitted. 
16. Bulten, J, Poddighe, P. J., Robben, J. C. M., Gemmink, J. H., de Wilde, P. C. M., and Hanselaar, A. G. J. M. Interphase cytogenetic analysis of cervical intraepithelial neoplasia, Am J Pathol. 152: 495-503, 1998.

17. Shackney, S. E., Smith, C.A., Miller, B. W., Burholt, D. R., Murtha, K., Giles, H. R. Ketterer, D. M., and Pollice, A. A. A. Model for genetic evolution of human solid tumors, Cancer Res. 49:3344-54, 1989.

18. Califario, J., van der Riet, P., Westra, W., Nawroz, H., Clayman, G., Piantadosi, S., Corio, A., Lee, D., Greenberg, B., Koch, W., and Sidransky, D. Genetic progression model for head and neck cancer: implications for field cancerization, Cancer Res. 56: 2488-92, 1996.

19. El-Naggar, A. K., Hurr, K., Batsakis, J. G., Luna, M. A., Goepfert, H., and Huff, $V$. Sequential loss of heterozygosity at microsatellite motifs in preinvasive and invasive head and neck squamous carcinoma, Cancer Res. 55: 2656-59, 1995. 


\section{Chapter 3}

\section{Specific steps in aneuploidization correlate with LOH of 9p21, 17p13 and $18 q 21$ in the progression of premalignant laryngeal lesions}

Joris A. Veltman, Ingrid S. F. M. van Weert, Michaela Aubele, Fredrik J. Bot, Frans C. S. Ramaekers, Johannes J. Manni, and Anton H. N. Hopman 
Laryngeal squamous cell carcinoma is often preceded by a clinically and histopathologically recognizable lesion that does not fulfill the morphological criteria for malignancy, but appears to have accumulated a number of genetic alterations. In this study we have analyzed premalignant as well as malignant laryngeal lesions using in situ hybridization for chromosomes 1, 7, 9, 17 and 18, and by p53 immunohistochemistry on tissue sections. Microsatelite analysis was performed on laser-microdissected tissue fragments with the aim of studying loss of heterozygosity ( $\mathrm{LOH}$ ) of chromosome regions $9 p 21$, $17 p 13$ and $18 q 21$.

The following genetic progression patterns were observed in these specimens:

1. Histologically normal mucosa and hyperplastic lesions without malignant progression are typically disomic for all chromosomes tested, show no or only basal cell layer positivity for p53 and no allelic loss at any of the loci investigated.

2. Hyperplastic lesions preceding dysplastic/invasive growth frequently show trisomy for chromosome 7 and LOH of $9 p 21$ and 17p13. Small foci within these lesions sometimes show tetraploidization and p53 positivity.

3. Dysplastic lesions are characterized by a tetraploid DNA content, $\mathrm{LOH}$ of $9 \mathrm{p} 21$ and $17 \mathrm{p} 13$ and $\mathrm{p} 53$ positivity.

4. Carcinoma in situ lesions and invasive laryngeal carcinomas show a more imbalanced chromosome pattern and an additional 18q21 $\mathrm{LOH}$.

These results show that allelic loss at $9 p 21$ and 17p13, together with a trisomy for chromosome 7, are early markers in laryngeal carcinogenesis, followed by a general tetraploidization and p53 positivity. Chromosome imbalances and allelic loss at $18 q 21$ appear to be markers for CIS and progression to invasive growth. 


\subsection{Introduction}

HNSCC often exhibit an aneuploid DNA content, loss of chromosome regions 3p14-21, 9p21, $17 p 13$ and 18q21, mutations in the p53 gene and amplifications of the cyclin D1 locus ${ }^{1-4}$. Many of these genetic alterations take place in premalignant stages of the disease, and some of them appear to be indicators of malignant transformation ${ }^{5 \cdot 7}$. Although the timing of the different genetic changes in malignant transformation is gradually being resolved, little is known about the correlation between the different genetic changes. At this moment it is for example unclear whether LOH of $9 p 21$ and/or $17 p 13$ occurs before, simultaneously with, or after the aneuploidization process in early stages of head and neck carcinogenesis.

In this study a series of premalignant laryngeal lesions were screened with ISH using centromeric probes for the chromosome 1, 7, 9, 17, and 18 to investigate the presence and the pattern of chromosomal abnormalities in the different parts of these lesions. The selection of the DNA probes was based on previous ISH studies on $\mathrm{HNSCC}^{8,9}$. In addition, p53 immunohistochemistry was performed on these lesions, since there are strong indications that alterations in this tumor suppressor gene may lead to an overall genetic instability ${ }^{10,}{ }^{11}$. Based on the data obtained by the ISH, laser-facilitated microdissection was used to isolate small premalignant regions with a specific chromosome content, followed by a fluorescent microsatellite-analysis using markers for 9p21, 17p13 and 18q21. The choice of these loci was based on a detailed allelotype of HNSCC published by Field et al. ${ }^{2}$ and on a $\mathrm{LOH}$ study by Califamo et al. ${ }^{5}$, using premalignant lesions of the head and neck. This approach allowed us to draw conclusions (a) on the type and extent of genetic alterations present in different stages of laryngeal carcinogenesis, (b) on the correlation between the process of aneuploidization and the loss of specific chromosome regions, and (c) on the role of p53 in the progression of the disease.

\subsection{Materials and methods}

\subsubsection{Patient material}

Formalin-fixed, paraffin-embedded biopsy specimens were available 
from 27 (pre)malignant laryngeal lesions of 18 patients. From all specimens a series of $4 \mu \mathrm{m}$ thick sections was used for detailed histological examination, in situ hybridization, laser-facilitated microdissection and p53 immunohistochemistry. One section was heamatoxylin-eosin stained and reviewed by an experienced pathologist (F.J.B.). Normal mucosa, hyperplasia, dysplasia, CIS or carcinoma areas were identified and the specific areas marked on the slide for detailed comparisons with the genetic data.

\subsubsection{In situ hybridization (ISH)}

ISH was essentially performed and evaluated as described previously (12). Briefly, after deparaffinization, the sections were pretreated with $85 \%$ formic acid containing $0.3 \% \mathrm{H}_{2} \mathrm{O}_{2}$, followed by an incubation at $80^{\circ} \mathrm{C}$ in $1 \mathrm{M}$ sodium thiocyanate. After digestion with pepsin from porcine stomach mucosa (800-1,200 U/mg protein; Sigma Chemical Co., St.Louis, MO) at a concentration of $4 \mathrm{mg} / \mathrm{ml}$ in $0.02 \mathrm{~N} \mathrm{HCl}$, individual sections were hybridized using centromere-specific probes for human chromosomes $1,7,9,17$ or $18^{13}$, all labeled with biotin-11-dUTP (Boehringer, Mannheim, Germany). Immunocytochemical detection was performed by a standard avidin-biotin complex procedure. Signals were developed using diaminobenzidine/ $\mathrm{H}_{2} \mathrm{O}_{2}$, sections were counterstained with heamatoxylin and mounted in Entellan (Merck, Darmstadt, Germany).

Based on the evaluation of the ISH results, lesions were classified as either disomic, trisomic, tetrasomic or polysomic based on the maximum chromosome copy number present in the lesion $(2,3,4$, or more than 4 , respectively).

\subsubsection{Laser-facilitated microdissection}

Laser-facilitated microdissection was essentially performed as described

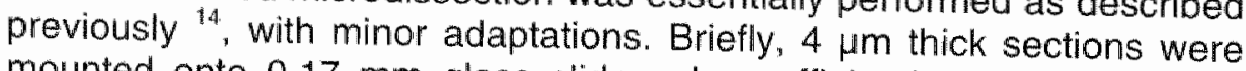
mounted onto $0.17 \mathrm{~mm}$ glass slides, deparaffinized, and stained with heamatoxylin and eosin. The UV laser microbeam used for microdissection (PALM GmbH, Wolfratshausen, Germany) consisted of a pulsed nitrogen laser coupled through the fluorescence illumination path of the microscope. Unwanted cells and tissue surrounding areas of interest were brought into the laser beam using a motorized, computercontrolled microscope-stage and were eliminated by the high photon 
density within the laser focus. In this way, a tissue free gap around the area of interest was created, and this area (often consisting of 1000 or more cells) was collected manually under a stereomicroscope using a sterile syringe needle. The cells were transferred to a $1.5 \mathrm{ml}$ microcentrifuge tube and could be stored for months at room temperature. Areas were selected for microdissection on basis of the histological classification and the ISH analysis of each specimen. These areas were microdissected from three to five serial sections. As source for normal DNA stromal cells and lymphocytes present in the same biopsy specimen were used. Histologically normal mucosa showing a disomic chromosome content (as detected by ISH) was also included in the analysis when present adjacent to a premalignant lesion.

\subsubsection{Fluorescent microsatellite analysis}

Genomic DNA was extracted using the QlAamp Tissue Kit (Qiagen

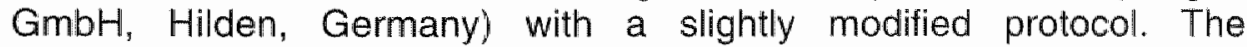
incubation of the tissue with Proteinase $K$ was prolonged to about $60 \mathrm{hrs}$ at $55^{\circ} \mathrm{C}$. After collumn purification the DNA was dissolved in $30 \mu \mathrm{l}$ of bidestilled water. PCR analysis targeted sequences containing highly polymorphic microsatellite repeat motifs at loci on chromosome 9p21 (D9S161), 17p13 (TP53) and 18q21 (D18S35). These microsatellite markers were specifically chosen because the PCR products obtained were of very small size (varying between 101 and $147 \mathrm{bp}$ ) which made them suitable for anplifications from the DNA isolated from formalinfixed and paraffin embedded cells. The oligonucleotides were labeled with either 6-FAM (D9S161), HEX (TP53) or TET (D18S35). PCR reactions were performed according to Erber et al. ${ }^{15}$ using $3 \mu$ of DNA and by adding a final extension step of $30 \mathrm{~min}$ at $72^{\circ} \mathrm{C}$. After amplification, PCR samples were diluted $1: 5$ in formamide, heated to $95^{\circ} \mathrm{C}$ for $2 \mathrm{~min}$, chilled on ice and analyzed on an ABI PRISM 310 Genetic Analyzer (ABI-Perkin-Elmer, Nieuwekerk a/d IJssel, The Netherlands) with Genescan Software. To estimate the degree of $\mathrm{LOH}$, i.e. the allelic loss in the heterozygously paired normal and (pre)malignant samples, a $\mathrm{LOH}$ value was calculated according to Cawkwell et al. ${ }^{16}$ as (T1/T2)/(N1/N2). T1 and $\mathrm{N} 1$ are the peak height values of the shorter allele for the (pre)malignant and the normal sample, respectively, and $\mathrm{T} 2$ and $\mathrm{N} 2$ are the peak height values of the longer allele for the (pre)malignant and normal sample, respectively. In cases when the allele ratio calculated by this equation was above 1.0 , the ratio was converted by using $1 /[(\mathrm{T} 1 / \mathrm{T} 2) /(\mathrm{N} 1 / \mathrm{N} 2)]$ to give a result in the range from $0.0-1.0$. A value at or below 0.50 was taken to indicate $\mathrm{LOH}$. Microsatellite instability was indicated by the presence of novel 
allele peaks in the premalignant or malignant DNA sample analyzed for a particular microsatellite marker, which was not present in the corresponding normal DNA analyzed for this marker.

\subsubsection{P53 immunohistochemistry}

An immunohistochemical assessment of (mutated) p53 protein expression was performed on $4 \mu \mathrm{m}$ thick paraffin sections. After deparaffinization, the sections were pretreated with $0.3 \% \quad \mathrm{H}_{2} \mathrm{O}_{2}$ in methanol to quench endogenous peroxidase activity. Antigen retrieval was performed by microwave heating in $0.01 \mathrm{M}$ citrate buffer $(\mathrm{pH} \mathrm{6.0)}$. Both normal and mutant p53 protein was detected using the monoclonal antibody clone DO-7 (DAKO A/S, Glostrup, Denmark). After incubation with the biotinylated secondary antibody, immunocytochemical detection was further performed as described for the ISH procedure. In each analysis a known p53-negative and p53-positive oropharynx tumor served as control. The extent of the p53 immunostaining reaction was scored visually as; (I) negative, (II) nuclear staining limited to the basal cell layer, (III) scattered positive nuclear staining in $5-10 \%$ of the cells, or (IV) positive nuclear staining in most of the cells in the lesion.

\subsection{Results}

\subsubsection{In situ hybridization}

Histologically normal mucosa, present in 15 of the 28 biopsy specimens, was used as internal control. The nuclei within these normal epithelia showed 0,1 , or 2 ISH signals for all chromosome probes used, with no evidence for nuclei with more than 2 ISH signals. Table 3.1 shows the $\mathrm{ISH}$ results obtained in 34 (pre)malignant lesions, which were histologically identified in the 28 specimens of the 18 patients. In figure $3.1 \mathrm{a}-\mathrm{c}$ examples of the obtained $\mathrm{ISH}$ results are presented. Four major chromosome patterns were distinguished in this series; (1) disomy for all chromosomes tested, (2) trisomy for chromosome 7 as the sole numerical chromosome change, (3) tetrasomy for all chromosomes tested, and (4) chromosome copy number imbalances and polysomy in one or more of the chromosomes tested. In general, patterns (1) and (2) were observed in hyperplastic lesions, whereas patterns (3) and (4) were observed in dysplastic lesions, CIS and SCC. 
In most cases, a homogeneous chromosome pattern was observed in a specific histological area. In four cases, however, small foci of 10 to 100 nuclei were identified containing a chromosome pattern that deviated from the pattern observed in the rest of the lesion. Trisomy for chromosome 7 was observed in part of the hyperplastic lesion in case 5. Cases 6,17 and 18 each contained small foci of nuclei with tetrasomy (and polysomy) for all chromosomes, while the rest of the lesion showed a trisomy for chromosome 7 .

Polysomy (i.e. over 4 ISH signals per nucleus) was observed in many dysplastic lesions and most of the CIS and SCC, often as a small subpopulation within a tetrasomic lesion. Polysomy occurred more or less randomly for the chromosomes 1, 7, 17 and 18. Polysomy for chromosome 9 was however not detected in this series. Imballances in chromosome copy numbers occurred predominantly in the group of CIS and SCC lesions, and appeared to be present throughout the entire lesion.

\subsubsection{Microsatellite-analysis of $9 p 21,17 p 13$ and $18 q 21$}

Laser-facilitated microdissection was performed on H\&E stained tissue sections from all specimens included in this study. Microdissection was guided by histology and ISH results, by which tissue compartments with and without chromosomal changes were precisely mapped (see figure 3.1). DNA was isolated and amplification for the microsatellites D9S161 (llocated on 9p21), TP53 (located on 17p13) and D18S35 (located on 18q21) was performed. The microsatellite-data for each specimen are presented in table 3.1 . Figure $3.1 \mathrm{~g}-\mathrm{k}$ illustrates typical $\mathrm{LOH}$ results obtained in this study. For these microsatellites the presence or absence of allelic loss could easily be determined on basis of the loss of heterozygosity $(\mathrm{LOH})$ value; all lesions classified as $\mathrm{LOH}$ contained values between 0 and 0,49 , whereas all lesions classified as presenting no $\mathrm{LOH}$ showed values between 0,60 and 0,98 . Histopathologically normal mucosa, isolated from 15 specimens included in this study, did not show allelic loss when compared to control non-mucosal samples. Most hyperplastic lesions also showed a retention of heterozygosity, although allelic loss for 9p21 was observed in all hyperplastic areas of case no.17, and allelic loss for $17 \mathrm{p} 13$ was observed in a hyperplastic region adjacent to a dysplasia in case no.18. Virtually all dysplastic lesions, CIS and SCC displayed LOH for at least one of the three loci. Allelic loss at 9p21 and $17 p 13$ was shown to occur at high frequencies both in dysplastic lesions as well as CIS and SCC. Only 1 of 6 dysplastic 
lesions displayed LOH of 18q21, whereas 2 out of 3 CIS and 2 SCCs revealed allelic loss at this locus. In only one case (no.15), microsatellite instability was observed for the microsatellite TP53, both in the dysplastic lesion and in the invasive carcinoma diagnosed 4 years later (figure $3.1 \mathrm{k}$ ).

\subsubsection{P53 immunohistochemistry}

Normal mucosa, present in 15 specimens adjacent to the (pre)malignant lesions showed either no p53 staining, or only a faintly positive nuclear staining in the basal cell layer. Identical results were obtained in most hyperplastic lesions, whereas a majority of the dysplastic lesions, CIS and SCC showed nuclear p53 staining in most of their cells (see table 3.1 and figure $3.1 \mathrm{~d}$ ).

\subsubsection{Correlation between histology, ISH-analysis, p53 IHC and LOH-analysis}

The approach chosen in this study allowed a detailed comparison between the genetic changes as detected by the different techniques in the different histological stages of laryngeal carcinogenesis. Table 3.2 illustrates the accumulation of genetic alterations with histological progression. In addition, table 3.3 shows the increase in LOH and p53 positivity with subsequent steps of aneuploidization as detected in these lesions by ISH. Neither LOH nor p53 overexpression was detected in lesions with disomy for all chromosomes. In contrast, 4 out of 7 lesions with trisomy for chromosome 7 displayed LOH of 9p21 and/or 17p13, and 2 of these lesions showed extensive p53 immunostaining. The percentage of lesions with $\mathrm{LOH}$ and p53 overexpression further increased in lesions that contained more extensive chromosomal alterations such as tetraploidization and chromosomal instability. LOH at $18 \mathrm{q} 21$ is only detected in lesions showing chromosome imbalances or polyploidization. $\mathrm{LOH}$ at either $9 \mathrm{p} 21$ or $17 \mathrm{p} 13$ is strongly correlated with an increased copy number (aneusomy) for the corresponding chromosomes as detected using a centromere-specific DNA probe in the in situ hybridization procedure. In contrast, only part of the lesions with aneusomy for chromosome 18 show $18 q 21 \mathrm{LOH}$. Immunostaining of the p53 gene (located on 17p13) is present in lesions that typically contain multiple copies of chromosome 17 and an allelic loss of the p53 locus. 


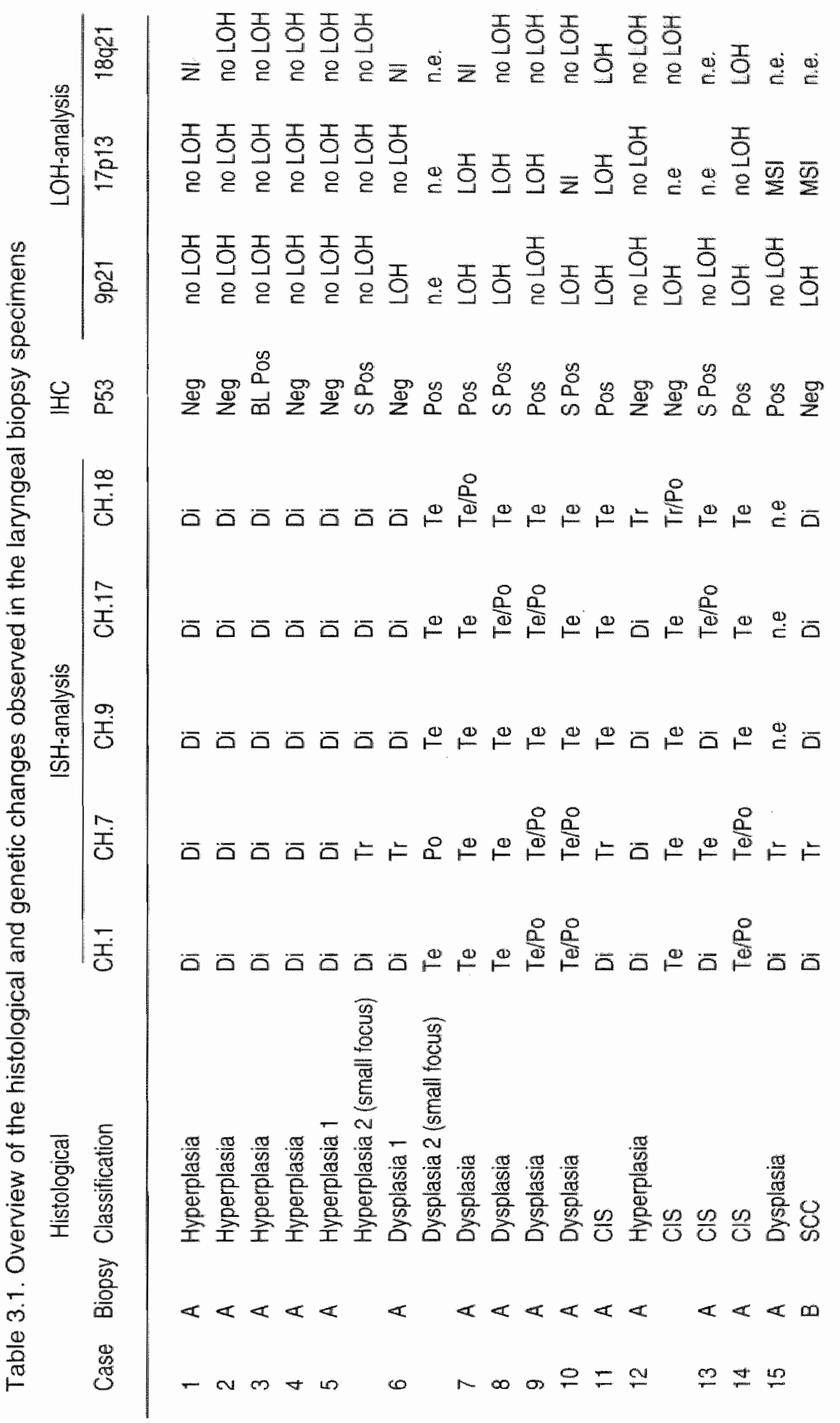




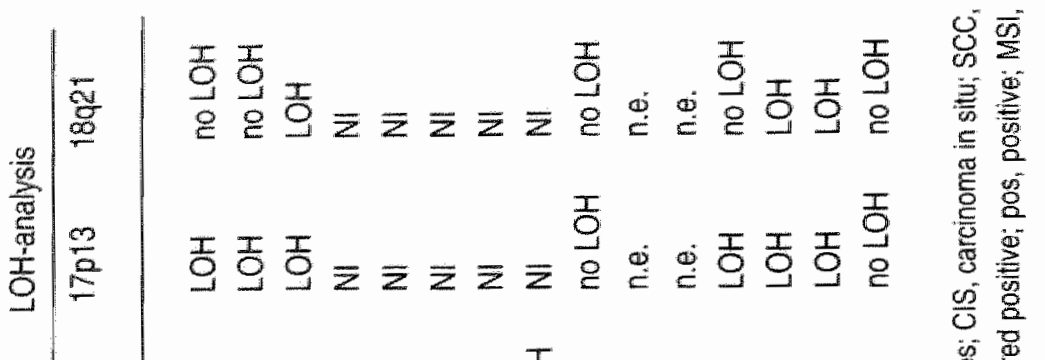

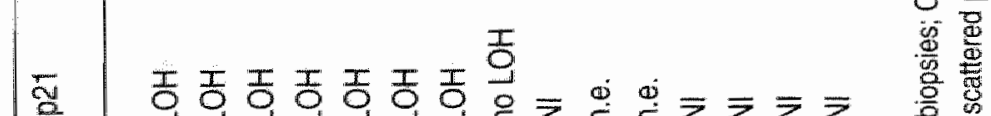

|

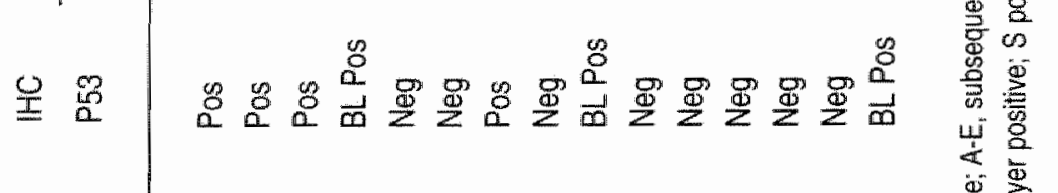

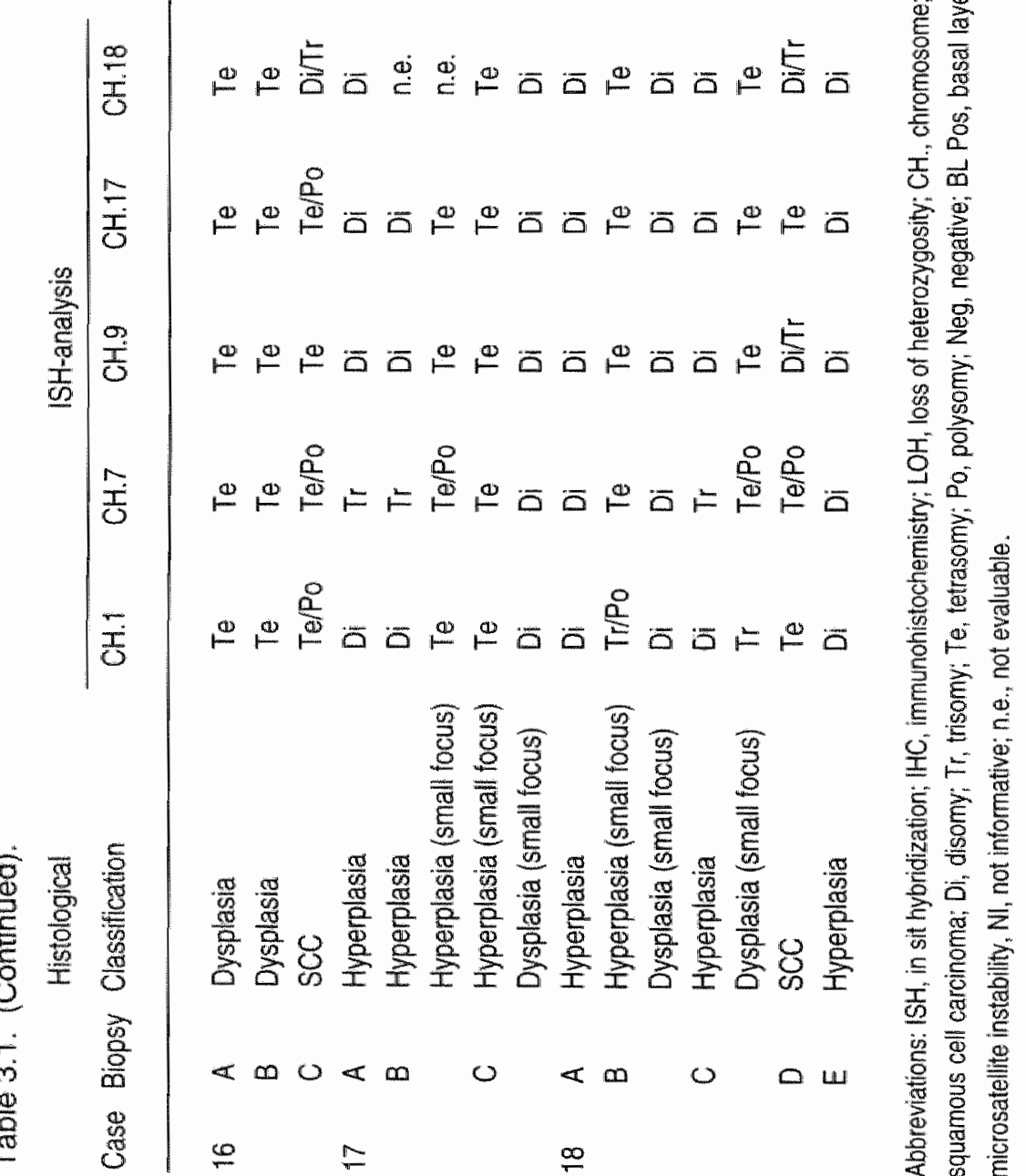


Table 3.2. Correlation between histology, $\mathrm{LOH}$ data and $\mathrm{p} 53$ status.

\begin{tabular}{|c|c|c|c|c|}
\hline \multirow[b]{2}{*}{ Histology } & \multicolumn{3}{|c|}{ Chromosomal locus } & \multirow{2}{*}{$\begin{array}{c}\text { P53 HC } \\
\text { Positive staining }\end{array}$} \\
\hline & $9 p 21$ & $17 p 13$ & $18 \mathrm{q} 21$ & \\
\hline Hyperplasia & $41110(36)$ & $1 / 10(10)$ & $0 / 8 \quad(0)$ & $2 / 15(13)$ \\
\hline Dysplasia & $6 / 9 \quad(67)$ & $7 / 8 \div(88)$ & $1 / 6(17)$ & $8 / 12(67)$ \\
\hline CISLLSCC & $5 / 6 \quad(83)$ & $4 / 5:(80)$ & $4 / 5(80)$ & (57) \\
\hline
\end{tabular}

${ }^{2}$ The positive group includes both the lesions with a scattered and complete positive nuclear staining.

- Values are given in loss/informative cases (\% loss).

- Including microsatellite instability in 1 lesion.

Table 3.3. Correlation between ISH pattern, $\mathrm{LOH}$ data and p53 status.

\begin{tabular}{|c|c|c|c|c|}
\hline \multirow{2}{*}{$\begin{array}{l}\text { ISH } \\
\text { Chromosome pattern a }\end{array}$} & \multicolumn{3}{|c|}{ Chromosomal locus } & \multirow{2}{*}{$\begin{array}{c}\text { P53 IHC } \\
\text { Positive staining }\end{array}$} \\
\hline & $9 p 21$ & $17 \mathrm{p} 13$ & $18 \mathrm{q21}$ & \\
\hline Overall disomy & $0 / 60^{\circ} \quad(0)$ & $0 / 7$ & $0 / 5$ & $0 / 9$ \\
\hline Sole trisomy 7 & $4 / 6 \quad(67)$ & $3 / 5^{d}(60)$ & $0 / 2$ & $2 / 7 \quad(29)$ \\
\hline Overall tetrasomy & $7 / 7(100)$ & $4 / 4(100)$ & $0 / 4$ & $6 / 9 \quad(67)$ \\
\hline Imbalances/Polysomy ${ }^{\ominus}$ & $4 / 6 \quad(67)$ & $5 / 6 \quad(83)$ & $5 / 7 \quad(71)$ & $6 / 8 \quad(75)$ \\
\hline
\end{tabular}

a Chromosome patterns are based on the ISH results of all 5 chromosomes tested.

$\checkmark$ The positive group includes both the lesions with a scattered and complete positive nuclear staining.

c Values are given in loss/informative cases (\% loss).

a Including microsatellite instability detected in 2 lesions.

* Chromosome copy number imbalances and/or polysomy, detected for at least 2 of the 5 chromosomes studied.

\subsubsection{Genetic changes correlated with progression of individual} cases

In table 3.4 a detailed scheme is presented of 4 cases from which progressive lesions were available. Genetic alterations such as allelic loss at 9p21, p53 positivity and chromosomal duplication were shown to persist in many of the biopsy specimens from these cases, even when the time interval between different biopsies was 1 to 4 years. In case of histological progression, additional genetic changes such as $\mathrm{LOH}$ of $18 \mathrm{q} 21$ arose (see also figure $3.1 \mathrm{~g}-\mathrm{j}$ ). Furthermore, the occurrence of chromosome copy number imbalances and polyploidization was a typical event occurring in these later stages. 
Table 3.4. Histological and genetic changes abserved in 4 cases with progressive disease.

\begin{tabular}{|c|c|c|c|c|c|c|c|}
\hline & Biopsy 1 & \multicolumn{2}{|c|}{ Biopsy 2} & \multicolumn{2}{|l|}{ Biopsy 3} & Biopsy 4 & Biopsy 5 \\
\hline \multicolumn{8}{|l|}{ Case 15} \\
\hline Year & 1992 & \multicolumn{2}{|l|}{1996} & & & & \\
\hline Histology & Dys & \multicolumn{2}{|l|}{$\mathrm{SCC}$} & & & & \\
\hline & Tri 7 & \multicolumn{2}{|l|}{$\operatorname{Tr} 7$} & & & & \\
\hline $\mathrm{P} 53 \mathrm{HC}$ & Pos & \multicolumn{2}{|l|}{ Neg } & & & & \\
\hline LOHMSI & $17 p 13$ (MSl) & \multicolumn{2}{|c|}{$\begin{array}{l}9 p 21 \\
17 p 13 \text { MSI) }\end{array}$} & & & & \\
\hline \multicolumn{8}{|l|}{ Case 16} \\
\hline Year & 1987 & \multicolumn{2}{|l|}{1991} & \multicolumn{2}{|l|}{1996} & & \\
\hline Histology & Dys & \multicolumn{2}{|l|}{ Dys } & \multicolumn{2}{|l|}{$\mathrm{SCC}$} & & \\
\hline ISH & Tetra & \multicolumn{2}{|l|}{ Tetra } & \multicolumn{2}{|l|}{$\begin{array}{l}\text { Poly } \\
\text { Imb }\end{array}$} & & \\
\hline P53 IHC & Pos & \multicolumn{2}{|l|}{ Pos } & \multicolumn{2}{|l|}{ Pos } & & \\
\hline LOHMSI & $9 p 21$ & \multicolumn{2}{|l|}{$9 \rho 21$} & \multicolumn{2}{|l|}{$9 p 21$} & & \\
\hline & $17 p 13$ & \multirow{2}{*}{\multicolumn{2}{|c|}{$17 p 13$}} & \multirow{2}{*}{\multicolumn{2}{|c|}{$\begin{array}{l}17 p 13 \\
18 q 21\end{array}$}} & & \\
\hline & & & & & & & \\
\hline \multicolumn{8}{|l|}{ Case 17} \\
\hline Year & 1982 & \multicolumn{2}{|l|}{1985} & \multicolumn{2}{|l|}{1986} & & \\
\hline Histology & Hyp & Hyp & $\begin{array}{l}\text { Hyp } \\
\text { focus }\end{array}$ & $\begin{array}{l}\text { Hyp } \\
\text { focus }\end{array}$ & $\begin{array}{l}\text { Dys } \\
\text { focus }\end{array}$ & & \\
\hline ISH & Tri 7 & Tri 7 & Tetra & Tetra & $\mathrm{Di}$ & & \\
\hline P53 $\| \mathrm{HC}$ & Neg & Neg & Neg & Pas & $\mathrm{Neg}$ & & \\
\hline LOH/MSI & $9 p 21$ & $9 p 21$ & $9 p 21$ & $9 p 21$ & No & & \\
\hline \multicolumn{8}{|l|}{ Case 18} \\
\hline Year & 1986 & \multicolumn{2}{|l|}{1988} & \multicolumn{2}{|l|}{1990} & 1991 & 1992 \\
\hline Histology & Hyp & $\begin{array}{l}\text { Hyp } \\
\text { focus }\end{array}$ & $\begin{array}{l}\text { Dys } \\
\text { focus }\end{array}$ & Hyp & $\begin{array}{l}\text { Dys } \\
\text { focus }\end{array}$ & $\mathrm{SCC}$ & Hyp \\
\hline $\mathrm{ISH}$ & $\mathrm{Di}$ & Tetra & $\mathrm{Di}$ & $\operatorname{Tri} 7$ & $\begin{array}{l}\text { Tetra } \\
\text { Poly } \\
\text { Imb }\end{array}$ & $\begin{array}{l}\text { Poly } \\
\text { mb }\end{array}$ & $\mathrm{Di}$ \\
\hline$P 531 / \mathrm{CC}$ & Neg & Neg & Neg & Neg & Neg & Neg & Neg \\
\hline LOH/MSI & No & n.e. & n.e. & $17 p 13$ & $\begin{array}{l}17 p 13 \\
18 q 21\end{array}$ & $\begin{array}{l}17 p 13 \\
18 q 21\end{array}$ & No \\
\hline
\end{tabular}

In this scheme, the results of chromosome in situ hybridization, $p 53$ immunohistochemistry and microsatellite-analysis are depicted for each lesion of these 4 cases. Abbreviations: ISH, in situ hybridization: $\mathrm{HC}$, immunohistochemistry; $\mathrm{LOH}_{3}$ loss of heterozygosity; MSI, microsatellite instability; Hyp, hyperplasia; Dys, dysplasia; SCC, squamous cell carcinoma; Di, disomy, Tri, trisomy; Tetra, tetrasomy, Poly, polysomy, Imb, imbalances; Pos, positive, Neg, negative; n.e., not evaluable.

In two of the cases depicted in table 3.4 genetic changes were observed in a hyperplastic area but not in the dysplastic area located in the same biopsy specimen. A small but clearly identified dysplastic region of case 
no.17 (biopsy c) did not display numerical chromosomal alterations or p53 overexpression. Microdissection of this dysplastic region followed by microsatellite-analysis did not reveal $\mathrm{LOH}$ for $9 \mathrm{p} 21$ (the other two markers were not informative). In contrast, a small hyperplastic region present in the same biopsy specimen contained tetrasomy for all chromosomes tested and was p53 positive. The microsatelite-analysis of this region did show a clear $\mathrm{LOH}$ at $9 \mathrm{p} 21$. In case no.18 (biopsy b) a similar result was obtained by $\mathrm{ISH}$, but unfortunately the two regions were two small (both contained approximately 50 nuclei per tissue section) for PCR amplification.

\subsection{Discussion}

In this study histologically different stages of laryngeal carcinogenesis were analyzed with chromosome in situ hybridization, p53 immunohistochemistry and microsatellite analysis. The ISH and $\mathrm{IHC}$ techniques were applied directly onto tissue sections and allowed a detailed investigation of the chromosome content and the p53 status in different areas present in a biopsy specimen. Based on the results of these analyzes specific tissue compartments were isolated using laserfacilitated microdissection, and a fluorescent microsatellite analysis was performed for the detection of LOH of the chromosome loci 9p21, 17p13 and $18 q 21$. In our opinion this approach has several advantages over the conventional approach whereby regions are isolated for $\mathrm{LOH}$ analysis on basis of histology. Firstly, as pointed out by many authors ${ }^{17}$, the histopathological features of premalignant lesions of the aerodigestive tract are subtle and overlap with non-neoplastic reactive processes. It does not appear logical to use the subjective morphological method as a starting point for a detailed molecular analysis that requires the use of a pure population with a minimal amount of non-aberrant "normal" cells. A screening of the biopsy specimens by means of chromosome in situ hybridization and p53 immunohistochemistry easily identifies tissue compartments within these specimens harboring the genetically most altered cell population. It is this cell population that was our target for the microsatellite analysis and which was therefore isolated by laser-facilitated microdissection. Secondly, this approach allows a detailed comparison of genetic alterations at different levels of the genome during the carcinogenic process, such as allelic loss of specific chromosome regions, different steps in the aneuploidization process and alterations in the expression of the p53 tumor suppressor gene. 
Based on the results obtained in this study, a three-step genetic progression model for early laryngeal carcinogenesis emerges (see tables 3.2 and 3.3 ):

1. The earliest detectable genetic changes appear to be the acquisition of trisomy for chromosome 7 and allelic loss at 9p21 and 17p13. The tissue containing these genetic alterations is typically hyperplastic.

2. This is followed by an overexpression of the (presumably mutated) p53 gene and tetraploidization. The tissue containing these genetic alterations is typically mild/moderately dysplastic.

3. Finally chromosome copy number imbalances and polyploidization occur together with an allelic loss at 18q21. The tissue containing these genetic alterations is typically CIS or SCC.

It has to be kept in mind that a small proportion of laryngeal lesions remains DNA diploid during progression, as for example illustrated by case no.15. Interestingly, in this case microsatellite instability was observed at the TP53 locus, indicating that in this case another form of genetic instability is present.

In agreement with the genetic progression model proposed by Califano et al. ${ }^{5}$ we observed $\mathrm{LOH}$ of $9 \mathrm{p} 21$ and $17 \mathrm{p} 13$ to be among the earliest detectable genetic changes in head and neck carcinogenesis. These changes appear to occur before tetraploidization, in contrast to $\mathrm{LOH}$ of 18q21, which was found only in advanced precursor lesions containing chromosome imbalances and polysomy. These data suggest that $\mathrm{LOH}$ of $9 p 21$ and $17 p 13$, containing the important cell cycle checkpoint genes $p 16^{\mathrm{NKK} A \mathrm{a}}$ and $\mathrm{p} 53$, respectively, may contribute to chromosome missegregation, resulting in aneuploidy. In this study, as well as in a previous study of our group on oral precursor lesions ${ }^{18}$, the impression is obtained that p53 overexpression indeed precedes the tetraploidization process. These genetic changes were shown to persist within the premalignant epithelium for several years and, thus, may be used in the follow-up of a given preneoplastic lesion. LOH of 18q21, although not of importance in early stages of laryngeal carcinogenesis, is very likely of relevance in tumor progression 19, 20. Candidate tumor suppressor genes on this locus are the DCC (deleted in colon cancer) gene ${ }^{21}$ and the DPC4 (deleted in pancreatic cancer) gene ${ }^{22}$.

How can LOH be explained in the light of the aneuploidization process? If a duplication of the whole chromosome 9 occurs before allelic loss at $9 p 21$, this loss would have to take place on two duplicate chromosome copies, whereas only one chromosome copy has to be affected if $\mathrm{LOH}$ occurs before duplication. This has recently also been discussed by Varella-Garcia et al. ${ }^{23}$, studying the relation between chromosome duplication and allelic loss in non-small cell lung carcinoma. 

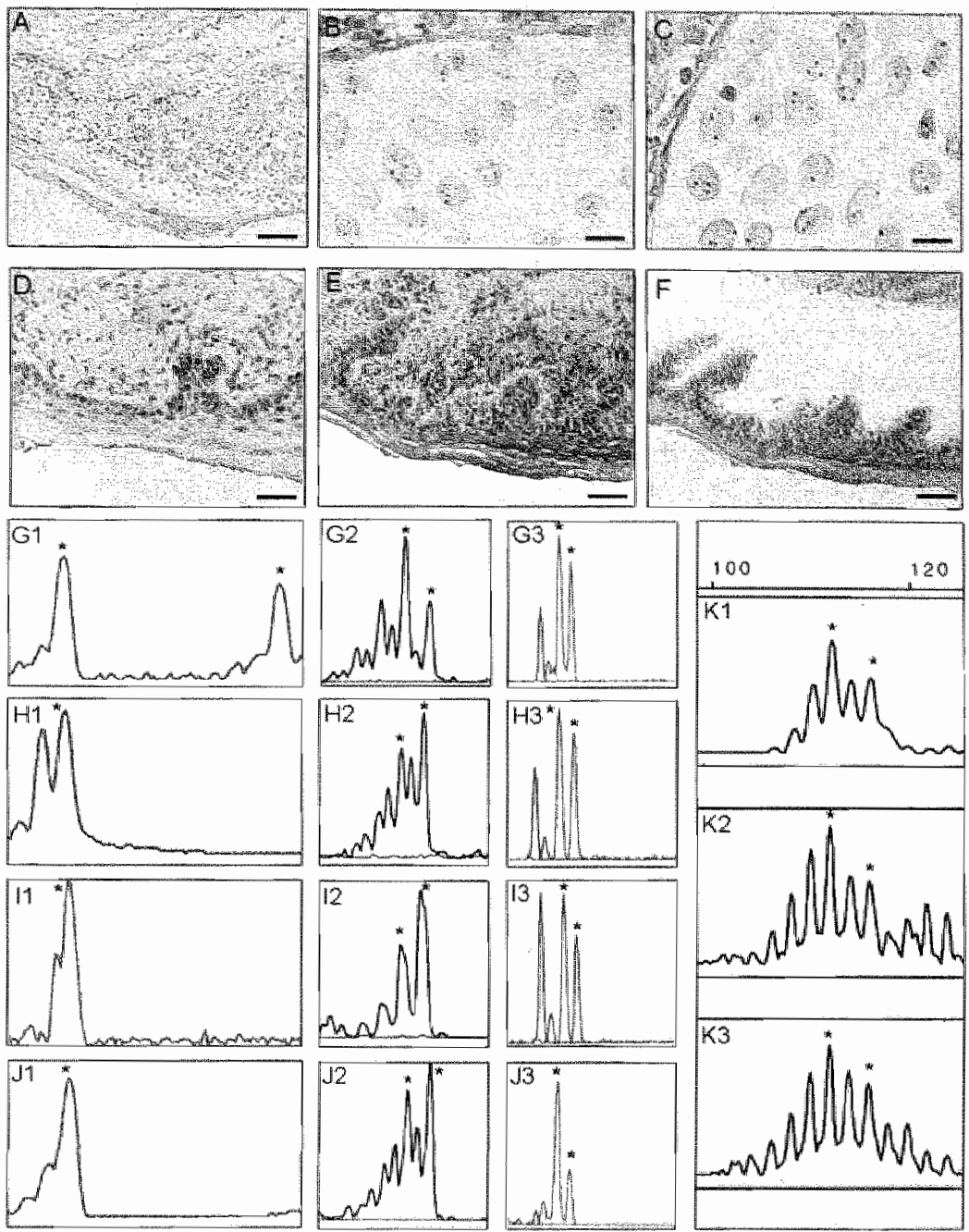

Figure 3.1. Typical examples of results obtained by in situ hybridization, p53 immunohistochemistry, laser-facilitated microdissection and fluorescent microsatellite-analysis.

A-F. ISH and $p 53$ IHC on the biopsy specimen of case 7 . Tetrasomy for chromosome 7 (overview in $A$, detail in $B$ ) and chromosome 17 (C) are present in the dysplastic region, which also shows $p 53$ positivity (D). This region is microdissected from a HE-stained section (E) by laser-facilitated microdissection (F). Stromall cells surrounding the region are eliminated and the region is manually collected. G.J. LOH-results of biopsies A (H), B (I) and C (J) of case 16 for the loci D9S161 (lane 1). TP53 (lane 2) and D18S35 (lane 3). In G the results for the normal mucosa from this case are depicted for comparison. For reasons of clarity, peaks representing specitic alleles are marked with an asterisks (*). other alleles are so-called slutter bands caused by inefficient amplification. D9S161 shows a complete loss of the second allele in both the dysplastic lesions as well as the SCC. TP53 shows a significant reduction of the first allele in the same lesions. A retention of heterozygosily is observed for D18S35 in the two dysplastic lesions, whereas the SCC displays LOH. K. Microsatellite-instability observed for TP53 in the dysplasia (lane 2) as well as the SCC (lane 3) of case 15. Scale bar, $80 \mu \mathrm{m}$ in $A, D, E, F$ and $10 \mu \mathrm{m}$ in $B$ and $C$. 
Our data strongly suggest that the allelic loss observed at $9 \mathrm{p} 21$ and $17 p 13$ occurred before tetraploidization, whereas allelic loss at 18q21 toke place after tetraploidization. In support of this hypothesis, allelic loss of 9 p21 was present in the entire dysplastic area of case no.6, whereas disomy for chromosome 9 was observed in the majority of this lesion. Interestingly, in a small focus of about 10 nuclei located within the dysplasia chromosome duplication, as well as nuclear p53 immunostaining was observed, possibly representing a next step in the carcinogenic process. In the majority of cases included in this study, however, both chromosome duplication and allelic loss were observed in the same region of a biopsy specimen, often together with overexpression of the tumor suppressor gene p53, suggesting that although LOH of $9 p 21$ and 17 p13 occur as a first change, this is followed by chromosome duplication and alterations in the p53 gene.

How can $\mathrm{LOH}$ at $18 \mathrm{q} 21$ be explained to take place after tetraploidization? The follow-up biopsies studied from case no.16 illustrate that allelic loss at this locus occurs after tetraploidization. It can be hypothesized that the presence of chromosomal instability is essential for $\mathrm{LOH}$ to take place in later stages of tumorigenesis when most chromosomes are present in four copies. This instability appears to be enhanced after tetraploidization and results in random chromosome gains and losses ${ }^{7,24}$. Chromosome 18 indeed showed a relative copy number loss in 2 out of 3 invasive carcinomas included in this study, both of which showed $\mathrm{LOH}$ at $18 \mathrm{q} 21$, suggesting that $\mathrm{LOH}$ at $18 \mathrm{q} 21$ is one of the direct results of chromosome instability, and this allelic loss may be important for malignant progression of laryngeal lesions.

Our ISH analysis frequently detected small groups of cells with chromosomal alterations, situated within lesions that showed an overall disomic chromosome pattern. In addition in 2 cases genetic changes were observed in a hyperplastic region but not in the dysplastic region located in the same biopsy (no.'s 17 and 18). This kind of disparity between genotype and phenotype has also been witnessed in a study by Mao et al. ${ }^{25}$, studying $\mathrm{LOH}$ in advanced lesions of the head and neck following chemoprevention therapy. These observations underline the importance of ISH as a screening method for the identification of the genetically most altered cell population in a biopsy specimen. Small groups of cells can be identified within a tissue section on basis of a deviation in the chromosome content, microdissected and studied by means of PCR amplification. In this study, a minimum of approximately 1000 nuclei was required for the microsatellite analyzes. The use of a whole genome amplification step before the microsatellite analysis will most probably reduce the acquired number of cells to the amount 
whereby even small groups of about 10 cells with a specific chromosome content can be studied for the presence of $\mathrm{LOH}^{26,27}$. In addition, this will allow the investigation of allelic loss at multiple loci. This kind of approach may prove to be invaluable for the implementation of microarray-based techniques in these research fields.

\subsection{Acknowledgements}

The authors wish to thank Dr. Franz Bosch for his helpful discussions and support and Dr. Ralf Erber and Dr. Axel Walch for advice on technical matters. 


\subsection{References}

1. Mitelman F. Catalog of chromosome aberrations in cancer, $5^{\text {th }}$ ed. New York: Wiley-Liss, 1994.

2. Field, J. K., Kiaris, H., Risk, J. M., Tsiriyotis, C., Adamson, R., Zoumpourlis, V. Rowley, H., Taylor, K., Whittaker, J., Howard, P., Beirne, J. C., Gosney, J. R., Woolgar, J., Vaughan, E. D., Spandidos, D. A., and Jones, A. S. Allelotype of squamous cell carcinoma of the head and neck: Fractional allele loss correlates with survival. Br J Cancer. 72: 1180-8, 1995.

3. Boyle, J. O., Hakim, J., Koch, W., van der Riet, P., Hruban, R. H., Roa, R. A., Correo, R., Eby, Y. J., Ruppert, J. M., and Sidransky, D. The incidence of p53 mutations increases with progression of head and neck cancer. Cancer Res. 53: 4477-80, 1993.

4. Akervall, J. A., Michalides, R. J., Mineta, H., Balm, A., Borg, A., Dictor, M. R., Jin, Y., Loftus, B., Mertens, F., and Wennerberg, J. P. Amplificiation of cyclin D1 in squamous cell carcinoma of the head and neck and the prognostic value of chromosomal abnormalities and cyclin D1 overexpression. Cancer. 79: 380-9, 1997.

5. Califano, J., van der Riet, P., Westra, W., Nawroz, H., Clayman, G., Piantadosi, S., Corio, R., Lee, D., Greenberg, B., Koch, W., and Sidransky, D. Genetic progression model for head and neck cancer: implications for field cancerization. Cancer Res. 56: 2488-92, 1996.

6. Mao, L., Lee, J. S., Fan, Y. H., Ro, J. Y., Batsakis, J. G., Lippman, S., Hittelman, W., and Hong, W. K. Frequent microsatellite alterations at chromosomes 9p21 and 3p14 in oral premalignant lesions and their value in cancer risk assessment. Nat Med. 2: 682-5, 1996.

7. Veltman, Jl. A., Bot, F. J., Huynen, F. C., Ramaekers, F. C. S., Manni, J. J., and Hopman, A. H. N. Chromosome instability as an indicator of malignant progression in laryngeal mucosa. Submitted.

8. Soder, A. I., Hopman, A. H. N., Ramaekers, F. C. S., Conradt, C., and Bosch, $F$. X. Distinct non-random patterns of chromosomal aberrations in the progression of squamous cell carcinomas of the head and neck. Cancer Res. 55: 5030-7, 1995.

9. Veltman, J. A, Hopman, A. H. N., Vlies, S. A. v. d., Bot, F. J., Ramaekers F, C. S., and Manni. J. J. Double-target fluorescence in situ hybridization distinguishes multiple genetically aberrant clones in head and neck squamous cell carcinoma. Cytometry. 34: 113-20, 1998.

10. Cross, S. M., Sanchez, C. A., Morgan, C. A., Schimke, M. K., Ramel, S., Idzerda, R. L., Raskind, W. H., and Reid, B. J. A p53-dependent mouse spindle checkpoint. Science. 267: 1353-6, 1995.

11. Fukasawa, K., Choi, T., Kuriyama, R., Rulong, S., and Vande Woude, G. F. Abnormal centrosome amplification in the absence of $p 53$. Science. 271: 1744-7, 1996.

12. Hopman, A. H. N., and Ramaekers, F. C. S. Processing and staining of cell and tissue material for interphase cytogenetics. In: P. Robinson (ed.), Current protocols in cytometry. Chapter 8.5.1-8.5.22. New York: John Wiley and Sons, Inc., 1998. 
13. Willard, $H$. and Waye, J. Hierarchical order in chromosome-specific human alpha satellite DNA. Trends Genet. 3: 192-8, 1987.

14. Becker, I., Becker "K. F., Rohrl, M. H., Minkus, G., Schutze, K., and Hofler, $H$. Single-cell mutation analysis of tumors from stained histologic slides. Lab Invest. 75: 801-7, 1996.

15. Erber, R., Conradt, C., Homann, N., Enders, C. Finckh, M., Dietz, A., Weidauer, $H_{\text {. }}$, and Bosch, F. X. TP53 DNA contact mutations are selectively associated with allelic loss and have a strong clinical impact in head and neck cancer. Oncogene. 16: 1671-9, 1998.

16. Cawkwell, L., Bell, S. M., Lewis, F. A., Dixon, M. F., Taylor, G. R., and Quirke, P. Rapid detection of allele loss in colorectal tumors using microsatellites and fluorescent DNA technology. $\mathrm{Br} J$ Cancer. 67: 1262-7, 1993.

17. Westra, W. H. and Sidransky, D. Phenotypic and genotypic disparity in premalignant lesions: Of calm water and crocodiles. J Natl Cancer Inst. 90: $1500-1,1998$.

18. Toorn, P. P. G. v. d., Veltman, J. A., Bot, F. J., de Jong, J. M. A., Manni, J. J., Ramaekers, F. C.S., and Hopman, A. H. N. P53 overexpression and chromosome instability are strongly correlated in early stages of oral carcinogenesis. Submitted.

19. Rowley, H., Jones, A. S., and Field, J. K. Chromosome 18: A possible site for a tumor suppressor gene deletion in squamous cell carcinoma of the head and neck. Clin Otolaryngol. 20: 266-71, 1995.

20. Carey, T. E., Frank, C. J., Raval, J. R., Jones, J. W., McClatchey, K. D., Beals, T. F., Worsham, M. J., and Van Dyke, D. L. Identifying genetic changes associated with tumor progression in squamous cell carcinoma. Acta Otolaryngol. (Stockh.). 529: 229-32, 1997.

21. Fearon, E., Cho, K. R., Nigro, J. M., Kern, S. C., Simons, J. W., Ruppert, J. M., Hamilton, S. R., Preisinger, A. C., Thomas, G., Kinzler, K. W., and Vogelstein, B. Identification of a chromosome $18 q$ gene that is altered in colorectal cancers. Science. 247: 49-56, 1990.

22. Hahn, S. A., Schutte, M., Shamsul Hoque, A. T. M., Moskaluk, C. A., da Costa, L. T., Rozenblum, E., Weinstein, C. L., Fischer, A., Yeo, C. J., Hruban, R. H., and Kerm, S. E. DPC4, a candidate tumor suppressor gene at human chromosome 18q21.1. Science. 271:350-3, 1996.

23. Varella-Garcia, M., Gemmill, R. M., Rabenhorst, S. H., Lotto, A., Drabkin, H. A., Archer, P. A., and Franklin, W. A. Chromosomal duplication accompanies allelic loss in non-small cell lung carcinoma. Cancer Res. 58: 4701-7, 1998.

24. Lengauer, C., Kinzler, K. W., and Vogelstein, B. Genetic instabilities in human cancers. Nature. 396: 643-9, 1998.

25. Mao, L., El-Naggar, A. K., Papadimitrakopoulou, V., Shin, D. M., Shin, H. C., Fan, Y. H., Zhou, X., Clayman, G., Lee, J. J., Lee, J. S., Hittelman, W. N., Lippman, S. M., and Hong, W. K. Phenotype and genotype of advanced premalignant head and neck lesions after chemopreventive therapy. $J$ Natl Cancer Inst. 90: 1545-51, 1998.

26. Telenius, H., Carter N. P., Bebb, C. E., Nordenskjold, M., Ponder, B. A., and Tunnacliffe, A. Degenerate oligonucleotide-primed PCR: general amplification of target DNA by a single degenerate primer. Genomics, 13: 
$718-25,1992$

27. Cheung, V. G. and Nelson, S. F. Whole genome amplification using a degenerate oligonucleotide primer allows hundreds of genotypes to be performed on less than one nanogram of genomic DNA. Proc Natl Acad Sci USA. 93: 14676-9, 1996. 


\section{Chapter 4}

\section{Double-target fluorescence in situ hybridization distinguishes multiple genetically aberrant clones in head and neck squamous cell carcinoma}

Joris A. Veltman, Anton H. N. Hopman, Saskia A. van der Vlies,

Fredrik J. Bot, Frans C. S. Ramaekers, Johannes J. Manni 
Genomic heterogeneity has been observed in several solid tumor types. To investigate this phenomenon in head and neck squamous cell carcinoma (HNSCC), we analyzed macroscopically distinct tissue samples of 12 resected tumors by a combination of fluorescence in situ hybridization (FISH) and DNA flow cytometry. Using a panel of centromeric DNA-probes, numerical chromosomal aberrations were detected in 10 tumors, 9 of which showed a single DNA aneuploid peak. Imbalances in chromosomal copy numbers resulted in unique patterns of chromosomal aberrations for each tumor case. Two types of tumors could be distinguished, i.e. tumors $(n=5)$ containing a single aneusomic clone, and tumors $(n=5)$ with multiple aneusomic clones. The center of these latter group of tumors was shown to be genetically more heterogeneous than the tumor margin.

in conclusion, this study showed that, (1) the pattern of chromosomal aberrations varies greatly between different HNSCCS, (2) a major clone with a specific pattern of chromosomal aberrations has spread throughout most HNSCCs, and (3) a subgroup of HNSCCs contains additional clones with a different pattern of chromosomal aberrations. Based on these results HNSCC can be divided into a genetically more homogeneous and a genetically more heterogeneous group. 


\subsection{Introduction}

Head and neck cancer is thought to develop through a multistep process in which well-defined clinical and histopathological stages are passed. Phenotypically distinct stages in this process can to some extent be characterized and distinguished by specific genetic changes ${ }^{1,2}$. Tumor progression is currently believed to result from genetic instability by generating new genetic properties in part of the growing tumor (see for a review Shackney et al. ${ }^{3}$ ). The occurrence of genetically distinct tumor cell populations within a single tumor mass is called intratumor heterogeneity (ITH). Extensive ITH has been demonstrated in several malignancies using classical karyotype and DNA cytometry ${ }^{4,5}$. One explanation for this phenomenon is the tendency of diploid cancer cells to spontaneously duplicate their chromosome number and to subsequently lose chromosomes randomly ${ }^{6}$.

ITH can be analyzed by fluorescence in situ hybridization (FISH) $7,8,9,10$. In contrast to karyotyping and flow cytometry this technique allows visualization and quantitation of individual chromosomes and genes on a single cell basis. This feature of the FISH technique enables the detection of subtle differences in the genetic constitution of small subpopulations of cells, thus providing evidence for ITH. In particular double-target FISH, using two DNA-probes simultaneously, can be used to verify the chromosomal content of small subpopulations and the presence of imbalances in chromosomal copy numbers.

Although many investigators have suggested that the presence of ITH has a clinical impact ${ }^{\prime \prime}$, there is little known about this phenomenon in head and neck squamous cell carcinoma (HNSCC). The purpose of this study was to analyze the patterns of numerical chromosomal aberrations in HNSCC with special emphasis on the presence or absence of multiple tumor clones. Frozen tissue material was analyzed from two macroscopically distinct parts of each tumor, i.e. one biopsy taken from the central part of the tumor and one from the tumor margin. All specimens were analyzed by DNA flow cytometry and by FISH using a panel of centromere-specific probes. 


\subsection{Material and methods}

\subsubsection{Patient material}

Tissue samples from 12 patients with head and neck squamous cell carcinoma (HNSCC) were included in this study (table 4.1). Specimens were collected from both the center and the border of the resected tumors, snap-frozen in liquid nitrogen and stored at $-80^{\circ} \mathrm{C}$. A $5 \mu \mathrm{m}$ thick frozen section of each tissue specimen was stained with heamatoxylineosin and the presence of tumor cells was verified by an experienced pathologist.

\subsubsection{DNA flow cytometry}

A nuclei suspension was prepared from a $50 \mu \mathrm{m}$ thick frozen section of each specimen by a proteolytic digestion step with pepsin from porcine stomach mucosa (2500-3500 U/mg protein; Sigma Chemical Co., St. Louis, MO, USA) at a concentration of $100 \mu \mathrm{g} / \mathrm{ml}$ in $0.01 \mathrm{~N} \mathrm{HCl}$ for 20 $\min$ at $37^{\circ} \mathrm{C}^{12}$. The nuclei were thereafter treated with $500 \mu \mathrm{g} / \mathrm{ml}$ RNase (Serva, Heidelberg, Germany) and stained with $50 \mu \mathrm{g} / \mathrm{ml}$ propidium iodide (Calbiochem, La Jolla, CA, USA). The fluorescence intensity was analyzed in a FACSort (Becton Dickinson, Sunnyvale, CA, USA) and displayed as a histogram of DNA content versus the number of nuclei. The DNA index was calculated by dividing the aneuploid mean channel number by the intrinsic diploid mean channel number. The coefficient of variation did not exceed $10 \%$ in any diploid peak.

\subsubsection{Fluorescence in situ hybridization (F/SH)}

A nuclei suspension was prepared from each frozen tumor specimen, as described above. This suspension was cytocentrifuged onto poly-Llysine coated slides, post-fixed in $1 \%$ paraformaldehyde $/ 0.1 \mathrm{M}$ phosphate buffer and air-dried. Individual slides were hybridized with centromere specific probes for the human chromosomes 1, 7, 9, 17 and $18^{13}$, labeled with biotin-11-dUTP (Boehringer, Mannheim, Germany). Cytochemical detection of the DNA probes was performed as previously described ${ }^{14}$. Double-target FISH was performed by hybridizing the same specimen simultaneously with a biotin-11-dUTP labeled probe for one of the chromosomes and a digoxigenin-11-dUTP labeled probe for another 
chromosome. The digoxigenin labeled probe was detected by subsequent incubation with mouse anti-digoxigenin (MADig, 1:2000; Sigma), tetramethylrhodamin isothiocyanate (TRITC)-conjugated rabbit anti-mouse IgG (RAMTRITC, 1:1000; DAKO A/S, Glostrup, Denmark), and TRITC-conjugated swine anti-rabbit IgG (SWARTRITC, 1:100; DAKO A/S). Nuclei were counterstained with 4',6-diamino-2-phenyl indole (DAPI; Sigma; $1.25 \mathrm{ng} / \mathrm{ml}$ ) diluted in $0.2 \mathrm{M} \mathrm{Tris-HCl} \mathrm{pH} 8.0$ / glycerol $(1: 9, \mathrm{v} / \mathrm{v})$ containing $2.3 \%$ of the anti-fading reagent $1,4-\mathrm{di}$ azobicyclo-(2,2,2)-octane (DABCO;Sigma).

Evaluation of the single-target FISH results was performed by counting the chromosome copy number of 200 nuclei per slide, according to the criteria described previously ${ }^{12,15}$. Samples were considered to contain an aberrant population for one of the investigated chromosomes when the frequency of cells showing an aberrant copy number exceeded $10 \%$. This rather high cut-off percentage was used to circumvent false classification due to technical artifacts or poor nuclear morphology, as a negative consequence small cell populations could not be classified (see also the Discussion section). In several cases, two or more different aberrations were found for the same chromosome (i.e. trisomy and tetrasomy) in more than $10 \%$ of the cells and a mixed classification was assigned for these cases. Double-target FISH was used in all cases for verification of chromosomal copy number imbalances, defined as a difference in the number of signals detected for individual chromosomes ${ }^{7}$, and for detailed analysis of specimens that contained a mixture of numerical aberrations. Double-target FISH results were evaluated by counting the copy number of both chromosomes in at least 100 nuclei. Microphotographs were recorded with the In Situ Image System (version 3.30, MetaSystems $\mathrm{GmbH}$, Altlussheim, Germany) using a black and white CCD camera. After digital acquisition in TIFF format, further processing of images was performed with the software package of Adobe Phatoshop (version 3.0, Adobe Photoshop Inc. Mountain View, CA, USA).

\subsection{Results}

\subsubsection{Clinical and histological features}

The patients included 1 woman and 11 men (table 4.1), ranging in age from 25 to 83 years (mean 60 years). Histologically all tumors were squamous cell carcinomas ( 2 well, 7 moderately, and 3 poorly 
differentiated). Most tumors were localized in the larynx $(n=9)$, while other sites were the oral cavity $(n=1)$, the tongue $(n=1)$ and the pharynx $(n=1)$. No or only minor variation was observed in the degree of differentiation of the two different tissue samples (center vs. border) analyzed for each neoplasm.

Table 4.1. Clinicopathological characteristics of the head and neck squamous cell carcinoma cases examined in this study.

\begin{tabular}{|c|c|c|c|c|c|}
\hline $\begin{array}{l}\text { Pal. } \\
\text { no. }\end{array}$ & Age & Sex & $\begin{array}{l}\text { Tumor } \\
\text { localization }\end{array}$ & $\begin{array}{l}\text { TNM classification } \\
\text { (UICC 1987) }\end{array}$ & $\begin{array}{l}\text { Histological } \\
\text { differentiation } \\
\text { grading }\end{array}$ \\
\hline 1 & 54 & $M$ & Larynx & T4N2bMO & Poor \\
\hline 2 & 58 & $M$ & Larynx & T4NOMO & Well \\
\hline 3 & 58 & $M$ & Larynx & T2NOMO & Moderate \\
\hline 4 & 59 & M & Orial cavity & T2N2bMo & Moderate \\
\hline 5 & 25 & M & Tongue & T2NOMO & Well \\
\hline 6 & 83 & $M$ & Larynx & T4NOMO & Moderate \\
\hline 7 & 60 & $\mathrm{~F}$ & Larynx & T4N2CMO & Moderate \\
\hline 8 & 55 & $M$ & Larynx & TANOMO & Moderate \\
\hline 9 & 63 & $M$ & Pharynx & TAN1MO & Moderate \\
\hline 10 & 60 & $M$ & Larymx & T4NOMO & Poor \\
\hline 11 & 65 & $M$ & Larynx & T3N2bMO & Poor \\
\hline 12 & 81 & $M$ & Larynx & T3NOMO & Moderate \\
\hline
\end{tabular}

\subsubsection{DNA flow cytometry}

Three of the tumors displayed a diploid DNA content, and nine tumors were aneuploid (table 4.2). In none of the tumors a discrepancy was detected among the two different samples (border vs. center) regarding the overall ploidy pattern. The DNA indices of the aneuploid cell populations ranged from 1.3 to 2.5 , none of the 9 aneuploid tumors exhibiting a major difference between the DNA indices of the aneuploid stemline in the different samples. The percentage of cells in the aberrant DNA peak was in general higher in the center biopsy sample (mean $36 \%$, ranging from 11 to $47 \%$ ) than in the border biopsy sample (mean $24 \%$, ranging from 10 to $38 \%$ ). All DNA aneuploid tumors showed a single aneuploid stemline. 
Table 4.2. Results of DNA flow cytometry and single-target FISH on nuclei suspensions from 12 HNSCC.

\begin{tabular}{|c|c|c|c|c|c|c|c|c|c|c|}
\hline \multirow{3}{*}{$\begin{array}{l}\text { Pat } \\
\text { no. }\end{array}$} & \multicolumn{4}{|c|}{ DNA flow cytometry } & \multicolumn{6}{|c|}{ Flubrescence in silu hybridization } \\
\hline & \multicolumn{2}{|c|}{ DNA-index } & \multicolumn{2}{|c|}{$\%$ Aneu } & \multicolumn{5}{|c|}{ Status of the individual chromosomes } & \multirow{2}{*}{$\begin{array}{l}\text { Gains } \\
\text { losses }\end{array}$} \\
\hline & $\mathbb{C}$ & $B$ & $\mathrm{C}$ & $\mathrm{B}$ & 1 & 7 & 9 & 17 & 18 & \\
\hline 1 & 1.0 & 1.0 & - & - & $\mathrm{Di}$ & Di & $\mathrm{Di}$ & Di & $\mathrm{Di}$ & \\
\hline 2 & 1.0 & 1.0 & - & - & Di & Di & $\mathrm{Di}$ & $\mathrm{Di}$ & Di & \\
\hline 3 & 1.0 & 1.0 & - & - & $\operatorname{Tr} * i$ & $\operatorname{Tr}$ & $\mathrm{Di}$ & Di & $\mathrm{Di}$ & $+7,+1^{4}$ \\
\hline 4 & 1.3 & 1.4 & 47 & 16 & TrfTe & $\operatorname{Tr}$ & Te & $\operatorname{Tr}$ & $\mathrm{Di}$ & .18 \\
\hline 5 & 1.4 & 1.5 & 46 & 38 & Di & $\mathrm{Tr}$ & $\pi r$ & $\operatorname{Tr}^{2}$ & $\operatorname{Tr}$ & $-1,-17^{ \pm 2}$ \\
\hline 6 & 1.5 & 1.5 & 42 & 29 & $\operatorname{Tr}$ & Te & ne & $\mathrm{Tr}$ & $\mathrm{Tr}$ & +7 \\
\hline 7 & $\$ .7$ & 1.5 & 32 & 33 & Te & Te & Di & $\mathrm{Te}$ & $\mathrm{Te}$ & .9 \\
\hline 8 & 1.7 & 1.6 & 36 & 10 & Te & $\mathrm{He}$ & Te & Te & $\mathrm{Te}$ & +7 \\
\hline 9 & 1.8 & 1.6 & 43 & 20 & $\operatorname{Tr}^{i} / \mathrm{Te}$ & $\mathrm{Tr}^{+} \mathrm{Te}$ & Te & $\mathrm{Tr} / \mathrm{Te}$ & $\mathrm{Te}^{\mathrm{x}^{2} / \mathrm{He}}$ & +18 \\
\hline 10 & 1.8 & 1.9 & 30 & 30 & $\mathrm{Te}$ & $\mathrm{Te}$ & $\mathrm{Te}$ & $\mathrm{Te}_{\mathrm{e}}$ & $\mathrm{Te}$ & \\
\hline 11 & 1.9 & ne & 11 & ne & Te & $\mathrm{Te}$ & Di & Te & $\mathrm{He}$ & $-9,+18$ \\
\hline 12 & 2.4 & 2.5 & 38 & 17 & $\mathrm{Te}^{1^{*}} / \mathrm{He}$ & HelOc ${ }^{1 "}$ & $\mathrm{Te}$ & $\mathrm{Tr}^{\circ} \mathrm{Te}$ & Difri & $+7 .-18$ \\
\hline
\end{tabular}

For FISH the data of border and center biopsy are combined. Only in case of differences between these regions, this is indicated by an asterisks $\left({ }^{* 1}=\right.$ only detected in the center-biopsy, ${ }^{* 2}=$ only detected in the border-biopsy). Abbreviations: Aneu, aneuploid; C, center biopsy; B, border biopsy; ne, not evaluable; $\mathrm{Di}$, disomy; $\mathrm{Tr}$, trisomy; $\mathrm{Te}$, tetrasomy; $\mathrm{He}$, hexasomy; Oc, octasomy.

\subsubsection{Fluorescence in situ hybridization}

Single- and double-target FISH on nuclei suspensions, using DNAprobes for the chromosomes $1,7,9,17$ and 18 , revealed numerical aberrations for one or more chromosomes in 10 of the 12 analyzed tumors. Aberrant copy numbers detected in this series included mainly tetrasomies and trisomies, but also hexasomies and octasomies. Table 4.2 summarizes these chromosomall copy number aberrations of the major clone(s) present in the tumors. From this table it is clear that chromosomal copy number imbalances are present in almost all tumor cases. Only the two disamic tumors (no.1 and 2) and one tetrasomic tumor (no.10) did not show these imbalances. Imbalances were not restricted to specific chromosomes, but seemed to occur more or less randomly, although chromosome 7 showed a relative gain in four cases and was never underrepresented. Chromosomal imbalances were in all cases verified by double-target FISH. Repeated single- and doubletarget FISH experiments revealed identical results in this study, with only a minor variation in the percentage of aneusomic cells present in each specimen (results not shown). As a result of these imbalances a unique pattern of chromosomal aberrations was identified for each of the tumors in this series. A clone containing this unique pattern of chromosomal aberrations was present in both biopsies taken from different sites of the 
tumor. However, in some cases multiple aneusomic clones were detected. Based on the number of aneusomic clones detected by FISH, the tumors could be distinguished as follows:

\section{Tumors containing a single tumor cell population}

These tumors $(n=5)$ showed a specific pattern of numerical chromosomal aberrations, however, several general features were observed:

The majority of nuclei (40-90\%) contains two FISH signals for most chromosomes and is classified as disomic. These cells represent normal stromal and epithelial cells and/or diploid tumor cells.

A major aberrant fraction (exceeding $10 \%$ of the total fraction) is detected for one or more chromosomes. Chromosomal copy number imbalances are present in most cases.

Next to this major aneusomic fraction, low percentages of nuclei are detected with other copy numbers than the copy number of the major fraction. These nuclei comprised of 0.5 to $10 \%$ of the total number of nuclei. Since no major differences are detected in the FISH pattern of the two samples from the same tumor, it appears that the same clone is present in both macroscopically distinct sites of the tumor. The percentage of aneusomic cells is in general lower in the border sample as compared to the center.

As a typical example of these tumors, figures $4.1 \mathrm{a} / \mathrm{b}, 4.2 \mathrm{a} / \mathrm{b}$, and $4.3 \mathrm{a} / \mathrm{b}$ show the FISH pattern obtained for the two samples of turnor no.8.

\section{Tumors containing multiple aneusomic clones}

In these tumor cases $(n=5)$, multiple genetically aberrant clones were detected in at least one of the two samples analyzed for each case. In three cases copy number heterogeneity was restricted to a single chromosome. An example of such a case (tumor no.3) is visualized in figures $4.1 \mathrm{c} / \mathrm{d}, 4.2 \mathrm{c} / \mathrm{d}$, and $4.3 \mathrm{c} / \mathrm{d}$. In the center biopsy of this tumor trisomy for chromosome 1 was present in $20 \%$ of all nuclei, but no aberrations were present for this chromosome in the border biopsy. Trisomy for chromosome 7 , however, was detected both in the center $(67 \%)$ and the border biopsy (54\%). Double-target FISH with probes for these two chromosomes revealed the presence of two aneusomic subpopulations in the center biopsy (chromosomal status of the two clones: disomy $1 /$ trisomy 7 and trisomy $1 /$ trisomy 7 ), whereas only one of these population was detected in the border biopsy (disomy $1 /$ trisomy 7). In tumor case no.4, two populations, one with trisomy for chromosome 1 and one with tetrasomy for chromosome 1 were detected. Again, also a "normal" disomic population and a small fraction 

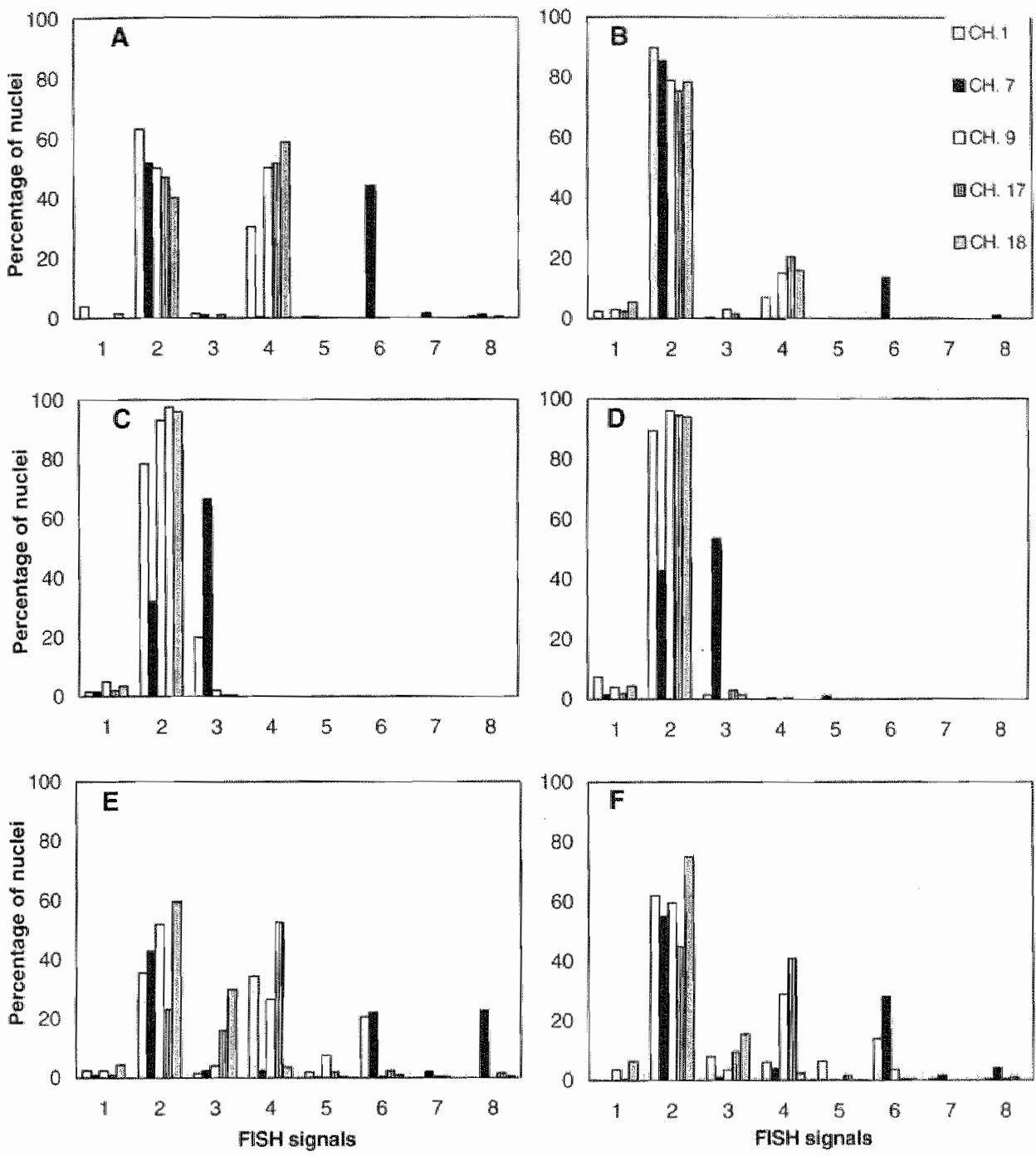

Figure 4.1. Representative patterns of chromosomal aberrations identified by FISH in two macroscopically distinct biopsies of three head and neck squamous cell carcinomas.

A, B) pattern of the center biopsy (A) and the border biopsy (B) of case no.8 is depicted. $C, D$ ) patterns identified in the same biopsies of case no 3. E, F) Patterns identified in these biopsies of case no. 12.

of nuclei with different amounts of FISH signals were detected with the chromosome 1 probe. The populations with trisomy 1 and tetrasomy 1 were present in both samples of this tumor. For the other chromosomes one aberrant copy number was detected in both samples of this tumor 
(trisomy 7 , tetrasomy 9 , trisomy 17 and disomy 18). The center biopsy of tumor case no. 3 did not contain numerical aberrations above the cut-off percentage for chromosome 17 , whereas in the border biopsy trisomy for chromosome 17 was found in $16 \%$ of all nuclei. The status of the other chromosomes was identical in both biopsy sites of this tumor.

In 2 cases copy number heterogeneity was detected for four of the five analyzed chromosomes. As an example the results of tumor case no.12 are depicted in figures $4.1 \mathrm{e} / f, 4.2 \mathrm{e} / \mathrm{f}$, and $4.3 \mathrm{e} / \mathrm{f}$. In this case multiple aneusomic cell fractions were identified in the center biopsy, whereas the border biopsy contained only one of the aneusomic clones. Extensive chromosomal copy number imbalances were also detected in this tumor; the chromosome copy numbers varied from disomy for chromosome 18 to octasomy for chromosome 7 . In case no. 9 the center biopsy also contained multiple clones with different copy numbers for most chromosomes, whereas only one of these populations was present in the border biopsy (except with the probe for chromosome 17 with which a trisomic and a tetrasomic population were detected in both biopsies).

\subsection{Discussion}

Intratumor heterogeneity (ITH) has been reported in several malignancies, and many investigators have suggested that the occurrence of this phenomenon has a clinical impact. Different clonal subpopulations of a tumor may for example differ in their capacity to metastasize ${ }^{3,16}$ and/or response to therapeutic modalities ${ }^{17,18}$. Head and neck squamous cell carcinomas (HNSCCs) comprise a clinically and histopathologically heterogeneous group of tumors, but as yet little is known about the genetic basis underlying this heterogeneity.

For this study, the chromosomal content of tumor cells isolated from two macroscopically distinct parts was determined in 12 resected HNSCC. One sample was taken from the center of the tumor and one part was taken close to the border of the same tumor. The genetic constitution of these tumor areas was studied by means of DNA flow cytometry (FCM) and fluorescence in situ hybridization (FISH). We defined ITH as the presence of more than one DNA aneuploid (FCM) or chromosomally aberrant (FISH) population within the same tumor. FCM analysis of these samples showed that 9 of the 12 tumors contained a single DNA aneuploid stemline with a nearly identical DNA index in the two different samples from the same tumor. Although similar results have been obtained in some studies ${ }^{19,20}$, they seem to be in sharp contrast with 
A

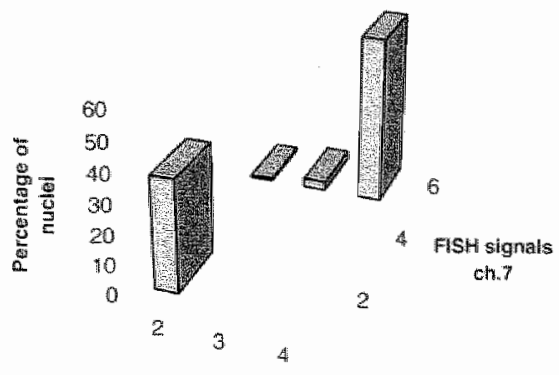

Filstit sichans, ch. IT

C

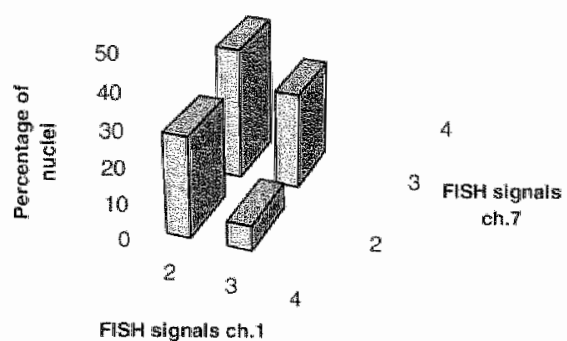

E

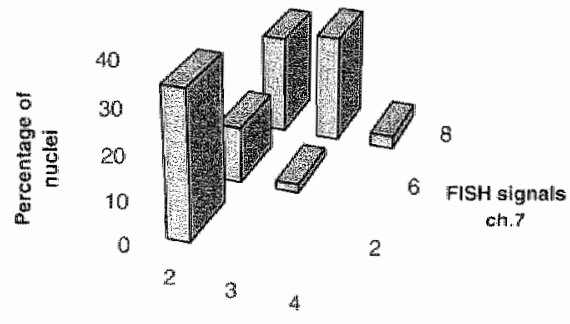

FisH silgntats ch. 18
B

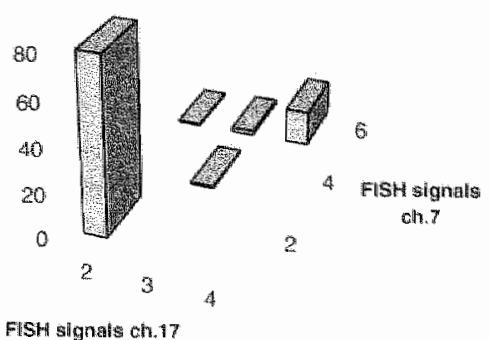

D

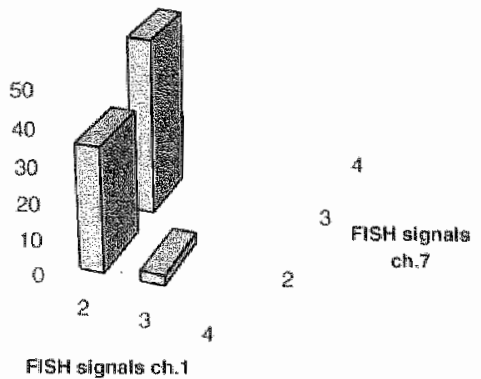

$\mathbf{F}$

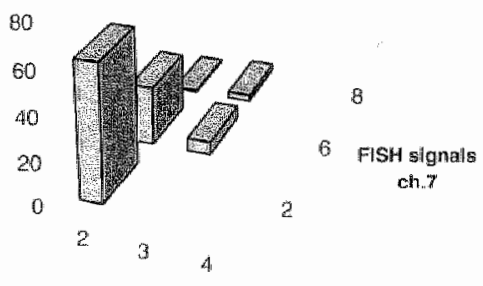

FISH gign

Figure 4.2. Frequency histograms of double-target FISH results in different parts of three HNSCC.

$A, B)$ histogram of the center biopsy $(A)$, and the border biopsy (B) of patient 8 is depicted. $C, D$ ) represent the histograms obtained in the same biopsies of patient 3. E, F) represent the histograms identified in these biopsies of palient 12.

others ${ }^{21,22}$. We feel that the ITH reported in the latter two studies can be explained by the variable admixture of normal diploid cells with aneuploid tumor cells, and hence does not reflect the presence of tumor cells with different DNA contents. This is also reflected in our results 
showing a difference in the percentage of aneuploid cells between the different samples of the same tumor. The border biopsy in general contained less aneuploid cells, a finding that was verified by FISH and might well be explained by the fact that more non-tumor cells were present in these samples.

We conclude that DNA flow cytometry is not sensitive enough for the detection of the genetically distinct clones present within HNSCC because this technique provides integrated data on the DNA content. In contrast, the FISH technique, enabling the detection of single chromosomes in individual cells, did show ITH in a considerable portion of the HNSCC included in this study.

FISH was used to study numerical aberrations of the chromosomes 1,7 , 9,17 and 18 in isolated nuclei from the same samples. The FISH results showed that 10 of the 12 tumors contained numerical chromosomal aberrations, 9 of which were DNA aneuploid as shown by FCM. Two cases displayed a concordant diploid DNA content and disomy for all chromosomes in both samples. These results once again show that most HNSCC exhibit numerical chromosomal aberrations. The patterns of chromosomal aberrations obtained showed great differences between the tumors included in this study. These were due to the presence of chromosomal copy number imbalances in most tumors. In fact only one DNA aneuploid tumor case (no.10) did not show imbalances for the chromosomes studied. In contrast to the results of Soder et al. ${ }^{2}$, the presence of these chromosomal copy number imbalances was not associated to lymph node metastasis in our study; i.e. 5 of the $7 \mathbb{N}_{0}$ tumors contained such imbalances. Comparison of the different samples from the same tumor showed that a tumor clone with an identical pattern of chromosomal aberrations was present throughout most tumors. The cytogenetic similarities observed between macroscopically distinct tumor lesions point to the presence of a genetically homogeneous cell population in these tumors. It might be hypothesized from these results that the complete pattern of chromosomal aberrations, including the extensive chromosomal copy number imbalances found in some tumors, is more or less stable during clonal expansion of the aneuploid cell population.

The present study, however, also provides evidence for ITH in HNSCC. Using single- and double-target FISH and by applying strict counting criteria, multiple cell populations with different numerical chromosomal aberrations were detected in 5 tumors.

Three tumors (no.'s 3, 4 and 5) showed copy number heterogeneity for a 
single chromosome in one or both of the analyzed samples, whereas an identical copy number was detected for the other chromosomes in both samples. In 2 of these cases (no.'s 4 and 5) DNA flow cytometry showed the presence of a single aneuploid peak, while the tumor from case no.3 was DNA diploid. FISH revealed trisomy for chromosomes 1 and 7 in the center biopsy of this tumor, while the border biopsy only contained trisomy 7 . From these results, it might be deduced that trisomy 7 was present in the expanding clone before trisomy 1. Interestingly. chromosome 7 was frequently overrepresented (tumor no.'s. 3, 6, 8, and 12), a finding also reported by others?

In 2 tumors, the center biopsy contained at least 2 aneusomic clones with differences in the copy number of 4 of the 5 analyzed chromosomes. In contrast, the border biopsy of these tumors contained only one of the clones detected in the center biopsy. These 2 tumors contained extensive chromosomal copy number imbalances and a polysomy (more than 4 copies) for at least one of the chromosomes. It has been suggested that cells with excessive chromosome numbers may be cytogenetically unstable, resulting in a random loss of chromosomes during subsequent cell divisions ${ }^{6}$. The fact that biopsies taken from the tumor border contained a lower percentage of tumor cells than the center biopsies, thereby reducing the chance that one or more aneusomic cell fractions are present above the cut-off percentage of $10 \%$, explains why less subpopulations were detected in these biopsies. Another explanation might be that several clones develop in the center of the tumor, while only the most expansive clone (selected on basis of growth advantage and/or protection against apoptosis) will spread and will be found in the tumor border.

Finally we want to comment on our evaluation criteria. Strict evaluation is essential to circumvent false classification due to technical artifacts or poor nuclear morphology. These evaluation criteria are in our opinion and the opinion of others ${ }^{11}$ essential for the detection of genuine ITH but have not always been applied in studies reported in the literature. A disadvantage of using these criteria is that we were unable to classify small cell populations, a problem also described by Schapers et al. ${ }^{7}$. In most cases such small subpopulations were identified next to the major tumor cell fraction. At this moment we are reluctant to classify these findings as prove for ITH since they might partially result from technical shortcomings. We feel that the genetic content of small subsets can best be analyzed on tissue sections allowing a direct correlation of the genetic data with the histological appearance of each tumor area (see Kim et al. ${ }^{23}$ and Wolf et al. ${ }^{24}$ ). 

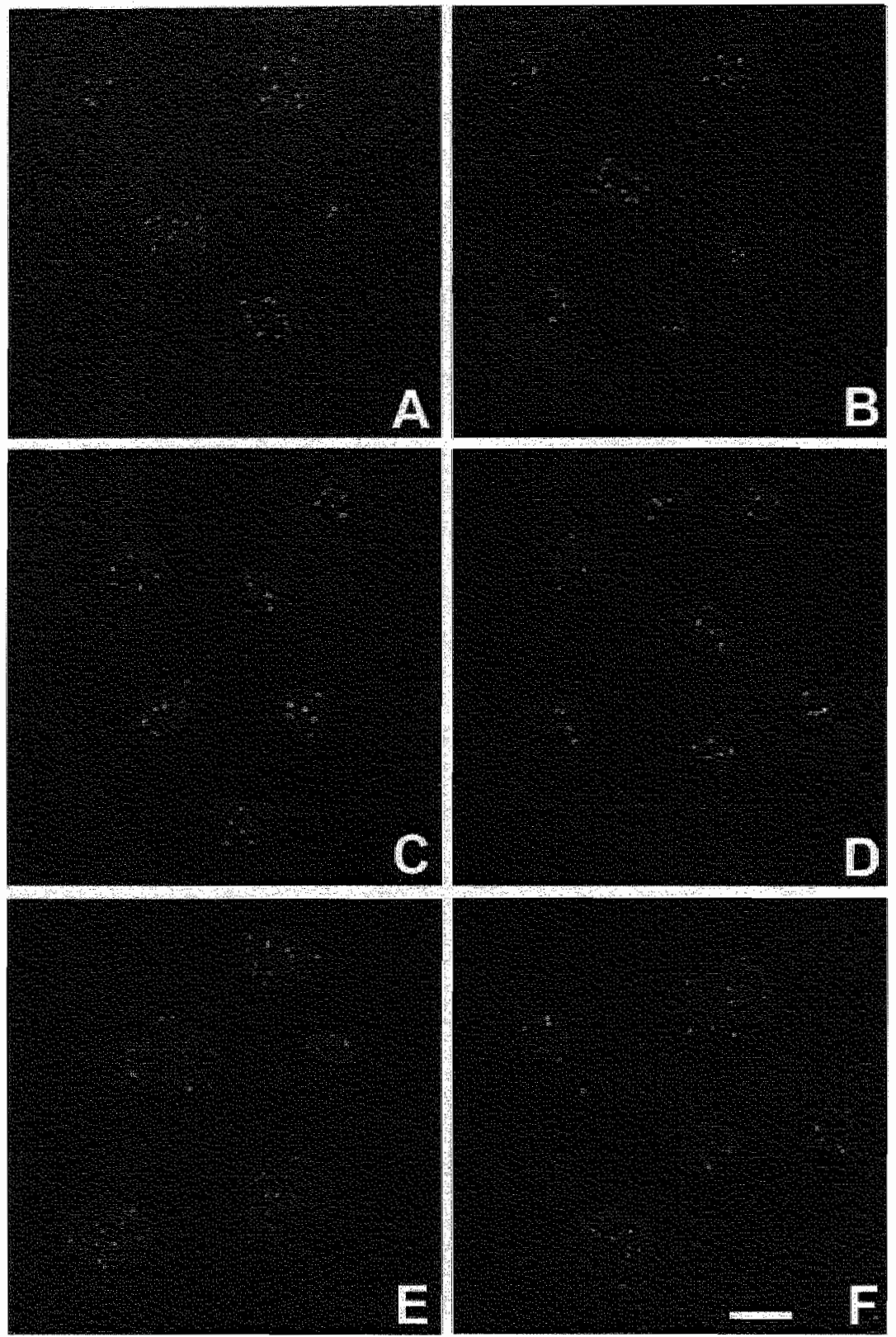

Figure 4.3. Examples of double-target FISH results as obtained in different parts of three HNSCC.

A, B) nuclei with double-target FISH signals (chromosome 7 in green, chromosome 17 in red) detected in the center $(A)$ and the border biopsy $(B)$ of patient 8 are shown. $C_{n}$ D) represent nuclei with double-target FISH signais (chromosome 1 in red, chromosome 7 in green) identified in the center and border biopsies of patient 3. E, F) nuclei with double-karget FISH signals (chromosome 7 in red, chromosome 18 in green) identified in these biopsies of patient 12. Representative nuclei present in different areas of a slide were merged into one picture (scale bar: 6 um). 
in conclusion, single- and double-target FISH on multiple biopsies of HNSCC revealed that, (1) great intertumor heterogeneity exists in the pattern of chromosomal aberrations, (2) a major clone containing a specific pattern of chromosomal aberrations has expanded relatively stable throughout most of these tumors, and (3) a subgroup of HNSCC contains additional clones with a different pattern of chromosomal aberrations, thereby providing evidence for intratumor heterogeneity in these tumors. These results show that the FISH-technique can be used to divide HNSCC into a genetically more homogeneous and a genetically more heterogeneous group. The clinical relevance of these findings will have to be investigated in a larger series of HNSCC with known follow-up. 


\subsection{References}

1. Califano, لl., van der Riet, P., Westra, W., Nawroz, H., Clayman, G., Piantadosi, S., Corio, R., Lee, D. Greenberg, B., Koch, W., and Sidransky, D. Genetic progression model for head and neck cancer: implications for field cancerization, Cancer Res. 56: 2488-92, 1996.

2. Soder, A. I., Hopman, A. H. N., Ramaekers, F. C. S., Conradt, C., and Bosch, F.X. Distinct non-random patterns of chromosomal aberrations in the progression of squamous cell carcinomas of the head and neck, Cancer Res. 55: 5030-7, 1995.

3. Shackney, S. E., Shankey, T. V. Common patterns of genetic evolution in human solid tumors, Cytometry. 29:1-27, 1997.

4. Pathak, S. Cytogenetic abnormalities in cancer: with special emphasis on tumorheterogeneity, Cancer Metastasis Rev. 8: 299-318, 1990.

5. Shankey, T. V., Jin, J. K., Dougherty, S., Flanigan, R. C. Graham, S., and Pyle, J. M. DNA ploidy and proliferation heterogeneity in human prostate cancers, Cytometry. 21: 30-9, 1995.

6. Shackney, S. E., Smith, C. A., Miller, B. W., Burholt, D. R., Murtha, K., Giles, H. R., Ketterer, D. M., and Pollice, A. A. Model for genetic evolution of human solid tumors, Cancer Res. 49:3344-54, 1989.

7. Schapers, R., Smeets, W., Hopman, A., Pauwels, R."Geraedts, J., and Ramaekers, F. Heterogeneity in bladder cancer as detected by conventional chromosome analysis and interphase cytogenetics, Cancer Genet Cytogenet. 70:56-61, 1993.

8. Sauter, G., Moch, H., Gasser, T. C., Mihatsch, M. J., and Waldman, F. M. Heterogeneity of chromosome 17 and erbB-2 gene copy number in primary and metastatic bladder cancer, Cytometry. 21: 40-6, 1995.

9. Simpson, J. F., Quan, D. E., Ho, J. P., and Slovak, M. L. Genetic heterogeneity of primary and metastatic breast carcinoma defined by fluorescence in situ hybridization, Am J Pathol. 149: 751-8, 1996.

10. Lengauer, C., Kinzler, K. W. Vogelstein, B. Genetic instability in colorectal cancers, Nature. 386:623-7, 1997.

11. Chapman, J-A., Wolman, E., Wolman, S., Remvikos, Y., Shackney, S., Axelrod, D. E., Baisch, H., Christensen, I. J., White, R. A., Liebowitch, L. S., Moore, D. H. Waldman, F. M., Comelisse, C. J., and Shankey, T. V. Assessing genetic markes of tumor progression in the context of intratumor heterogeneity, Cytometry. 31:67-73, 1998.

12. Hopman, A. H. N., and Ramaekers, F. C. S. Processing and staining of cell and tissue material for interphase cytogenetics. In: P. Robinson (ed.) Current protocols in cytometry. Chapter 8.5.1-8.5.22. New York: John Willey and Sons, Inc., 1998.

13. Willard, H. Waye, J. Hierarchical order in chromosome-specific human alpha satellite DNA, Trends Genet. 3: 192-8, 1987.

14. Pinkel, D., Straume, T., Gray, J. W. Cytogenetic analysis using quantitative high-sensitivity, fluorescence hybridization, Proc Natl Acad Sci USA. 83: 2934-8, 1986.

15. Hopman, A. H. N, Ramaekers, F. C. S, Raap, A. K., Beck, J. L. M., Devilee, 
P., van der Ploeg, M., and Vooijs, G. P. In situ hybridization as a tool to studynumerical chromosome aberrations in solid bladder tumors, Histochemistry. 89: 307-16, 1988.

16. Poste, G., Doll, J., Fidler, I. J. Interactions among clonal subpopulations affect stability of themetastatic phenotype in polyclonal populations of $\mathrm{B} 16$ melanoma cells, Proc Natl Acad Sci. USA. 78: 6226-30, 1981.

17. Leith, J. T., Dexter, D. L., DeWyngaert, J. K., Zeman, E. M., Chu, M. Y., Calabresi, $P_{x,}$ and Glicksman, A. S. Differential responses to $x$-irradiation of subpopulations of two heterogeneous human carcinomas in vitro, Cancer Res. 42: 2556-61, 1982.

18. Shapiro, W. R., Yung, W. A., Basler, G. A., and Shapiro, J. R. Heterogeneous response to chemotherapy of human gliomas grown in nude mice and as clones in vitro, Cancer Treat Rep. 65 (suppl 2): 55-9, 1981.

19. Tytor, M., Wingren, S.. Olofsson, J. Heterageneity of squamous cell carcinomas of the oral cavity studied by flow cytometry, Pathol Res Pract. 187: $30-5,1991$.

20. Goldsmith, M. M., Cresson, D. H., Arnold, L. A., Postma, D. S., Askin, F. B., and Pillsbury, H. C. Part 1. DNA flow cytometry as a prognostic indicator in head and neck cancer, Otolaryngol Head Neck Surg. 96: 307-18, 1986.

21. El-Naggar, A. K., Lopez Varela, V., Luna, M. A., Weber, R., and Batsakis, J. G. Intratumoral DNA content heterogeneity in laryngeal squamous cell carcinoma, Arch Otolaryngol Head Neck Surg. 118: 169-73, 1992.

22. Jacob, R., Welkoborsky, H. J., Mann, W. J., Hofken, F., Dienes, H. P., and Freije, J. E. Heterogeneity of squamous cell carcinomas of the head and neck-analysis of tumor biologic factors and proliferation rates, Laryngoscope. 106:1170-5, 1996.

23. Kim, S. Y., Lee, J. S., Ro, J. Y., Gay, M. L., Hong, W. K, and Hittelman, W. $N$. Interphase cytogenetics in paraffin sections of lung tumors by nonisotopic in situ hybridization. Mapping genotype/phenotype heterogeneity, Am J Pathol. 142: 307-17, 1993.

24. Wolf, N. G., Abdul Karim, F. W., Schork, N. J., and Schwartz, S. Origins of heterogeneous ovarian carcinomas. A molecular cytogenetic analysis of histologically benign, low malignant potential, and fully malignant components, Am J Pathol. 149: 511-20, 1996. 


\section{Chapter 5}

\section{P53 overexpression and chromosome instability are strongly correlated in early stages of oral carcinogenesis}

Peter-Paul G. van der Toorn, Joris A. Veltman, Fredrik J. Bot, Joseph M. A. de Jong, Johannes J. Manni, Frans C. S. Ramaekers and Anton $\mathrm{H}_{\text {. N. N. Hopman }}$ 
Oral squamous cell cancers (OSCC) have a high local recurrence rate partly due to problems in the recognition of minimal residual disease. The use of molecular markers to detect such cells with malignant potential will influence treatment with the aim of decreasing local recurrence. We combined p53 immunohistochemistry with in situ hybridization for chromosomes 1 and 7 to determine the presence of genetically instable cells in resection specimens of OSCC containing invasive cancer, precursor lesions and histologically normal mucosa. We observed an increased frequency of genetically aberrant cells, as detected by p53 overexpression and/or aneusomy, with histological progression. A strong correlation was observed between the presence of chromosomal aberrations and p53 overexpression, in particular in the dysplastic stage. Of clinical importance was the finding that 11 of 20 resection margins, all of which were initially diagnosed as being tumorfree, were found to contain genetically aberrant cells. Closer histological examination of the genetically aberrant compartment within these margins often revealed small dysplastic areas that were missed in the initial diagnosis, showing that this genetic approach can assist in the diagnosis. 


\subsection{Introduction}

The acquisition of genetic instability is an essential step during carcinogenesis 1.2 . In most tumors, including oral squamous cell carcinomas (OSCC), such a genomic change is observed at the chromosome level, resulting in numerical and structural chromosome alterations ${ }^{3.4}$. Although the molecular basis of this chromosomal instability is as yet unknown, mutations in one or more mitotic checkpoint genes have been suggested to cause abnormal cell division, leading to an abnormal chromosome constitution ${ }^{5}$. One of the candidate genes is $\mathrm{p} 53$, being one of the most frequently altered tumor suppressor genes known to date ${ }^{6.7}$. Several studies have suggested that a loss of normal p53 function leads to a destabilization of the genome and facilitates development of DNA aneuploidy ${ }^{8,9}$. This would suggest that alterations in p53 (which can be easily detected immunocytochemically because of its stabilization) precede the acquisition of chromosomal alterations. On the contrary, there are also indications that genetic instability can lead to loss of tumor suppressor genes like p53 in solid cancers ${ }^{10}$, indicating that the relationship between both processes is still unclear. It has been shown that both p53 immunoreactivity and numerical chromosomal alterations can be detected in premalignant stages of head and neck carcinogenesis ${ }^{11-15}$, but both processes have not been correlated so far.

In the underlying study we have therefore combined p53 immunohistochemistry with chromosome in situ hybridization for the detection of numerical aberrations of the chromosomes 1 and 7 in the subsequent steps of oral carcinogenesis. The correlation between both processes was studied in resection specimens of OSCC containing invasive cancer, precursor lesions and histologically normal mucosa. From a clinical point of view, these markers for genetic instability may be useful to detect the presence of minimal residual disease. It is generally believed that the presence of (pre) malignant cells in a resection margin constitutes a high risk for the development of local recurrence, one of the major problems in head and neck oncology 16.18. The histopathological features of premalignant lesions, which might be present within the resection margin, are very subtle and consequently the interpretation of these features is subjective ${ }^{19}$. In contrast, a direct visualization of genetic changes in tissue sections by either immunohistochemistry or in situ hybridization gives objective information on the extent of genetic damage present within these margins, and might therefore be of value in diagnosis. 


\subsection{Material and methods}

\subsubsection{Patient material}

Formalin fixed, paraffin-embedded tumor specimens were obtained from 21 patients with radically resected (resection margin $>5 \mathrm{~mm}$ free of invasive carcinoma) squamous cell carcinoma of the tongue, diagnosed between 1995 and 1997. All patients had a history of smoking and drinking. Patients were treated by surgery only and classified as pT1NOMO $(n=13)$, pT2NOMO $(n=7)$ and pT3NOMO $(n=1)$ (UICC 1987). From these 21 patients a specimen, representative for the free resection margin, was selected after reviewing the original heamatoxylin-eosin stained sections. In 6 cases these specimens contained also a part of the tumor. To obtain a representative cohort of tumor samples, 7 additional tumor specimens were selected randomly from the remaining 15 patients. In total 28 specimens were studied, 15 containing a free margin only, 13 containing both tumor and adjacent epithelium. As a control group, 4 patients with a benign lesion of the oral tongue were included ( 2 hyperkeratotic papillomas and 2 fibromas). From all cases 4 $\mu \mathrm{m}$ thick tissue sections were used for detailed histological examination, p53 immunohistochemistry and chromosome in situ hybridization.

\subsubsection{Histological examination}

All specimens were heamatoxylin-eosin stained and subsequently reviewed by an experienced pathologist (F.J.B.). Normal, hyperplastic, dysplastic, carcinoma in situ (CIS) and tumor areas, if present, were identified and marked on the slide for detailed comparisons with the genetic data.

In addition to the standard histological examination performed at the beginning of this study, a detailed histological examination was performed after the chromosome in situ hybridization and p53 analyzes were completed and all tissue areas containing genetic abnormalities were mapped precisely. During re-examination the pathologist focussed on the areas containing genetic abnormalities. These regions were often very small, consisting in some cases of no more than 10-20 cells. 


\subsubsection{In situ hybridization}

In situ hybridization was essentially performed using a recently optimized protocol and evaluated according to well-established criteria 20.21 . Briefly, after deparaffinization the $4 \mu \mathrm{m}$ thick sections were pretreated with $85 \%$ formic acid containing $0.3 \% \quad \mathrm{H}_{2} \mathrm{O}_{2}$, followed by incubation at $80^{\circ} \mathrm{C}$ in $1 \mathrm{M}$ sodium thiocyanate. After digestion with pepsin ( $4 \mathrm{mg} / \mathrm{ml}$ in $0,02 \mathrm{~N} \mathrm{HCl}$ ) individual sections were hybridized with either a centromere specific probe for chromosome 1 or $7^{22}$, labeled with biotin11-dUTP (Boehringer, Mannheim, Germany). Immunochemical detection of hybrids was performed by the standard avidin-biotin complex (ABC) procedure (Vectastain, Vector Laboratories, Burlingame, California, USA). Peroxidase activity was detected using diaminobenzidine (DAB)/ $\mathrm{H}_{2} \mathrm{O}_{2}$, sections were counterstained with heamatoxylin and mounted in Entellan (Merck, Darmstadt, Germany).

Evaluation was performed qualitatively by analyzing in detail the complete epithelium independently by two of the authors (P.P.G. v.d. T. and J.A.V). The sections were analyzed to identify whether nuclei containing aberrant chromosome copy numbers were present. Histologically described epithelial areas were classified as either disomic (normal) when no nuclei with three or more ISH signals were observed, or aneusomic (abnormal) when multiple nuclei with three or more ISH signals were present for one or both chromosomes.

\subsubsection{P53 immunohistochemistry}

An immunohistochemical assessment of p53 protein overexpression was performed on $4 \mu \mathrm{m}$ thick sections from paraffin-embedded tissue. After deparaffinization, the sections were pre-treated with $0.3 \% \mathrm{H}_{2} \mathrm{O}_{2}$ in methanol to quench endogenous peroxidase activity. Antigen retrieval was performed by microwave heating in $0.01 \mathrm{M}$ citrate buffer $(\mathrm{pH} 6.0)$. Both normal and mutant p53 protein was detected using a monoclonal antibody (clone DO-7; DAKO A/S, Glostrup, Denmark). After incubation with the biotinylated secondary antibody, immunochemical detection was further performed as described for the in situ hybridization. In each analysis a known p53-negative and p53-positive oropharynx tumor served as control. Evaluation of the complete lesion was performed qualitatively by three authors (P.P.G. v.d. T., J.A.V. and F.J.B.). The extent of the P53 immunohistochemical reaction was scored visually as negative (less than $5 \%$ of the cells with a positive nuclear staining) or positive (more than $5 \%$ of the celis evidently positive). 


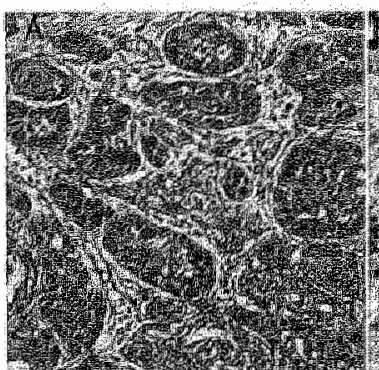

D

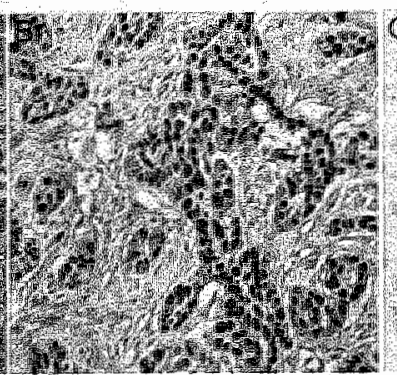

E
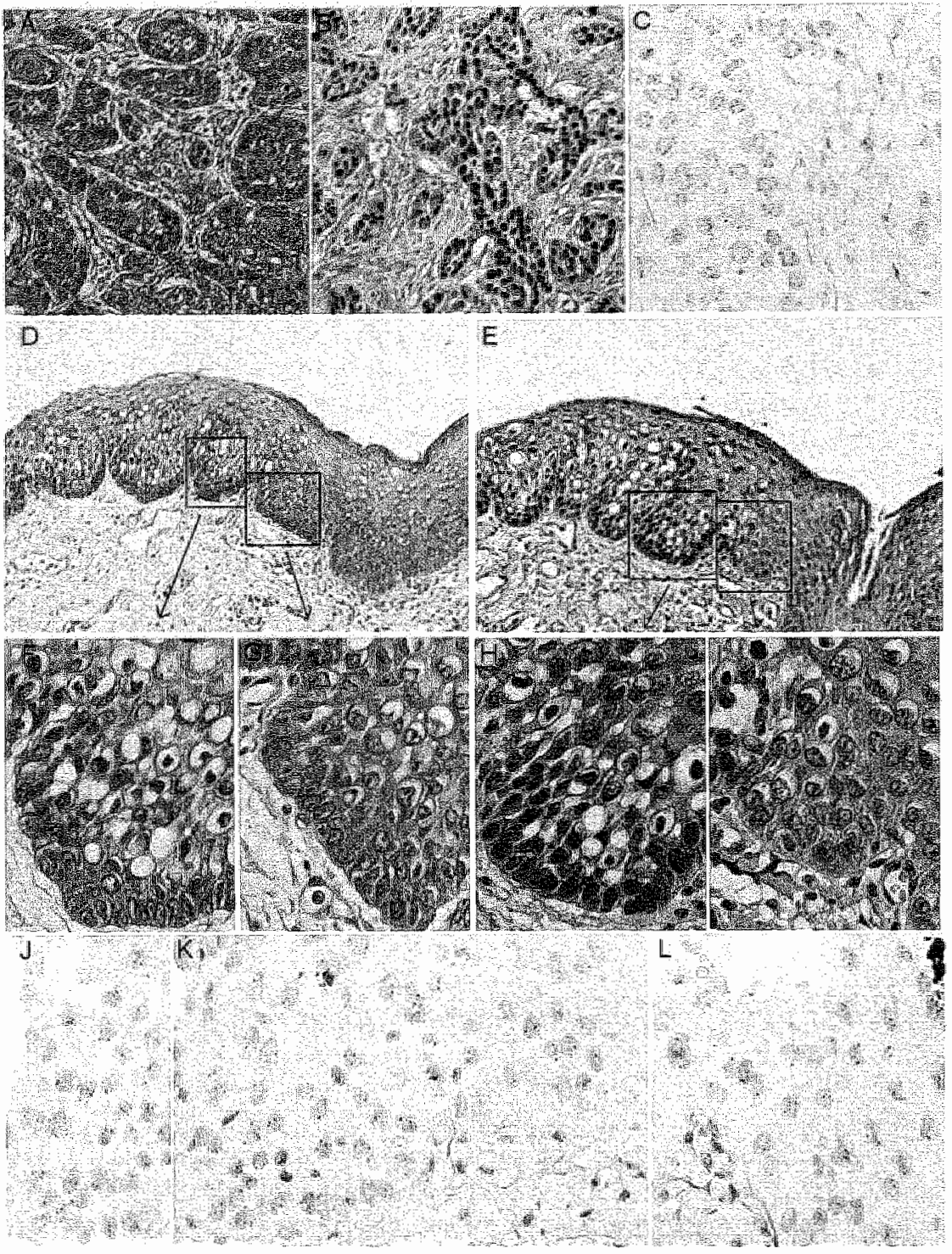

Figure 5.1. Histology, p53 immunohistochemistry and ISH analysis of the tumor and the resection margin of OSCC case no. 16.

(A.C) Analysis of the OSCC (A), with p53 immunostaining (B) and ISH with a probe for chromosome 7 (C). The tumor cells are clearly overexpressing p53 and contain multiple copies (with a maximal copy number of 8) of chromosome 7 .

(D-L) Analysis of the resection margin (overvitew in D, details in F and G), by p53 immunohistochemistry (overview in $\mathrm{E}$, details in $\mathrm{H}$ and $\mathrm{I}$ ), and ISH with a probe for chromosome 7 of the corresponding area $(\mathrm{U}, \mathrm{K}$, L). This part of the resection margin was classified as hyperplastic but shows both overexpression of $p 53$ and numerical aberrations for chromosome 7 in part of the epithellum in this case with a maximal copy number of 4), whereas an adjacent part is negative for p53 staining and contains no numerical chromosome aberrations. Note that the area showing 153 staining perfectly matches the area containing chromosome abertations. 


\subsection{Results}

\subsubsection{Histological re-examination guided by results of the genetic} analyzes

Both p53 immunohistochemistry and chromosome in situ hybridization could be evaluated from the tissue sections of 20 out of 21 patients $(95 \%)$ with OSCC and all control patients. In the control group, neither cells showing p53 overexpression, nor cells containing abnormal copy numbers of chromosomes 1 and 7 were detected after detailed analysis of the complete epithelium of these lesions. P53 overexpression and abnormal chromosome copy numbers were detected frequently in the resection specimens, often in small foci (sometimes consisting of no more than 10-20 cells) located within areas that were initially diagnosed as normal or hyperplasia. For this reason the specimens were reexamined histologically, with special focus on the genetically aberrant tissue compartments. In contrast to the results from the initial histological examination, in which dysplasia was only identified in 3 samples, the reexamination revealed dysplasia in 12 samples.

\subsubsection{Correlation between histology, genotype and p53 status}

Figure 5.1 illustrates typical p53 staining and ISH results in the OSCC and in part of the resection margin of case no.16. As can be seen in this figure, the tumor cells are p53 positive and contain multiple copies of chromosome 7 . In part of the resection margin, histologically classified as hyperplasia, a distinct area with p53 overexpression and chromosome abnormalities was detected immediately adjacent to a (histologically identical) area without these genetic changes. Interestingly, in this case the area with hyperplasia contained trisomy for chromosome 1 and tetrasomy for chromosome 7. whereas the tumor area contained hexasomy for chromosome 1 and octasomy for chromosome 7 , indicating that an endoreduplication has occurred in the transition from hyperplasia to invasive SCC.

Table 5.1 summarizes in detail the results for the p53 immunohistochemical staining and chromosome in situ hybridization for each of the 20 patients with OSCC. Results for the chromosomes 1 and 7 are combined in this table. As a typical example, the resection margin of case no.10 contains histologically normal, hyperplastic and dysplastic areas, whereas an additional sample of the same case contains the 
Table 5.1. Results of the p53 and ISH analyzes of 20 patients with OSCC.

\begin{tabular}{|c|c|c|c|c|c|c|c|c|}
\hline \multirow{3}{*}{$\begin{array}{l}\text { Pat. } \\
\text { no. }\end{array}$} & \multicolumn{8}{|c|}{ Histological classification } \\
\hline & \multicolumn{2}{|c|}{ Nonmal } & \multicolumn{2}{|c|}{ Hyperplasia } & \multicolumn{2}{|c|}{ Dysplasia } & \multicolumn{2}{|c|}{ CISIOSCC } \\
\hline & P53 & ISH & P53 & ISH & P53 & ISH & P53 & $\mathrm{ISH}$ \\
\hline 1 & N & $N$ & $\mathbb{N}$ & N & - & - & - & $=$ \\
\hline 2 & . & - & $\mathbb{N}$ & $N$ & - & - & . & - \\
\hline 3 & . & . & $\mathbb{N}$ & $N$ & - & - & - & - \\
\hline 4 & . & . & $\mathbb{N}$ & $\mathrm{N}$ & . & - & $N$ & $\mathbb{N}$ \\
\hline $5 a / b$ & $\mathbb{N} / \mathbb{N}$ & $N / N$ & $-\mathbb{N}$ & $/ \mathbb{N}$ & 4 & $\gamma$ & $-N$ & $-/ N$ \\
\hline 6 & $\mathrm{~N}$ & $N$ & . & - & . & . & $N$ & $\mathrm{~A}$ \\
\hline $7 a / b$ & $N / N$ & $N / N$ & $-\mathbb{N}$ & $-\mathbb{N}$ & $-/ N$ & $-\mathbb{N}$ & $-/ N$ & $/ A$ \\
\hline $8 \mathrm{a} / \mathrm{b}$ & $\mathbb{N} / \mathbb{N}$ & $N / N$ & $\%$ & $\%$ & 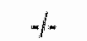 & 4 & $/ A$ & $-/ A$ \\
\hline $9 a / b$ & $\%$ & 4 & $\mathbb{N} / \mathbb{N}$ & N/N & $\mathbb{A} / A$ & AA & $-1 A$ & $-/ A$ \\
\hline $10 \mathrm{a} / \mathrm{b}$ & $\mathbb{N} /$ & N/- & $\mathbb{N} / \mathbb{N}$ & $\mathbb{N} / \mathbb{N}$ & $\mathbb{A} / \mathrm{A}$ & A/A & $-/ A$ & $-/ A$ \\
\hline $11 \mathrm{a} / \mathrm{b}$ & N/ & $\mathrm{N} / \mathrm{-}$ & N/- & $N$ & $\mathrm{~A} / \mathrm{A}$ & ANA & $-/ A$ & $-/ A$ \\
\hline 12 & . & . & $\mathrm{N}$ & $\mathrm{N}$ & A & $N$ & - & $=$ \\
\hline 13 & . & . & $N$ & $\mathbb{N}$ & $A$ & $A$ & . & - \\
\hline 14 & . & . & - & . & $N$ & $A$ & $N$ & $A$ \\
\hline $15 \mathrm{a} / \mathrm{b}$ & $\mathrm{N} / \mathrm{N}$ & NNN & $-1 A$ & $-/ A$ & -1 & 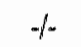 & $-/ A$ & $-/ A$ \\
\hline 16 & $\mathrm{~N}$ & $N$ & A & A & A & A & A & A \\
\hline 17 & . & - & $N$ & $\mathrm{~A}$ & - & - & . & - \\
\hline 18 & - & - & $A$ & $\mathbb{N}$ & A & $A$ & - & - \\
\hline 19 & . & - & $A$ & $\mathbb{N}$ & - & - & $\mathbb{N}$ & A \\
\hline 20 & $N$ & $\mathbb{N}$ & A & $\mathbb{N}$ & - & - & $\mathrm{A}$ & A \\
\hline
\end{tabular}

Abbreviations: CIS: carcinoma in situ; OSCC: oral squamous cell carcinoma; ISH: in situ hybridization; $a, b$ : In 7 cases two samples taken from different locations were analyzed. In these cases sample "a" contains the margin of resection, and sample "b" contains the tumor and adjacent mucosa; N: classified as normal (P53 negative / ISH disomic), A: classified as abnormal (P53 overexpression / ISH showing abnormal chromosome copy numbers).

tumor and adjacent to the tumor region also a hyperplastic and a dysplastic region. The normal and the hyperplastic regions are genetically normal (i.e. no p53 overexpression and no nuclei with more than 2 copies of chromosomes 1 and 7), whereas the dysplastic areas and the tumor region show both p53 overexpression and abnormal chromosome copy numbers. In some other cases the relation between histology, p53 overexpression and the presence of chromosomal alterations is less clear. For example in case no.19, p53 overexpression is present in an hyperplastic area without chromosomal abnormalities. In contrast, the tumor region of this case contains numerical aberrations for both chromosomes but does not show p53 overexpression.

In total 7 out of 20 OSCC patients showed both $\mathrm{p} 53$ overexpression and numerical chromosomal aberrations in the resection margin. In 4 
patients either p53 overexpression or chromosomal alterations were detected in the resection margin, whereas the resection margin of the remaining 9 patients did not show abnormalities with both techniques.

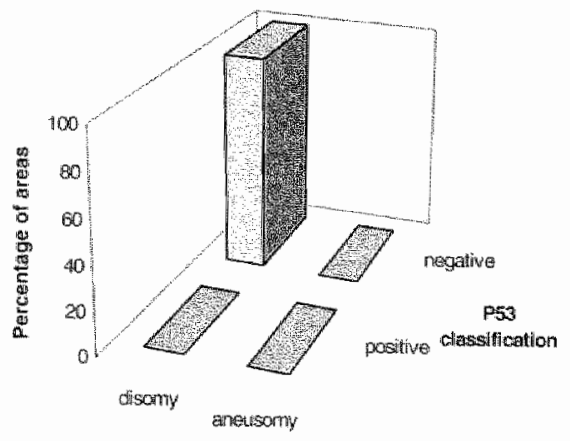

ISH classification

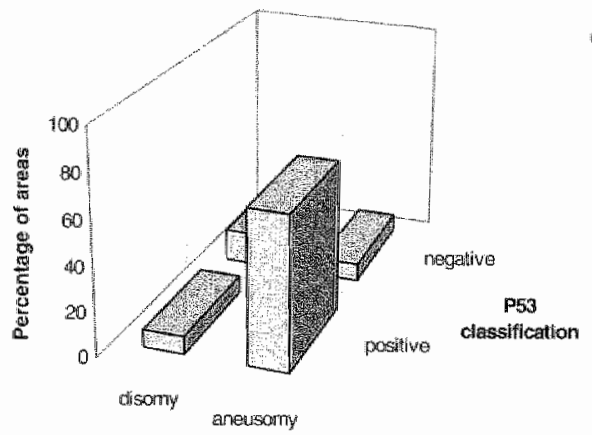

ISH classification
A

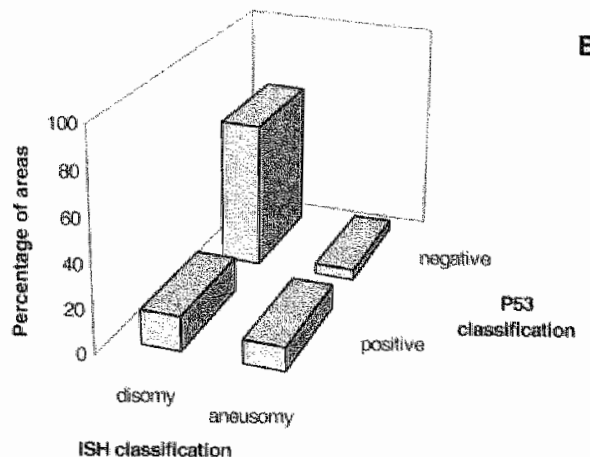

C

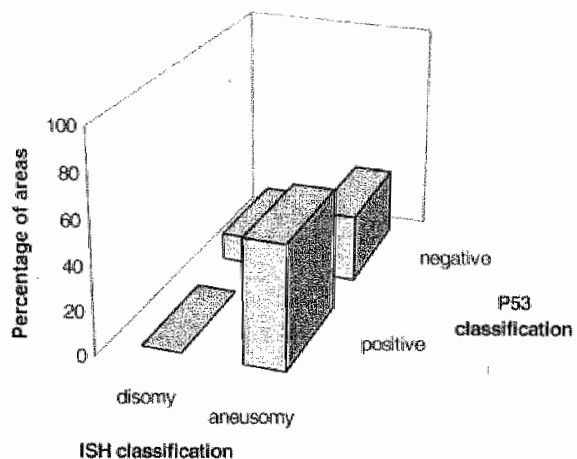

Figure 5.2. Frequency histograms showing the correlation between p53 staining and the ISH classification in different stages of oral carcinogenesis.

(A) Normal tongue epithelium ( $n=14)$. (B) Hyperplastic epithelium ( $n=19$ ). (C) Dysplastic epithelium ( $n=12$ ).

(D) $\mathrm{CIS} / \mathrm{SCC}(n=13)$.

Figure 5.2 shows the correlation between p53 overexpression and abnormal chromosome copy number with regard to the different histological areas present in the various samples of all 20 patients. As can be seen in this illustration, neither p53 overexpression nor chromosomal abnormalities were detected in tissue compartments consisting of histologically normal epithellium. A low percentage of hyperplastic tissue compartments showed p53 overexpression and/or chromosomal abnormalities. In contrast, most dysplastic lesions 9 out of 12) showed both p53 overexpression as well as aberrant chromosome copy numbers. Chromosomal alterations were also present in 11 out of $13 \mathrm{CIS} / \mathrm{SCC}$ areas with only 7 of these areas showing p53 
owerexpression.

\subsection{Discussion}

In this study we used p53 immunohistochemistry and chromosome in situ hybridization to analyze in detail the resection margins of tongue tumors for the presence of genetically aberrant cells, and compared the obtained data with a detailed histological analysis.

Genetically aberrant cells, as detected by either p53 overexpression and/or aneusomies for chromosomes 1 and 7 , were ideritified in the resection margins from 11 of 20 OSCC patients. Importantly, 7 of these 11 resection margins showed genetically aberrant cells with both techniques. Especially this last finding is in our view a strong indication for the presence of (pre) malignant cells located in an area close to the border of resection. In a previous study on premalignant laryngeal lesions, we detected numerical aberrations for the chromosomes 1 and/or 7 in 14 out of 15 dysplastic lesions, whereas only 1 out of 11 hyperplastic lesions showed chromosomal alterations ${ }^{15}$. This finding underlines the use of chromosomal alterations as markers for a dysplastic phenotype in head and neck carcinogenesis. It also emphasizes that the presence of mild or moderate dysplasia within a resection margin constitutes a significant risk for the development of recurrences, since the cells within these lesions have already accumulated extensive genetic changes.

Many authors have claimed the detection of genetic abnormalities in histologically normal mucosa adjacent to HNSCC ${ }^{11,14,23}$. Also during this study we frequently identified p53 overexpression and/or chromosomal aberrations in small tissue compartments that were classified as normal in the standard histological examination. However, after revision during which the pathologist was guided by the genetic abnormalities in the tissue, the classification of these areas was altered from normal to hyperplasia or even dysplasia. These areas were not detected during the standard histological examination at the beginning of our study because of their very small size (consisting in some cases of no more than 10-20 cells). This observation underlines the subjective character of histological examinations, as recently discussed by for example Westra and Sidransky ${ }^{19}$. Our data clearly show that conclusions about DNA changes in normal mucosa can only be drawn after a detailed histological revision of the genetically aberrant tissue compartments. 
As a result of the in depth histological examination of the resection margins, a complex pattern of histologically different areas emerged, consisting of normal, hyperplastic and dysplastic epithelium. Neither the 14 areas with normal epithelium nor the epithelium in 4 control specimens showed chromosomal aberrations or p53 overexpression. Chromosomal aberrations were detected in $16 \%$ of the hyperplastic areas, in $77 \%$ of the dysplastic areas, and in $88 \%$ of the CIS/SCC areas. P53 overexpression was detected in $26 \%$ of the hyperplastic areas, in $77 \%$ of the dysplastic areas, and in $56 \%$ of the CIS/SCC areas.

Since the most common mechanism for generating genetic diversity in solid tumors involves the development of p53 abnormalities and DNA aneuploidy ${ }^{24}$, the correlation between p53 overexpression and the acquisition of chromosomal abnormalities was examined. There are strong indications that these events are closely linked, although the molecular mechanisms underlying the development of p53-induced aneuploidy are not fully understood. In the underlying study, the concomitant overexpression of p53 and chromosome aneusomy detected in serial sections, showed a clear correlation between positive p53 staining and the presence of chromosomal alterations in precisely mapped tissue compartments. This correlation is most evident when the results obtained in histologically normal epithelium are compared with those in dysplastic tissue compartments (figure $5.2 \mathrm{a}$ vs. $5.2 \mathrm{c}$ ). It indicates that both genetic changes take place simultaneously during the histological transition from normal to dysplastic epithelium. When the results for the hyperplastic epithelium (figure 5.2b), as an intermediate between normal epithelium and dysplasia, are taken into consideration, the impression is obtained that p53 overexpression precedes the occurrence of aneusomy.

The finding that the association between p53 staining and chromosome alterations is not evident in the group of CIS/SCC areas suggests that the acquisition of genetic instability is of more importance in premalignant stages of disease. It remains to be established whether the p53 gene is mutated in hyperplastic or dysplastic areas showing p53 overexpression, or whether the overexpression identified in this epithelium is merely a response of the normal non-mutated gene to DNA damage as described ${ }^{13}$.

We conclude that p53 overexpression and the acquisition of chromosome alterations are strongly correlated in premalignant stages of oral carcinogenesis, leading to a genetic instability essential for malignant progression. In addition this study showed that a combined analysis of p53 overexpression and the chromosome content gives detailed information about the extent of genetic alterations present in 
precisely mapped epithelial areas of oral resection margins. Genetic alterations are frequently present in these margins, even in tissue compartments that do not show extensive histological changes. Therefore we state that these genetic techniques should supplement histological examinations. 


\subsection{References}

1. Nowell, P. C. The clonal evolution of tumor cell populations, Science. 194: 23$8,1976$.

2. Loeb, L. A. Mutator phenotype may be required for multistage carcinogenesis, Cancer Res. 51: 3075-9, 1991.

3. Lengauer, C., Kinzler, K. W., and Vogelstein, B. Genetic instabilities in human cancers, Nature. 396: 643-9, 1998.

4. Soder, A. I., Hopman, A. H. N., Ramaekers, F. C. S., Conradt, C., and Bosch, F. X. Distinct non-random patterns of chromosomal aberrations in the progression of squamous cell carcinomas of the head and neck, Cancer Res. 55: 5030-7, 1995.

5. Cahill, D. P., Lengauer, C., Yu, J., Riggins, G. J., Willson, J. K., Markowitz, S. D., Kinzler, K. W., and Vogelstein, B. Mutations of mitotic checkpoint genes in human cancers, Nature. 392: 300-3, 1998.

6. Hollstein, M., Sidransky, D., Vogelstein, B., and Harris, C. C. p53 mutations in human cancers, Science. 253: 49-53, 1991.

7. Prives, C., and Hall, P. A. The p53 pathway, J Pathol. 187: 112-26, 1999.

8. Cross, S. M., Sanchez, C. A., Morgan, C. A., Schimke, M. K., Ramel, S., Idzerda, R. L., Raskind, W. H., and Reid, B. J. A p53-dependent mouse spindle checkpoint, Science. 267: 1353-6, 1995.

9. Fukasawa, K., Choi, T., Kuriyama, R., Rulong, S., and Vande Woude, G. F. Abnormal centrosome amplification in the absence of $p 53$, Science. 271: 1744-7, 1996.

10. Albertoni, M., Daub, D. M., Arden, K. C., Viars, C. S., Powell, C., and Van Meir, E. G. Genetic instability leads to loss of both p53 alleles in a human glioblastoma, Oncogene. 16:321-6, 1998.

11. Shin, D. M., Kim, J., Ro, J. Y., Hittelman, J., Roth, J. A., Hong, W. K., and Hittelman, W. N. Activation of p53 gene expression in premalignant lesions during head and neck tumorigenesis, Cancer Res. 54: 321-6, 1994.

12. Sauter, E. R., Cleveland, D., Trock, B., Ridge, J. A., and Klein-Szanto, A. J. p53 is overexpressed in fifty percent of pre-invasive lesions of head and neck epithelium, Carcinogenesis. 15: 2269-74, 1994.

13. Nees, M., Homann, N., Discher, H., Andl, T., Enders, C., Herold-Mende, C., Schuhmann, A., and Fosch, F. X. Expression of mutated p53 occurs in tumor-disant epithelia of head and neck cancer patients: A possible molecular basis for the development of multiple tumors, Cancer Res. 53: 4189-96, 1993.

14. Voravud, N., Shin, D. M., Ro, J. Y., Lee, J. S., Hong, W. K., and Hittelman, W. N. Increased polysomies of chromosomes 7 and 17 during head and neck multistage tumorigenesis, Cancer Res. 53: 2847-83, 1993.

15. Veltman, J. A., Bot, F. J., Huynen, F. C., Ramaekers F. C. S., Manni, J. J., and Hopman, A. H. N. Chromosome instability as an indicator of malignant progression in laryngeal mucosa. Submitted.

16. Kowalski, L. P., Magrin, J., Waksman, G., Santo, G. F., Lopes, M. E., de Paula, R. P., Pereira, R. N., and Torloni, H. Supraomohyoid neck dissection in the treatment of head and neck tumors: survival results in 212 cases, Arch 
Ololaryngol Head Neck Surg. 119: 958-63, 1993.

17. Looser, K., Shah, J, and Strong. E. The significance of "positive" margins in surgically resected epidermoid carcinomas, Head Neck Surg. 1: 107-11, 1978.

18. Jesse, R., and Sugarbaker, E. Squamous cell carcinoma of the oropharynx; why we lail. Am IS Surg. 132: 435-8, 1976.

19. Westra, W. H. and Sidransky, D. Phenotypic and genotypic disparity in premalignant lesions: Of calm water and crocodiles, J Natl Cancer Inst. 90: $4500-1,1998$.

20. Hopman, A. H. N., van Hooren, E., van de Kaa, C. A., Vooijs, P. G. P., and Ramaekers, F. C. S. Detection of numerical chromosome aberrations using in situ hybridization in paraffin sections of routinely processed bladder cancers, Mod Pathol. 4:503-13, 1991.

21. Hopman, A. H. N., and Ramaekers, F. C. S. Processing and staining of cell and tissue material for interphase cytogenetics. In: Robinson P, ed. Current protocols in cytometry. New York: John Wiley and Sons, Inc., 1998; chapter 8.5.1-8.5.22.

22. Willard, $H$. and Waye, J. Hierarchical order in chromosome-specific human alpha satellite DNA, Trends Genet. 3: 192-8, 1987.

23. Brennan, J. A., Mao, L., Hruban, R. H., Boyle, J. O., Eby, Y. J., Koch, W. M., Goodman, S. N. and Sidransky, D. Molecular assessment of histopathological staging in squamous-cell carcinoma of the head and neck. N Engl J Med. 332: 429-435, 1995.

24. Shackney, S. E., and Shankey, T. V. Common patterns of genetic evolution in human solid tumors, Cytometry. 29: 1-27, 1997. 


\section{Chapter 6}

Detection of chromosomal aberrations in cytologic brushes from head and neck squamous cell carcinoma

Joris A. Veltman, Anton H. N. Hopman, Fredrik J. Bot, Frans C. S. Ramaekers, Johannes J. Manni. 
Detection of genetic changes in the mucosa of the upper aerodigestive tract may provide a target for screening of cytologic specimens to identify (pre)malignant transformation in this region. In this pilot study, the feasibility of the fluorescence in situ hybridization (FISH) technique to detect genetically aberrant cells in brush specimens was evaluated. Brush specimens taken from the tumors of 20 patients with head and neck squamous cell carcinoma (HNSCC) and from normal mucosa of 8 control patients were analyzed by FISH using DNA probes for the chromosomes 1 and 7 . These FISH results were compared with DNA flow cytometry (FCM) and FISH results of the solid tumor specimens. The results of this study showed that 15 of the 20 tumor brush specimens contained numeric chromosomal aberrations in at least $5 \%$ of the cells collected. Chromosomal aberrations were detected in all brush specimens taken from tumors that were DNA aneuploid and showed aneusomy. The presence of these aberrations correlated well with the classification "suspicious for malignancy", which was based on Papanicolaou stained slides of the same specimens. In the control group the percentage of chromosomally aberrant cells did not exceed $2 \%$; in addition, no suspiciously malignant cells were observed in this group. In conclusion, this study reveals that the FISH technique can be applied diagnostically to brush specimens of HNSCC. The presence of chromosomal aberrations in $>5 \%$ of the cells in these specimens can be considered as a marker for malignancy. 


\subsection{Introduction}

The detection of genetic changes in the cytologic specimens of persons at high risk for the development of head and neck carcinoma may provide a target for screening of premalignant transformation in these persons. Epithelial cells can be obtained in an easy, non-invasive manner by brushing the mucosa. Although exfoliate cytology using standard Papanicolaou staining is a valuable tool for the diagnosis of several types of (pre)malignancies and can be used in the head and neck region for tumor diagnosis, the validity of the method depends strongly on the representativity of the specimen and the experience of the investigator ${ }^{1,2}$. Therefore, additional techniques have to be applied to obtain more objective diagnostic criteria. Fluorescence in situ hybridization (FISH) can be used to study the chromosomal constitution of cytologic specimens ${ }^{3}$ and has recently been reported to be of use in the cytopathological diagnosis of cervical neoplasia 4,5 . By using chromosome specific DNA probes, this technique allows a targeted detection of numerical chromosomal aberrations in interphase nuclei on a single cell basis ${ }^{6}$.

Recently the FISH technique was applied to biopsy specimens obtained from HNSCC ${ }^{7}$. Specific chromosomal changes were reported to be associated with different stages of HNSCC progression. In early stages ( $\mathrm{N}_{0}$-tumors) a distinct loss of chromosome 9 and gain of chromosomes 1, 7 and 17 was observed. The development of tetrasomy or polysomy and the presence of chromosomal copy number imbalances were associated strongly with tumor progression. Hittelman et al. ${ }^{8}$ recently reported the presence of numerical aberrations for chromosomes 7 and 17 in morphologically normal epithelium adjacent to head and neck tumors, using in situ hybridization on paraffin tissue sections. It was suggested that these aberrations are markers for a generalized genetic change and also that the presence of these aberrations might be useful as a genetic biomarker for malignant transformation.

To the authors" knowledge, until now studies on chromosomal aberrations in cytologic specimens of HNSCC have not been described. In the current study the feasibility of the FISH technique was tested for the identification of aberrant cells in cytologic brush specimens from HNSCC. 


\subsection{Material and methods}

\subsubsection{Patient material}

Brush specimens were obtained from 20 patients presenting with HNSCC (17 men and 3 women; age range, 42-79). Most tumors were localized in the larynx $(n=10)$; other sites were the palate $(n=2)$, the pharynx $(n=3)$, the tongue $(n=2)$ and the tonsils $(n=3)$. The tumors varied in UICC 87 stage from T1NO to T4N2; in seven patients lymph node metastasis was identified. Under general anesthesia, prior to diagnostic evaluation, cells were brushed from the tumor area using an interdental cleaner (Enta-Lactona bv., Bergen op Zoom, The Netherlands). A control group was comprised of 8 patients who were admitted for nonmalignant disease. Brush specimens from the control group also were obtained under general anesthesia prior to surgery, by brushing healthy appearing mucosa from the vocal cords, the posterior pharyngeal wall and the floor of mouth. Brushes were fixed immediately in Carbowax ( $2 \%$ polyethylene-glycol mol. wt. 1450 (Sigma Chemical Co., St. Louis, MO, USA) in $50 \%$ ethanol) and stored at $4^{\circ} \mathrm{C}$ in this fixative. Fresh tumor tissue was collected from 12 patients after resection or biopsy, snapfrozen and stored at $-80^{\circ} \mathrm{C}$.

\subsubsection{Histological and cytologic examination}

From 14 tumor and 24 control brush samples (taken from 3 regions of the 8 patients) a cell suspension was cytocentrifuged onto glass slides. The slides were coded, followed by the Papanicolaou staining procedure. The samples were graded in normal, atypia and suspiciously malignant by an experienced pathologist. Tumor brush samples from 6 patients could not be evaluated with the Papanicolaou procedure. A 5 fum thick frozen tissue section from each of the 12 tumor biopsies was stained with heamatoxylin and eosin and tumor diagnosis and grading were confirmed by the same pathologist.

\subsubsection{Fluorescence in situ hybridization}

From each specimen (both brush and frozen tissue) a nuclei suspension was prepared by a proteolytic digestion step with pepsin from porcine stomach mucosa (2500-3500 U/mg protein; Sigma) at a concentration of 
$100 \mu \mathrm{g} / \mathrm{ml}$ in $0.01 \mathrm{~N} \mathrm{HCl}$ for $20 \mathrm{~min}$ at $37^{\circ} \mathrm{C}$. This suspension was cytocentrifuged onto poly-L-lysine coated slides, post-fixed with $1 \%$ paraformaldehyde in $0.1 \mathrm{M}$ phosphate buffer and air-dried. Separate slides were hybridized with the biotin-11-dUTP (Boehringer, Mannheim, Germany) labeled chromosomes 1 ( $p$ U C1.77) and $7(p 7 t 1)^{9}$ centromere specific probes. When the single-target FISH procedure indicated an imbalance between the copy number of both chromosomes, doubletarget FISH was performed. This was done by hybridizing the same specimen simultaneously with a biotin-11-dUTP labeled probe for one of the chromosomes and a digoxigenin-11-dUTP probe for the other chromosome. Cytochemical detection of the biotin-11-dUTP probe was performed as previously described ${ }^{10}$. Detection of the digoxigenin labeled probe was performed by subsequent incubation with mouse antidigoxigenin (MADig, 1:2000; Sigma), tetramethylrhodamin isothiocyanate (TRITC)-conjugated rabbit anti-mouse IgG (RAMTRITC, 1:1000; Dako, Glostrup, Denmark), and TRITC-conjugated swine antirabbit IgG (SWARTRITC, 1:100; Dako). Nuclei were counterstained with 4',6-diamino-2-phenyl indole (DAPI; Sigma; $1.25 \mathrm{ng} / \mathrm{ml}$ ) diluted in $0.2 \mathrm{M}$ Tris- $\mathrm{HCl}, \mathrm{pH} 8.0 /$ glycerol $(1: 9, \mathrm{v} / \mathrm{v})$ containing $2.3 \%$ of the anti-fading reagent 1,4-di-azobicyclo-(2,2,2)-octane (DABCO;Sigma).

Evaluation of the single-target FISH results was performed by counting the chromosome copy number of 200 nuclei per slide, according to the criteria described before ${ }^{11}$. In the control group, the mean plus three times the standard deviation was $1 \%$ for numerical chromosomal aberrations. In order to obtain reliable results, the cut-off percentage for the different aberrant chromosome copy numbers was set at $5 \%$. A tumor sample was classified as disomic, when the frequency of aberrant cells did not exceed this cut-off value. When the frequency of aberrant cells exceeded this percentage, the tumor was classified as trisomic when the cells contained 3 FISH signals per nucleus, tetrasomic with 4 signals per nucleus, and polysomic with more than 4 signals per nucleus. When cell populations with different aberrant copy numbers were present, a combined classification was given. Microphotographs were recorded with the Metasystems Image Pro System (black and white CCD camera), with TRITC in red, FITC in green and DAPI in blue.

\subsubsection{DNA Flow Cytometry}

From each frozen tumor specimen, a nuclei suspension was prepared from a $50 \mu \mathrm{m}$ thick section as described above. The nuclei were treated with $500 \mu \mathrm{g} / \mathrm{ml}$ RNase (Serva, Heidelberg, Germany) and stained with 50 $\mu \mathrm{g} / \mathrm{ml}$ Propidium lodide (Calbiochem, La Jolla, CA, USA). The 
fluorescence intensity was analyzed in a FACSort (Becton Dickinson, Sunnyvale, CA, USA) and displayed as a histogram of DNA content versus number of nuclei. The DNA index was calculated by dividing the aneuploid mean channel number by the iritrinsic diploid mean channel number.

\subsection{Results}

\subsubsection{Detection of chromosomal aberrations in cytologic brush}

\section{specimens}

In the control group of 8 patients, the mean plus three times the standard deviation was $1 \%$ for numerical chromosomal aberrations. In order to obtain reliable results, the cut-off percentage for the different aberrant chromosome copy numbers was set at $5 \%$. Figure 6.1 a shows the disomic pattern that was obtained in this control group with doubletarget FISH. In the tumor group, numerical aberrations for the chromosomes 1 and 7 were detected above the cut-off percentage in 15 of the 20 tumor brushes for either one or both chromosomes (table 6.1). Numerical chromosomal aberrations detected in the cytologic specimens included trisomies, tetrasomies, polysomies or combinations thereof. Imbalances between the copy numbers of chromosomes 1 and 7 were frequently observed. Chromosome 7 showed a relative gain in 7 cytologic specimens, while a relative gain for chromosome 1 was detected in 2 specimens. The presence of these imbalances was in all cases confirmed by double-target FISH. Figure $6.1 \mathrm{~b}$-e shows some examples of double-target FISH patterns in brush specimens of HNSCC.

\subsubsection{Cytologic grading and comparison with the FISH results}

From the control group, 23 brush specimens were classified as normal and in 1 specimen a group of atypical cells was observed. In the tumor group, 2 specimens were classified as normal, in 2 specimens atypical cells were observed and 10 specimens contained suspiciously malignant cells. No numerical chromosomal aberrations were detected above the cut-off percentage in the 2 samples with atypia and in 1 normal sample, but a trisomy for chromosome 7 was detected in one sample without atypical cells. Chromosomal aberrations were detected in 9 of the 10 brush specimens classified as suspicious for malignancy (table 6.1). 
Table 6.1. Cytopathological and genomic characteristics of the HNSCC examined in this study.

\begin{tabular}{|c|c|c|c|c|c|c|}
\hline \multirow{2}{*}{$\begin{array}{l}\text { Pat. } \\
\text { no. }\end{array}$} & \multirow{2}{*}{$\begin{array}{l}\text { Cytologic } \\
\text { grading }\end{array}$} & \multicolumn{2}{|c|}{ FISH in brush specimens } & \multicolumn{3}{|c|}{ FCM and FISH in solid tissue specimens } \\
\hline & & $\mathrm{CH} 1$ & $\mathrm{CH} .7$ & DNA-index & $\mathrm{CH} .1$ & $\mathrm{CH} .7$ \\
\hline 1 & Normal & Di & Di & - & - & - \\
\hline 2 & Normal & $\mathrm{Di}$ & Trin & 11.0 & Di & Di \\
\hline 3 & Atypia & Dï & Di & 1.0 & Di & Di \\
\hline 4. & Atypia & $\mathrm{Di}$ & Di & - & - & - \\
\hline 5 & Susp.mal. & $\mathrm{Di}$ & Di & 1.0 & Di & Di \\
\hline 6 & Suspmal. & Tri & Tetra & 1.3 & $\operatorname{Tri}$ & Tetre/Poly \\
\hline 7 & Susp.mal. & Tri & Tetra & 1.4 & $\operatorname{Tri}$ & Tetra \\
\hline 8 & Susp.mal. & $\mathrm{Di}$ & Tetra & 1.6 & $\mathrm{Di}$ & Tetra \\
\hline 9 & Susp.mal. & Tri & Tetra Poly & 1.7 & Tetra & Tetra/Poly \\
\hline 10 & Susp.mal. & Tri & Tri & 1.8 & Tetra / Poly & Tetra/Poly \\
\hline 11 & Susp.mal. & Di & Tetra & 1.9 & TrilTetra & TriTetra \\
\hline 12 & Susp.mal. & Tri & Tetra & 2.0 & Tri & Tetra \\
\hline 13 & Susp.mal. & Tri & $\mathrm{Di}$ & - & - & - \\
\hline 14 & Suspmal. & Tetra & Tetra & $=$ & - & 一 \\
\hline 15 & n.e. & Tri/Tetra/Poly & Tetra/Poly & 1.8 & ThiTetra/Poly & Tri/Tetra \\
\hline 16 & n.e. & Tetra & Tetra & 1.9 & Tetra Poly" & Poly \\
\hline 17 & m.e. & Di & Di & - & - & - \\
\hline 18 & n.e. & $\operatorname{Tr}$ & $\mathrm{Di}$ & - & - & - \\
\hline 19 & n.e. & Tri/Tetra & TrivTetra & - & . & * \\
\hline 20 & n.e. & Di & Tetra & - & - & - \\
\hline
\end{tabular}

Abbreviations: FISH, fluorescence in situ hybridization; FCM, flow cytometry; $\mathrm{CH}$, chromosome; Susp. mall, suspicious for malignancy; Di, disomy; Tri, trisomy; Tetra, tetrasomy; Poly, polysomy, n.e., not evaluated.

\subsubsection{DNA flow cytometry and FISH analysis of solid tumor}

\section{tissue}

A frozen tissue specimen taken from the tumor was available for analysis from 12 of the 20 patients in this series. Flow cytometric analysis showed that 3 of these specimens contained diploid tumor cells (DNA-index $=1.0$ ), whereas 9 tissue specimens contained DNA aneuploid tumor cells (DNA-index >1.0) (table 6.1). In addition, the FISH analysis of these solid tissue specimens showed that all DNA aneuploid tumors contained numerical aberrations for chromosomes 1 and/or 7 . No chromosomal aberrations were detected in the DNA diploid tumors. Chromosomal aberrations were detected in all brush specimens taken from DNA aneuploid tumors with aneusomy. In addition, trisomy 7 was detected in one brush specimen whereas the matching solid tissue specimen did not show an aberrant copy number for this chromosome or 
an aberrant DNA content.

Differences also were abserved when the FISH results of the brush specimens and the matching solid tissue specimen were compared. In some cases a chromosome was classified as trisomic in one specimen, but as tetrasomic in the other specimen taken from the same tumor. In addition a minor polysomic population was detected occasionally in the solid tissue specimen that could not be detected in the brush specimen. To exclude that these differences were the result of technical problems involving specimen pre-treatment and classification on basis of 200 nuclei, the authors repeatedly analyzed these samples and obtained identical results (results not shown). The average percentage of cells harboring numerical chromosomal aberrations was lower in the brush specimen $(20 \%)$ than in the solid tissue specimen $(43 \%)$.

\subsection{Discussion}

The feasibility of the FISH technique to detect chromosomal aberrations in cytologic specimens from tumors of the upper aerodigestive tract was examined in this study. For this purpose the copy number of the chromosomes 1 and 7 was determined by interphase cytogenetics in cells brushed from tumor sites and in cells obtained from normal mucosa. In all specimens studied a high detection efficiency could be achieved. Numerical aberrations for chromosome 1 and/or 7 were detected in all brush specimens taken from DNA aneuploid tumors. In total $75 \%$ of all brush specimens, taken randomly from tumors of different clinical stages, contained chromosomal aberrations, whereas in the control group the percentage of cells with abnormal chromosomal copy numbers did not exceed the cut-off percentage. The presence of chromosomal aberrations in the tumor brushes did not correlate to tumor localization, clinical stage and/or stage of differentiation. In our study, the cytologic specimens from 11 out of the 13 No-tumors contained numerical aberrations for chromosomes 1 and 7 . This points to an early accumulation of generalized genetic changes in head and neck tumorigenesis, and indicates that the detection of chromosomal aberrations in cytologic specimens is a relevant marker for risk assessment in (pre)clinical stages of this disease.

Studies using flow cytometry to measure the DNA content of HNSCC showed that $60-70 \%$ of these tumors was DNA aneuploid "I . In the underlying study 9 out of 12 analyzed solid tumor tissue specimens 


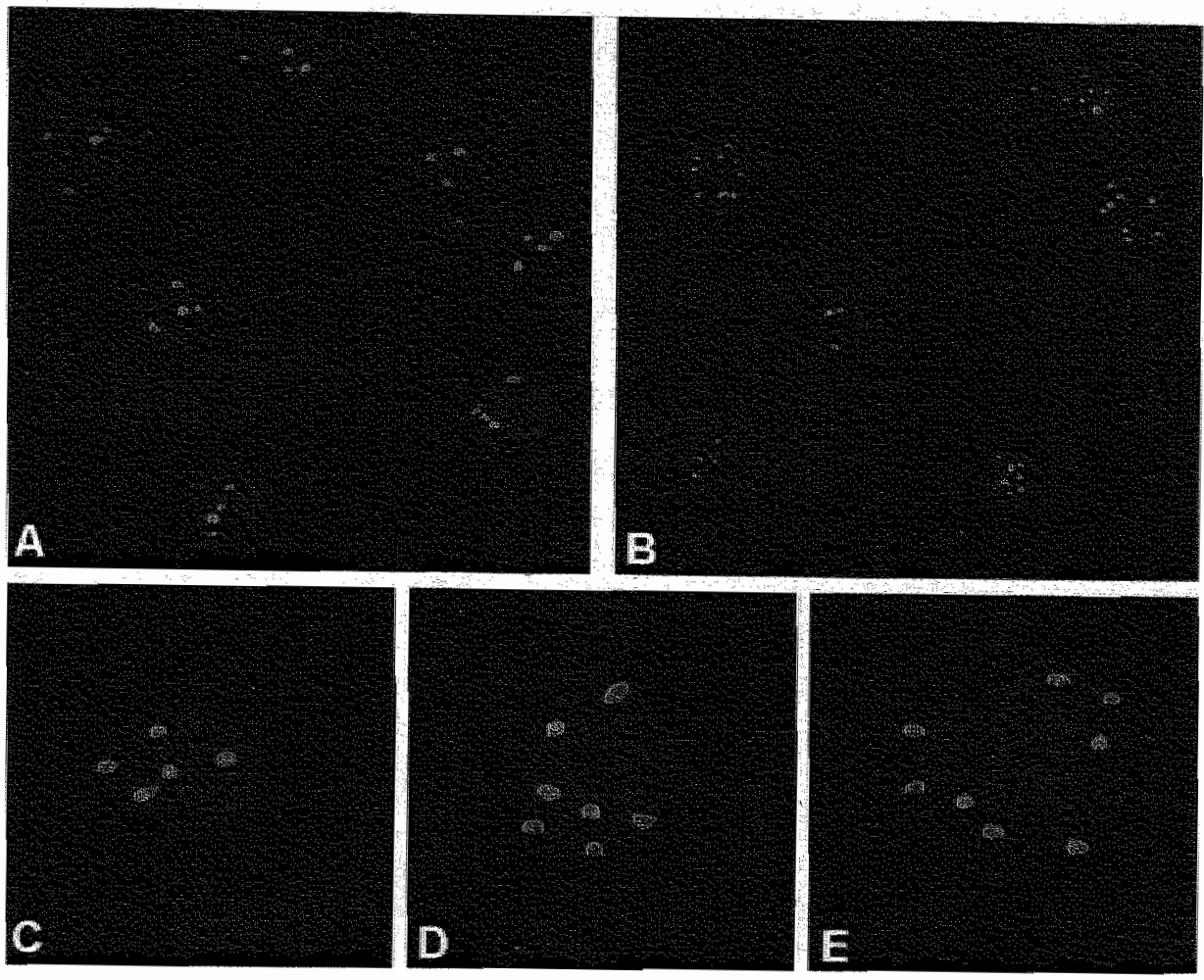

Figure 6.1. FISH results in tumor brush specimens from head and neck squamous cell carcinoma.

Probes hybridized to the centromeric regions of chromosomes 1 and 7 were detected with TPITC (red) or FITC (green). Nuclei were counterstained with DAPI (blue). A. Control sample showing nuclei with a disomy for both chromosomes 1 (green) and 7 (red). B. Sample from patient no.15, showing nuclei with numerical aberrations for both chromosomes (red) and 7 (green). C. A nucleus from the sample of palient na.2, with disomy for chromosome 1 (green) and trisomy for chromosome 7 (red). D. Nucleus from the sample of patient no.7 showing trisomy for chromosone 1 (red) and letrasomy for chromosome 7 (green). E. Nucleus from the sample of patient no.15 showing polysomy for chromosome 7. Magnifications: $1000 \mathrm{x}$ for $\mathrm{A}, \mathrm{B}$; $2000 \times$ for $C-E$.

showed DNA aneuploidy (75\%) and chromosomal aberrations were detected in all these tissue specimens. This is in agreement with the study of El-Naggar et al. ${ }^{13}$, reporting the presence of chromosomal aberrations in all examined DNA aneuploid head and neck tumors. The results of our study showed that chromosomal aberrations were detected in brush specimens from all of the DNA aneuploid tumors. This result therefore validates the use of $\mathrm{FISH}$ in head and neck cytopathology. It is important to notice that the percentage of cells with chromosomal aberrations in the brush specimen was in general lower than in tissue specimen. This can be explained by contamination of 
tumor cells with normal mucosal cells in a brush specimen and by difficulties encountered in brushing for example a glottic tumor, which is often presented as a small lesion. Also, aberrant cells present in deeper parts of the tumor will not be collected by the brush procedure.

In 5 cases the FISH technique did not reveal chromosomal aberrations in the brush specimen. Two cases had matching solid tumor specimen with a normal DNA index and disomy for the chromosomes 1 and 7 . The remaining 3 cases had no suspiciously malignant cells in the brush specimen with Papanicolaou-staining.

In 6 solid tissue specimens and in 4 brush specimens a mixed classification of the chromosomal copy numbers was given. The presence of such genetically different cell populations within one tumor is a strong indication for intratumoral heterogeneity. This might also explain the frequent differences that were detected between copy numbers in the brush specimen and solid tissue specimen, and in particular the trisomy for chromosome 7 that was detected in the brush specimen of patient no.2, which could not be detected in the solid tissue sample of this patient.

In conclusion, this study showed that application of the FISH technique in cytologic specimens of tumors present in the upper aerodigestive tract provides valuable information as to the genetic constitution of the tumor cells. Detection of chromosomal aberrations in $>5 \%$ of the cells is a strong indication for malignancy.

\subsection{Acknowledgements}

The authors wish to thank Dr. E.J.M. Speel for his useful advice on technical matters and for proofreading this article. 


\subsection{References}

1. Plath, P., Gorba, P., Lenart, R., Wierich, W. Die Wertigkeit der Exfoliativzytologie nach Papanicolaou in der Diagnostik von Karzinomen des oberen Aerodigestivtraktes, HNO. 40:140-3, 1992.

2. Gaafar, H., Hussein, M., El Assi, H. Cytopathology in cancer of larynx, ORL. 51:216-20, 1989.

3. Moore, L., Titenko-Holland, N., Smith, M. Use of fluorescence in situ hybridization to detect chromosome-specific changes in exfoliated human bladder and oral mucosa cells, Environ Mol Mutagen. 22: 130-7, 1993.

4. Segers, P., Haesen, S., Castelain, P., Amy, J-J., de Sutter, P., van Dam, P., and Voldwers, K. Study of numerical aberrations of chromosome 1 by fluorescent in situ hybridization and DNA content by densitometric analysis on (pre)-malignant cervical lesions, Histochem J. 27: 24-34, 1995.

5. Hariu, $H$., Matsuta, M. Cervical cytology by means of fluorescence in situ hybridization with a set of chromosome-specific DNA probes, $J$ Obstet Gynaecol Res. 22: 163-70, 1996.

6. Hopman, A. H. N., Voorter, C. E., Ramaekers, F. C. S. Detection of genomic changes in cancer by in situ hybridization, Mol Biol Rep. 19: 31-44, 1994.

7. Soder, A. I., Hopman, A. H. N., Ramaekers, F. C. S., Conradt, C., and Bosch, F. X. Distinct non-random patterns of chromosomal aberrations in the progression of squamous cell carcinomas of the head and neck, Cancer Res. 55: 5030-7, 1995.

8. Hittelman, W. N., Voravud, N., Shin, D. M., Lee, J. S., Ro, J. Y., and Hong, W. K. Early genetic changes during upper aerodigestive tract tumorigenesis, J Cell Biochem. Supp/ 17f: 233-6, 1993.

9. Willard, $H_{\text {. }}$ and Waye, J. Hierarchical order in chromosome-specific human alpha satellite DNA, Trends Genet. 3: 192-8, 1987.

10. Pinkel, D., Straume, T., Gray, J. W. Cytogenetic analysis using quantitative, high-sensitivity, fluorescence hybridization, Proc Natl Acad Sci USA. 83: 2934-8, 1986.

11. Hopman, A. H. N. Ramaekers, F. C. S, Raap, A. K., Beck, J. L. M., Devilee, P., van der Ploeg, M., and Vooijs, G. P. In situ hybridization as a tool to studynumerical chromosome aberrations in solid bladder tumors, Histochemistry. 89: 307-16, 1988.

12. Stell, P. M. Ploidy in head and neck cancer: a review and meta-analysis, Clin Otolaryngol. 16:510-6, 1991.

13. El-Naggar, A. K., Dinh, M., Tucker, S., Luna, M. A., Goepfert, H., Hsu, P., and Batsakis, J.G. Genotypic analysis of primary head and neck squamous carcinoma by combined fluorescence in situ hybridization and DNA flow cytometry, Am J Clin Pathol. 105: 102-8, 1996. 
Chapter 7

General Discussion 


\subsection{The acquisition of chromosomal aberrations during head and neck carcinogenesis}

Head and neck carcinogenesis provides a good system to study genetic alterations occurring in subsequent stages of cancer development. The generation of abnormal chromosome numbers (aneuploidy) is a key characteristic of most solid tumors, including HNSCC 1,2. Recent observations have shed light on the mechanisms that generate this altered genetic state. There are now strong indications that defects in mitotic spindle formation and/or mitotic checkpoint control can lead to chromosome missegregation, resulting in aneuploidy ${ }^{3,4}$. Recent literature has also indicated that aneuploidy is a specific driving force in tumor progression, rather than a distracting epiphenomenon of this disease ${ }^{5}$. Cells with an aneuploid DNA content are genetically more instable than cells with a diploid DNA content ${ }^{6}$, and will therefore acquire alterations in their genome at a much higher rate, thereby speeding up tumor progression. Little is known, however, about the timing and the different steps in the development of this process during tumorigenesis, especially during head and neck carcinogenesis.

In this thesis it is shown for laryngeal and oral carcinogenesis that:

1. Histologically normal mucosa and the majority of hyperplastic lesions do not contain numerical chromosomal alterations, allelic loss and detectable expression of the p53 tumor suppressor gene.

2. A minority of hyperplastic lesions displays trisomy for chromosome 7 and $\mathrm{LOH}$ at $9 \mathrm{p} 21$ and/or $17 \mathrm{p} 13$.

3. The process of tetraploidization is correlated with the histological switch from benign hyperplasia to (mild) dysplasia. A strong increase in frequency of losses at $9 \mathrm{p} 21$ and $17 \mathrm{p} 13$, together with a detectable p53 expression are also observed in the frame of this transition.

4. Overall genomic instability is enhanced after tetraploidization, resulting in chromosome copy number imbalances and polyploidization during the histological change from dysplasia to CIS. The detection of these markers is a strong indicator for malignant progression of precursor lesions. Allelic loss of $18 \mathrm{q} 21$ also takes place at this transition.

5. The chromosome patterns established in the CIS stage remain relatively stable during clonal expansion in the invasive carcinoma stage.

With these findings we were able to fine-tune the genetic progression model for head and neck carcinogenesis as presented in chapter 1, and this updated model is shown in figure 7.1. Different steps in the 
aneuploidization process are placed on specific histological transitions and are correlated with other well-described early genetic events such as LOH of $9 p 21$ and $17 p 13$.
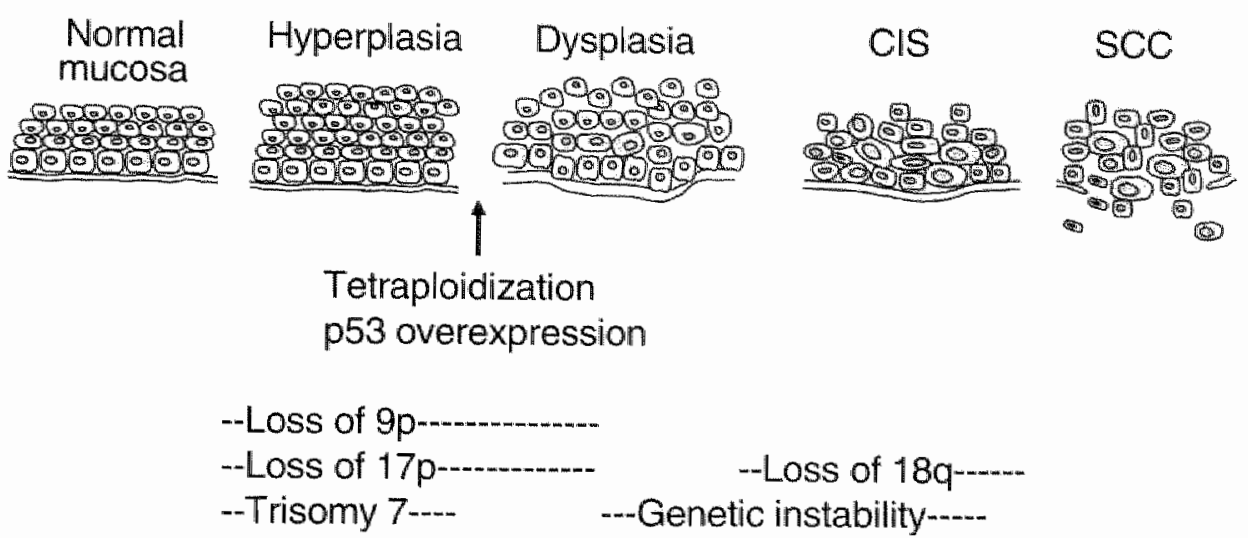

Figure 7.1. The genetic progression model for head and neck carcinogenesis as proposed on basis of the results described in this thesis.

The importance of the aneuploidization process was evidenced by the fact that these chromosome changes were observed in more than $90 \%$ of the lesions with dysplasia, CIS and SCC. Clonal expansion of cells with an aneusomic chromosome content was shown in all stages of head and neck carcinogenesis. In a few cases (reported in chapters 3 and 5) we could detect small foci of 10-20 nuclei with an aneusomic chromosome content located within hyperplastic/mild dysplastic areas otherwise containing no chromosome changes. Such a small group of cells may represent the first outgrowth of an aneusomic clone that could have resulted in a more advanced precursor lesion if it would not have been removed.

The data presented in this thesis clearly indicate that multiple genetic alterations have to accumulate in a cell clone before invasive growth can occur. Cell populations with a tetraploid DNA content, allelic loss at 9p21 and 17p13, and an aberrant p53 expression were shown to persist as dysplastic lesions during many years before invasive growth was observed. The acquisition of additional alterations, such as allelic loss at $18 \mathrm{q} 21$ and a more imbalanced chromosome content, may be essential for invasion to take place. Interestingly, a homogeneous genetic profile 
was observed in most cells from individual head and neck lesions. Typical examples are (a) the presence of tetrasomy for different chromosomes throughout an entire dysplastic lesion, (b) the complete absence of one microsatellite allele in a PCR product obtained from DNA isolated from an entire lesion, and (c) the identical chromosome patterns observed in macroscopically distinct regions of resected HNSCCs. This indicates that the acquisition of an advantageous mutation is immediately followed by clonal expansion, as described by Tomlinson et al. ${ }^{7}$. This finding appears to be in contrast, however, with the idea that especially aneuploid cells have a highly instable genome, resulting in a constant acquisition of new genetic alterations and hence extensive genetic heterogeneity ${ }^{8-10}$. Enhanced instability may speed up genomic mutability, but not interfere with the wave of clonal expansion following the selection of an advantageous mutation. Therefore, although cells from a (pre)cancerous lesion may have a more instable genome as compared to normal cells, the cells within a population will have a more or less identical genetic profile.

\subsection{Chromosomal alterations as diagnostic and prognostic markers}

One of the most difficult aspects in head and neck oncology is to determine the prognosis of patients with preinvasive stages of disease. A premalignant lesion is a morphologically altered tissue in which cancer is more likely to occur as compared to its normal counterpart. The current risk assessment of premalignant lesions is based mainly on morphology, which can only partially predict the clinical outcome for individual patients. This is explained by the fact that these lesions are often very small and have very subtle histopathological features. In addition, if occurring at all, progression to invasive growth may take years, after which it is hard to prove on basis of histology that the tumor developed from the premalignant cells detected years before. Precursor lesions are also often detected in the neighborhood of resected tumors or even at distant sites in the upper aerodigestive tract, causing a high frequency of local recurrences, metastases and second primary tumors in the head and neck region.

Obviously, it is clinically desirable that additional markers can be identified and used for cancer risk assessment in these patients. A number of informative genetic markers are available to study specific genomic alterations that have occurred in premalignant lesions of the 
head and neck region. In this thesis numerical chromosomal alterations, as well as allelic loss of specific chromosomal regions involved in head and neck carcinogenesis have been shown to occur in a high percentage of precursor lesions. An important conclusion of this work is that up to $90 \%$ of the lesions with cellular atypia can be characterized by the presence of aneuploidy as detected by means of interphase cytogenetics. In contrast, extensive analyzes did not reveal the presence of cells containing chromosomal aberrations in histologically normal mucosa, not even when these mucosa were located next to a (pre)malignant lesion. An advantage for the diagnostic implementation of this approach is that it can relate genetic markers to tissue pathology by detecting these changes directly in tissue sections from paraffinembedded biopsy material. It allows a sensitive detection of the cell population that carries specific chromosomal abnormalities. Chromosomal aberrations can be detected in small precancerous lesions, even when the histological evaluation is difficult. In this thesis it is shown that the ISH technique can be applied routinely to clinically detected precursor lesions in patients without frank malignancy and in the evaluation of minimal residual disease in patients with a resected cancer. In addition, the approach can easily be applied in head and neck cytopathology for the objective detection of malignant cells. Apart from the diagnostic application of chromosomal markers, the prognostic value of these markers was also tested. Interestingly, progression to invasive cancer was significantly more common in patients with a premalignant lesion containing chromosome imbalances or polyploidization than in patients with a lesion containing a tetrasomic chromosome status (chapter 2). This finding can be appreciated in view of our observation that these imbalances and polyploidization represent a late step in the aneuploidization process, occurring after tetraploidization.

Next to the numerical chromosomal aberrations that can characterize a precursor lesion in the head and neck region, allelic loss of specific loci on chromosomes 3,9 , and 17, methylation of the p16 gene, and mutations in the p53 gene have been shown to occur in preinvasive stages of the disease. Some of these genetic events appear to occur before tetraploidization and may therefore be of more use in early detection. Especially the use of microsatellite alterations has been suggested to be of value in cancer risk assessment ${ }^{11}$. LOH of $9 \mathrm{p} 21$ may indicate a switch from normal controlled growth to a more proliferative stage, whereas other markers such as $\mathrm{LOH}$ of $18 \mathrm{q} 21$ may indicate progression from a localized dysplastic stage to a more aggressive and possibly invasive stage. Analysis of a number of these microsatellitemarkers can thus be of great use in distinguishing the different stages of head and neck carcinogenesis. In concordance with reports in literature 
11,12 it is shown in chapter 3 of this thesis that even the use of only one microsatelite-marker for each studied chromosome region results in a high detection frequency of $\mathbb{L O H}$. This finding is important for a clinical application of these markers because precursor lesions often comprise a limited number of cells and can therefore not be analyzed with many markers. A disadvantage of this technique is that $\mathrm{LOH}$ for a given microsatellite can only be detected in a cell population if at least $50 \%$ of the cells display allelic loss. This will hamper the detection of cells with $\mathrm{LOH}$ in a background of cells without $\mathrm{LOH}$, as will be the case in resection margins or cytologic specimens. Other PCR-based molecular methods detecting tumor-specific mutations, microsatellite instability or p16 methylation may be more sensitive for the identification of low numbers of neoplastic cells ${ }^{13}$.

\subsection{Future perspectives}

Recent technical developments such as laser-facilitated microdissection and whole genome amplification allow the molecular analysis of microsamples or even single cells present in fixed paraffin-embedded tissue samples. At the moment these lesions can be studied for specilific deletions or mutations, but in future microarray technology will allow a rapid detection of the major genetic alterations present throughout the genome. A prerequisite for a reliable application of this expensive highthroughput technology will be the selection of the starting material. Interphase cytogenetics can be of great guidance in this selection, because it provides a direct link between genetic changes and cellular morphology. A tissue section of a biopsy specimen can be screened by ISH using one or more probes indicative of early transformation (such trisomy for chromosome 7). Areas or cell clusters displaying an aberrant ISH pattern can be microdissected and a detailed genetic profile of these lesions can be obtained by microarray analysis. This multi-parameter analysis will be essential for a better understanding of the genetic progression of head and neck cancer, and may ultimately become of great importance in the classification and prognosis of precancerous lesions. 


\subsection{References}

1. Mitelman, F. Catalog of chromosome aberrations in cancer, Vol. 5. New York: Wiley-Liss, 1994.

2. Soder, A. 1., Hopman, A. H. N., Ramaekers, F. C. S., Conradt, C., and Bosch, F. X. Distinct non-random patterns of chromosomal aberrations in the progression of squamous cell carcinomas of the head and neck, Cancer Res. 55: 5030-7, 1995.

3. Cahill, D. P., Lengauer, C., Yu, J., Riggins, G. J., Willson, J. K., Markowitz, S. D., Kinzler, K. W., and Vogelstein, B. Mutations of mitotic checkpoint genes in human cancers, Nature. 392: 300-3, 1998.

4. Pihan, G. A., Purohit, A., Wallace, J., Knecht, H., Woda, B., Quesenberry, P., and Doxsey, S. J. Centrosome defects and genetic instability in malignant tumors, Cancer Res. 58: 3974-85, 1998.

5. Orr Weaver, T. L. and Weinberg. R. A. A checkpoint on the road to cancer, Nature. 392: 223-4, 1998.

6. Lengauer, C., Kinzler, K. W., and Vogelstein, B. Genetic instability in colorectal cancers, Nature. 386: 623-6, 1997.

7. Tomlinson, I. P. M., Novelli, M. R., and Bodmer, W. F. The mutation rate and cancer, Proc Natl Acad Sci USA. 93: 14800-3, 1996.

8. Loeb, L. A. Mutator phenotype may be required for multistage carcinogenesis, Cancer Res. 51:3075-9, 1991.

9. Hartwell, L. Defects in a cell cycle checkpoint may be responsible for the genomic instability of cancer cells, Cell. 71: 543-6, 1992.

10. Lengauer, C., Kinzler, K. W., and Vogelstein, B. Genetic instabilities in human cancers, Nature. 396: 643-9, 1998.

11. Mao, L., Lee, J. S., Fan, Y. H., Ro, J. Y., Batsakis, J. G., Lippman, S., Hittelman, W., and Hong, W. K. Frequent microsatellite alterations at chromosomes 9p21 and 3p14 in oral premalignant lesions and their value in cancer risk assessment, Nat Med. 2: 682-5, 1996.

12. Califano, J., van der Riet, P., Westra, W., Nawroz, H., Clayman, G., Piantadosi, S., Corio, R., Lee, D., Greenberg, B., Koch, W., and Sidransky, D. Genetic progression model for head and neck cancer: implications for field cancerization, Cancer Res. 56: 2488-92, 1996.

13. Ahrendt, S. A., Chow, J. T., Xu, L., Yang, S. C., Eisenberger, C. F., Esteller, M. Herman, J. G., Wu, L., Decker, A., Jen, J., and Sidransky, D. Molecular detection of fumor cells in bronchoalveolar lavage fluid from patients with early stage lung cancer J Natl Cancer Inst. 91: 332-9, 1999. 
Chapter 8

Summary 
The overall aim of this thesis was to obtain more insight into the genetic changes underlying head and neck carcinogenesis. Attention was focussed on chromosomal changes in premalignant head and neck lesions, and on the potential use of chromosomal markers for diagnostic and prognostic purposes.

In chapter 1 an overview is presented of the current theories concerning the genetic evolution of neoplasia, with special focus on head and neck carcinogenesis. Although much insight has been gained on the different genetic alterations involved in the development of these neoplasms, the sequence of events and the effects on the biological behavior of the cancerous cells are still poorly understood. Head and neck carcinogenesis provides an ideal model to study these phenomena since the mucosa of the head and neck are easily accessible and precursor lesions progressing to invasive cancer are frequently identified in these mucosa.

In chapter 2, the acquisition of chromosome copy number changes was studied in subsequent stages of laryngeal carcinogenesis. In this study, tissue sections from a large series of premalignant laryngeal lesions were hybridized with DNA probes for the chromosomes 1 and 7 . This in situ hybridization (ISH) analysis did not reveal numerical chromosomal aberrations in histologically normal laryngeal mucosa and in most lesions with only hyperplasia. In contrast, approximately $90 \%$ of the lesions with dysplasia were shown to contain an abnormal chromosome content, a percentage also obtained for invasive laryngeal cancer. Clonal expansion of these aneusomic cell populations was evidenced by the fact that the entire dysplastic lesion contained nuclei with abnormal chromosome numbers, whereas adjacent non-dysplastic areas did not contain chromosome aneusomy. An analysis of the pattern of chromosome abnormalities revealed that most lesions with mild or moderate dysplasia were tetrasomic for both chromosomes, whereas most lesions with severe dysplasia or carcinoma in situ (CIS) contained chromosome copy number imbalances and polyploidization. Of clinical importance was our finding that the presence of these latter markers for genomic instability predicted progression towards invasive growth.

These findings, which were confirmed in chapter 3 with ISH analyzes for chromosomes 9,17 , and 18 , indicate that different steps in chromosome aneuploidization can be detected in subsequent steps of laryngeal carcinogenesis. It is concluded that tetraploidization precedes a phase of genetic instability during which cells show a random gain or loss of chromosomes. In addition, it was shown that chromosomal aberrations are occasionally present in small groups of cells not showing histological signs of nuclear atypia. Strikingly, a number of hyperplastic lesions 
preceding invasive cancer were shown to contain a trisomy for chromosome 7.

Another genetic change frequently observed in solid tumors is the functional inactivation of specific tumor suppressor genes. Loss of heterozygosity ( $\mathrm{LOH}$ ) of loci on chromosome 9p21 and $17 \mathrm{p} 13$ has been reported to be among the earliest detectable genetic changes in head and neck carcinogenesis. Two of the potential target genes at these loci, i.e. $p 16^{\mathrm{INK} \text { a }}$ and $\mathrm{p} 53$, are both involved in cell cycle control and a functional inactivation of these genes leads to uncontrolled cell division and possibly DNA aneuploidy. In contrast, $\mathrm{LOH}$ of $18 \mathrm{q} 21$ appears to be associated with tumor progression. In chapter 3 it was shown that $\mathrm{LOH}$ of $9 p 21$ and $17 p 13$ are among the earliest genetic events in laryngeal carcinogenesis, detectable a number of hyperplastic lesions with trisomy for chromosome 7. LOH of these loci was present in most dysplastic lesions that were typically tetraploid and p53 positive. LOH of $18 \mathrm{q} 21$ was present in histologically more advanced lesions containing chromosome copy number imbalances and polyploidization.

Since genetic instability seems to be an intrinsic factor in fumorigenesis, it might be expected that the cells that form an invasive tumor are not genetically alike, although they are monoclonal of origin. In chapter 4 we investigated whether invasive HNSCCs consist of one clone with a specific pattern of chromosomal abnormalities, or whether multiple clones with distinct chromosomal constitutions are present within such malignancies. We showed that double-target fluorescence in situ hybridization was highly suited for the mapping of chromosome patterns in nuclear suspensions of cancers. It is concluded that great inter-tumor heterogeneity exists in the pattern of chromosomal aberrations, indicating that these patterns arise as a result of random chromosome gains and losses, caused by an overall genomic instability in a premalignant stage of the disease. This instability is less evident during invasive growth, because only limited intra-tumor heterogeneity was observed in the chromosome constitution.

In chapters 5 and 6 the usefulness of genomic markers has been explored for the detection of malignancy in both resection margins of HNSCCs as well as in head and neck cytopathology. These markers may be more objective parameters of the malignant potential of a cell population than the histological features.

The presence of (pre)malignant cells in the resection margin of a tumor specimen constitutes a high risk for the development of local recurrence, one of the major problems in head and neck oncology. In chapter 5 we 
show that genetic abnormalities, as detected by either in situ hybridization and/or p53 immunohistochemistry, are frequently present in the resection margins of oral squamous cell carcinomas. These genetic abnormalities can serve as indicators of the completeness of the surgical resection. In this study also a strong correlation between the presence of numerical chromosomal aberrations and p53 overexpression was demonstrated in premalignant stages of disease. This indicates that the p53-aneuploidy route is important for the generation of genetic instability in these stages of head and neck carcinogenesis.

Non-invasive methods for the detection of (pre)malignant cells are of great importance in the screening of high risk populations, such as heavy smokers and alcohol consumers, and in the clinical follow-up of HNSCC patients at risk for the development of local recurrences and second primary tumors. In chapter 6 we report the applicability of the FISH technique to detect genetically aberrant cells in brush specimens taken from the tumor regions of HNSCC patients. $75 \%$ of these cytologic specimens were found to contain chromosomal alterations in more than $5 \%$ of the cells collected. Chromosomal aberrations were detected in all cytologic specimens taken from DNA aneuploid HNSCCs, indicating that the cells in these specimens correctly reflect the cells within the solid tumor.

Finally in chapter 7 the fundamental as well as the clinical implications of the results described in this thesis are discussed, and the future perspectives are pointed out. 
Chapter 9

Samenvatting 
Het doel van dit promotie-onderzoek was inzicht te verkrijgen in de genetische veranderingen zoals die optreden tijdens de ontwikkeling van tumoren in het slijmvlies van het hoofd-halsgebied. In detail werd gekeken naar de chromosoom-inhoud van klinische en histologische voorloperstadia van hoofd-halstumoren (zogenaamde premaligne laesies). Verder werd de mogelijkheid onderzocht om chromosomale veranderingen te gebruiken voor diagnostische en prognostische doeleinden.

In hoofdstuk 1 wordt een overzicht gegeven van de literatuur betreffende de genetische evolutie van tumoren, met speciale aandacht voor de groep van hoofd-halstumoren. Alhoewel reeds veel inzicht is verkregen in de genetische veranderingen betrokken bij de ontwikkeling van deze tumoren, is nog grotendeels onduidelijk wanneer en in welke volgorde bepaalde veranderingen optreden. Het hoofd-halsgebied is bij uitstek geschikt voor het in kaart brengen van genetische kanker progressie, aangezien dit gebied goed toegankelijk is voor inspectie en er bovendien frequent premaligne laesies worden waargenomen die zich progressief ontwikkelen.

In hoofdstuk 2 wordt een studie beschreven waarin gekeken is naar veranderingen in chromosoom-aantallen in opeenvolgende histologische stadia van de carcinogenese van stembandepitheel (normaal epitheel, hyperplasie, dysplasie, carcinoma in situ, carcinoma). Voor deze studie werden weefselcoupes van een grote serie premaligne laesies van de stemband onderzocht met behulp van in situ hybridisatie (ISH) voor de chromosomen 1 en 7 . Deze ISH analyse toonde geen numerieke chromosoom-veranderingen in histologisch normaal stembandepitheel. Hetzelfde gold voor het merendeel van de laesies met uitsluitend hyperplasie. In sterk contrast hiermee was de observatie dat ongeveer $90 \%$ van alle dysplastische laesies een afwijkend chromosoom patroon vertoonden. Deze chromosomaal afwijkende celpopulaties zijn zeer waarschijniijk ontstaan door klonale uitgroei, aangezien de afwijkingen meestal in een histologisch begrensd gebied gevonden werden. Een verdubbeling van de chromosoom-inhoud (tetraploidisatie) werd waargenomen in de meeste laesies met milde of matige dysplasie. In een volgend histologisch stadium (ernstige dysplasie of carcinoma in situ) bleken de chromosoom-aantallen niet meer in ballans en werden vaak 5 tot 8 kopieën van de chromosomen 1 en 7 gevonden. Deze laatste chromosoom patronen vormen een sterke indicatie voor genetische instabiliteit en bleken statistisch significant geassocieerd met maligne ontaarding van premaligne laesies.

Deze bevindingen, die in hoofdstuk 3 werden bevestigd met ISH analyses voor de chromosomen 9,17 en 18, tonen aan dat 
verschillende stappen in chromosoom aneuploidisatie gedetecteerd kunnen worden in histologisch opeenvolgende fasen van de stembandepitheel carcinogenese. Na tetraploidisatie ontstaat genetische instabiliteit, hetgeen ervoor zorgt dat chromosoom-aantallen willekeurig toe- of afnemen. Bovendien werd aangetoond dat chromosomale afwijkingen soms in kleine groepen hyperplastische cellen zonder histologische kenmerken van dysplasie voorkomen.

Naast veranderingen in chromosoom-aantallen wordt vaak inactivatie van specifieke tumor suppressor genen gevonden in solide tumoren. Dit verlies van heterozygositeit ( $\mathrm{LOH}$ ) van gebieden op de chromosomen 9 (9p21) en 17 (17p13) lijkt zeer vroeg op te treden tijdens de ontwikkeling van hoofd-halstumoren. Twee belangrijke tumorsuppressorgenen die in deze gebieden liggen, $16^{\mathbb{N N K 4 a}}$ en $\mathrm{p53}$, zijn beiden betrokken bij de controle van de celdeling. Een functionele inactivatie van deze genen leidt tot ongecontrolleerde celdeling met als mogelijk gevolg DNA aneuploïdie. Door het onderzoek beschreven in hoofdstuk 3 wordt inderdaad bevestigd dat LOH van 9p21 en $17 p 13$ zeer vroeg optreedt in de ontwikkeling van stemband-kanker. Deze afwijkingen werden geconstateerd in enkele hyperplastische laesies met beperkte veranderingen in chromosoom-aantallen. Dysplastische laesies worden gekenmerkt door een tetraploïde DNA inhoud, $\mathrm{LOH}$ voor zowel $9 p 21$ als 17 p13 en een afwijkende expressie van het p53 gen. $\mathrm{LOH}$ voor 18q21 bleek duidelijk later op te treden in het proces van tumorprogressie en geassocieerd te zijn met de fase waarin genetische instabiliteit optreedt, nog voor invasieve tumorgroei.

Over het algemeen wordt aangenomen dat kanker ontstaat uit één enkele ontregelde cel (een kloon) en dat de cellen in een tumor dus sterk genetisch verwant zijn. Aangezien genetische instabiliteit een belangrijke eigenschap is van tumorcellen, kan toch een diversiteit aan genetische profielen in een invasieve tumor verwacht worden. Hoofdstuk 4 beschrijt een studie waarin werd onderzocht of hoofdhalstumoren bestaan uit één kloon met een specifiek chromosoompatroon, of dat meerdere klonen met verschillende patronen aanwezig zijn in deze tumoren. Het bleek dat simultane detectie van 2 chromosomen middels fluorescente ISH zeer geschikt is voor het in kaart brengen van chromosoom-patronen van tumor celsuspensies. Eén van de conclusies van dit onderzoek is dat er grote verschillen bestaan in de chromosoom-patronen tussen de individuele hoofd-halstumoren. Dit betekent dat deze patronen ontstaan zijn als gevolg van een min of meer willekeurig proces van chromosoomverlies en -winst in premaligne stadia. Is de tumor eenmaal invasief groeiend dan blift het genetisch profiel redelijk stabiel aangezien er maar een beperkte heterogeniteit in 
chromosoom-patronen werd gevonden binnen individuele hooldhalstumoren.

In de hoofdstukken 5 en 6 is de mogelijke toepassing van chromosomale merkers voor de detectie van maligne cellen onderzocht in zowel de snijranden van geopereerde tongtumoren als in cytologische uitstrijkjes van hoofd-halstumoren. Deze merkers vormen mogelijk meer objectieve parameters ter bepaling van het maligne potentieel van een celpopulatie dan de histologie.

Het nog aanwezig zijn van maligne cellen in de snijrand van een tumorpreparaat is sterk geassocieerd met de ontwikkeling van een lokaal recidief na operatie en is één van de voornaamste klinische problemen in de hoofd-halsoncologie. In hoofdstuk 5 wordt aangetoond dat genetische afwijkingen, zoals te detecteren met ISH en/of p53 immunohistochemie, frequent voorkomen in de snijranden van tongtumoren. Deze genetische afwijkingen kunnen mogelijk dienen als indicatoren ter bepaling van de uitgebreidheid van de tumor. In deze studie werd bovendien in voorstadia van tongkanker een sterke correlatie gevonden tussen de aanwezigheid van numerieke chromosoom-veranderingen en de aberrante expressie van het p53 gen. Dit geeft aan dat de p53-aneuploïdie route belangrijk is voor het ontstaan van genetische instabiliteit in de eerste fasen van de hoofdhalscarcinogenese.

Niet-invasieve methoden voor de detectie van (pre)maligne cellen zijn van groot belang voor de screening van patiënten die een hoog risico lopen hoofd-halskanker te ontwikkelen, zoals tabak- en alcoholgebruikers, alsmede bij de tollow-up van patiënten met een hoofdhalstumor. In hoofdstuk 6 wordt de toepasbaarheid van de fluorescente ISH techniek aangetoond voor de detectie van chromosomaal afwijkende cellen in cytologische uitstrijkjes van hoofd-halstumoren. $75 \%$ van de onderzochte cytologische preparaten bevatte genetische afwijkingen in meer dan $5 \%$ van de cellen. Vergelijkbare chromosomale veranderingen werden gevonden in alle cytologische preparaten en de DNA aneuploïde tumoren waarvan ze waren afgenomen, hetgeen aantoont dat de cellen in deze preparaten een correcte afspiegeling zijn van de cellen in de solide tumor.

Tenslotte worden in hoofdstuk 7 de implicaties van de resultaten voor zowel het fundamentele kankeronderzoek als ook voor de diagnostiek en behandeling van hoofd-halstumoren besproken en wordt aangegeven welke richting het kanker-onderzoek van het hoofd-halsgebied in de komende jaren zou kunnen inslaan. 


\section{Dankwoord}

Het onderzoek is afgerond en opgeschreven, de lay-out is bijna voltooid en de drukker staat al klaar; een mooi moment voor het schrijven van het dankwoord.

Vier jaar lang heb ik onderzoek mogen verrichten in een voortreffelijke samenwerking tussen de afdeling Keel-, Neus-, en Oorheelkunde van het Azm en de capaciteitsgroep Moleculaire Celbiologie en Genetica van de UM. Voor mij was het zeer leerzaam om het kankeronderzoek van zowel de klinische kant als de biologische kant te benaderen.

Allereerst wil ik mijn beide promotores, Hans Manni en Frans Ramaekers, en mijn co-promotor, Ton Hopman, bedanken voor hun ondersteuning.

Beste Hans, jouw niet-aflatende enthousiasme voor de moleculaire benadering van de hoofd-halsoncologie heeft mij enorm gemotiveerd. Bovendien droeg jij er in grote mate aan bij dat ik mij snel thuis voelde tussen de witte jassen.

Beste Frans, waarschijnlijk heb ik het meest geleerd van de pittige discussies zoals die zich maandelijks tussen ons afspeelden. Zoals het hoort kon ik je regelmatig schieten maar soms moest ik gewoon toegeven dat je een goed punt had.

Beste Ton, jij was het die me regelmatig met beide benen terug op de grond plaatste en vond dat ik de experimenten eerst maar eens moest uitvoeren voordat mooie hypotheses bedacht werden. Het leukst waren toch well de discussies achter de microscoop ("zeg niets, laat mij maar zelf kijken").

Vanuit de afdeling Pathologie van het Azm was Freek Bot betrokken bij de histologische classificatie van ontelbare (pre)maligne laesies en cytologische preparaten. Beste Freek, jouw ondersteuning was van essentieel belang voor een groot deel van dit onderzoek. De genetica en de histopathologie kwamen vaak redelijk overeen, nu de geneticus en de patholoog nog!

Manonneke, je begrijpt wel dat ik jouw het liefst bovenaan had willen plaatsen in dit dankwoord, maar zoals je ziet ben je wederom geen eerste geworden! Samen hebben we iedere AlO-crisis doorstaan, samen konden we die lummels hierboven aan. Ik zal je nog weleens missen......

Ook dank aan "mijn" studenten Saskia, Ference en Ingrid, alle drie waren jullie een enorme hulp op het lab en goede discussie-partners.

Ich möchte gerne die Leute vom Molekular Biologisches Labor der HNOKlinikum danken für die gute Zeit in Heidelberg, vor allem Franz Bosch und Andreas "FISHerman's friend" Pfuhl. Auch bin ich Michaela Aubele in Neuherberg sehr erkenntlich für die Hilfe mit der LäserMikrodissection. 
Wie nog meer? Nou uiteraard AnnickBerndBertClaudiaEduardElena ErikaErnst-JanFrancienFrankGuillaumeHansHarriëtHelmaHermanIwan Jaap Jan (2x) Jannie Janny JeroenJohanJorike Jos(2x) LiesbethLucien LysandraMarie-HélèneMaurice MichelMickeyMiekeMiriamMoniqueNancy PimRicoRobertRomainRonSanderStefanSusanVictorWendyWiel..... Een heleboel van deze mensen kennen elkaar nog niet en dat is jammer voor ze, loop dus eens binnen bij KNO of MCB, het is maar twintig meter naar links/rechts en drie verdiepingen omhoog/omlaag! Robert en Peter, jullie horen eigenlijk ook in dit rijtje als halve-MCB-ers, en dat is uiteraard als een compliment bedoeld. Berry en Henry zal ik dat laatste niet aandoen, in ieder geval bedankt voor jullie hulp bij het genescannen.

Je vrienden en familie bedanken omdat het je vrienden en familie zijn is erg Amerikaans, en daarom wil ik allereerst Simon bedanken voor het feit dat hij regelmatig vanuit Wageningen en later Joure naar het zuiden afzakte voor een goed glas port (en over drie jaar versla je me op de tennisbaan, toch?). Ellen, jij blijft een fantastische vriendin en een groot voorbeell. Frank, het was goed er iemand uit Hoensbroek bij te hebben! Aangezien jij in mijn voorspellingen gelooft wil ik je nog wel melden dat Roda JC de UEFA-cup wint en Michael Boogerd het WK, volgend millenium. Pa, ma, Rinse en Imke, jullie zijn pas echt onvervangbaar! Tenslotte mijn excuses aan het gehele bestuur van B.C. de Sjöttel, ooit zal ik terugkeren in jullie midden.

Enne... Elvis, jij bleef van ons tweetjes wel het coolst, zelfs als ik je weer eens drie weken weg liet kwijnen! Zuilen wij elkaar ooit echt begrijpen? 


\section{Curriculum Vitae}

Joris Veltman werd op 28 augustus 1971 geboren te Heerlen. In 1989 behaalde hij het atheneum B diploma aan het Sint Jans College te Hoensbroek. In datzelfde jaar begon hij met de studie Moleculaire Wetenschappen aan de Landbouwuniversiteit Wageningen, waar hij in 1995 afstudeerde in de chemisch-biologische richting. Tijdens deze studie heeft hij onderzoekservaring opgedaan bij de vakgroepen Moleculaire Biologie (Prof. Dr. T. Bisseling) en Experimentele Diermorfologie en Celbiologie (Dr. R. Stet) van de Landbouwuniversiteit. Tevens heeft hij in het kader van het Erasmus-uitwisselingsprogramma stage gelopen bij de vakgroep Moleculaire Immunologie en Pathologie (Prof. Dr. M. de Sousa) van de Universiteit van Porto in Porto en het Centrum voor Immunopathologie en Humane Genetica (Dr. M-P. Roth) in Toulouse. Na zijn afstuderen in 1995 tradt hij als assistent in opleiding in dienst bij de afdeling Keel-, Neus-en Oorheelkunde (Prof. Dr. J.J. Manni) van het Academisch Ziekenhuis Maastricht in een samenwerkingsverband met de capaciteitsgroep Moleculaire Celbiologie en Genetica (Dr. A.H.N. Hopman, Prof. Dr. F.C.S. Ramaekers) van de Universiteit Maastricht. Gedurende deze periode werd het in dit proefschrift beschreven onderzoek uitgevoerd. In 1997 ontving hij de René Vogels Oncologie beurs. Sinds oktober 1999 is hij werkzaam als postdoc bij het Centrum voor Kankeronderzoek van de Universiteit van Californië San Francisco (Prof. Dr. F. Waldman). 


\section{List of publications}

Arosa, F. A., Oliveira, L., Porto, G., da Silva, B. M., Kruijer, W., Veltman, J. A., de Sousa, M. Anomalies of the $C D 8^{+} T$ cell pool in heamochromatosis: HLA-A3-linked expansions of $\mathrm{CD} 8^{+} \mathrm{CD} 28^{\circ} \mathrm{T}$ cells. Clinical Experimental Immunology, 107:548-54, 1997.

Veltman, J. A., Hopman, A. H. N., Bot, F. J., Ramaekers, F. C. S., Manni, J. J. Detection of chromosomal aberrations in cytologic brush specimens from head and neck squamous cell carcinoma. Cancer (Cancer Cytopathology), 81: 309-14, 1997.

Veltman, J. A., Hopman, A. H. N., Vlies, S. A. v. d., Bot, F. J., Ramaekers, F. C. S., Manni, J. J. Double-target fluorescence in situ hybridization distinguishes multiple genetically aberrant clones in head and neck squamous cell carcinoma. Cytometry (Communications in Clinical Cytometry), 34: 113-20, 1998.

Veltman, J. A., Hopman, A. H. N., Ramaekers, F. C. S., Manni, J. J. Genetische veranderingen in premaligne laesies. Kanker, 23: 32-4, 1999.

Veltman, J. A., Bot, F. J., Huynen, F. C., Ramaekers, F. C. S., Manni, J. J., Hopman, A. H. N. Chromosome instability as an indicator of malignant progression in laryngeal mucosa. Submitted for publication.

Toorn, P. P. G. v. d., Veltman, J. A., Bot, F. J., de Jong, J. M. A., Manni, J. J. Ramaekers, F. C. S., Hopman, A. H. N. P53 overexpression and chromosome instability are strongly correlated in early stages of oral carcinogenesis. Submitted for publication.

Veltman, J. A., van Weert, I. S. F. M., Aubele, M.y Bot, F. J., Ramaekers, F. C. S., Manni, J. J. Hopman, A. H. N. Specific steps in aneuploidization correlate with $\mathrm{LOH}$ of $9 \mathrm{p} 21,17 \mathrm{p} 13$ and $18 \mathrm{q} 21$ in the progression of premalignant laryngeal lesions. Submitted for publication. 